\title{
EFICIÊNCIA E CUSTOS DA PRODUÇÃO DE MAÇÃ NA REGIÃO CAMPOS DE LAGES, ESTADO DE SANTA CATARINA
}

\author{
ARMANDO GOCKS \\ Engenheiro-Agrônomo
}

Orientador: Prof. Dr. PEDRO VALENTIM MARQUES

Dissertação apresentada à Escola Superior de Agricultura "Luiz de Queiroz", da Universidade de São Paulo, para obtenção do título de Mestre em Agronomia, Área de Concentração: Economia Agrária.

PIR A C I C A B A

Estado de São Paulo - Brasil

Dezembro - 1988 


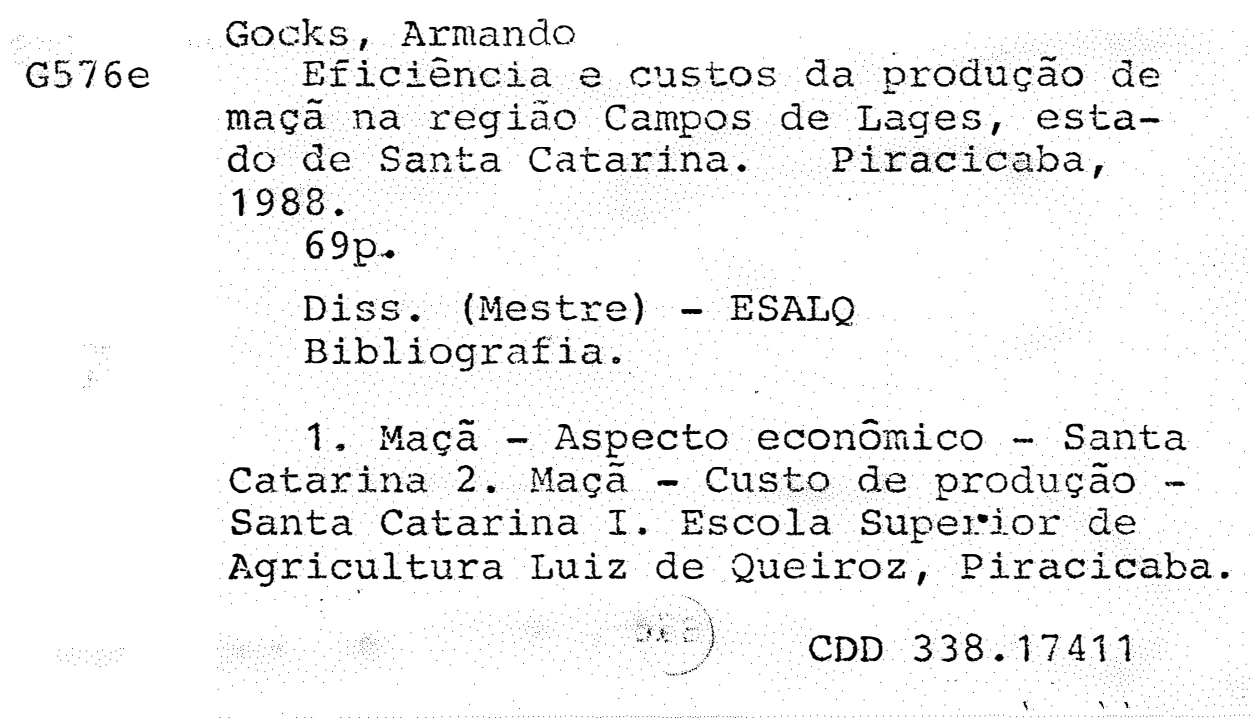




\section{EFICIENCIA E CUSTOS DA PRODUMOO DE MAGE NA REQTAO CAHPOS}

DE LABES, ESTADO DE SANTA CATARTMA

Aprovada en: $16,12,1988$

Comisso julgaroma:

Pros. Dr. Fedro Valent in Maraues

Esthorap

Prot. Dr. Jose F. Noronha

Dr. Antonio A. Amaro

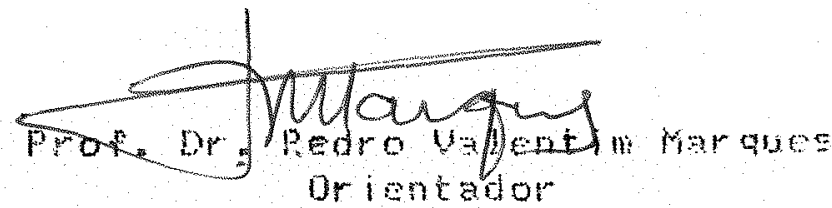


A Nara

Ao Andre Luis

Ao Luis Felpe

s Ana Panla

a w I1

Aog mens pais

dedican 


\title{
ACRADECIMENTOS
}

\begin{abstract}
o autor deseja expessar seu protundo agradecimento

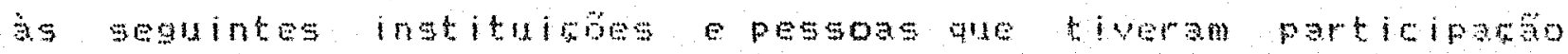
decielua nesterabalto:
\end{abstract}

- A Universidade pra o Desenvoluimento do Estado de Sanka Catarina - UDESC - por ter permitido o med atastamento da dochoia para frequentar o curso de pos-graduarao;

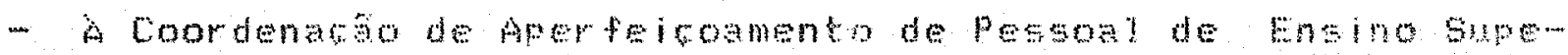

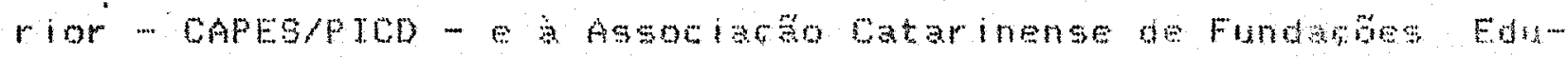
cacionats - ACAFE - pela conossub de bolsa de estudo dutante o $\cos 50$

- A Associajo do Credtro Assistoncla Rural de anta Catarina -- ACARESC - nas pessos do Enge Agre Rogue Hentscre, Engi Agr

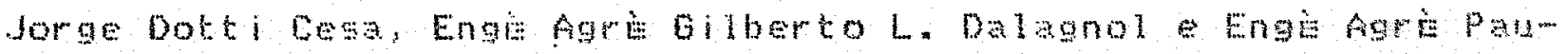
$10 \mathrm{M} . \mathrm{L}, \mathrm{Baggio}$

- Ao Prot. Dr. Pedro valentim Marques pela disposisa, sugesm ties or ientages prestadas;

- Aos Proteseres do Departamento de Economia a sociologia fural da ESAlo e em emecial aos Profeseores zilda P. de b. Hattos, Fernando C. Pores, Jose F. Noromha, Evaristo M. Netes e Rodolfo Hoftmann, por sugestes oferecidas;

- ADs colega de curso prla amade wriada desenvolyida da rante operiodo, em especial a Vania e Francisco ouinarses. 


\section{SUWARTO}

$p \sin 3$

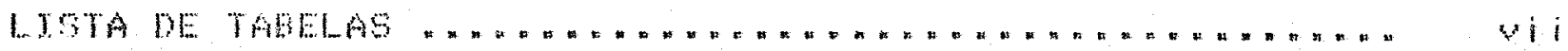

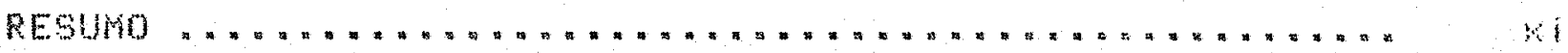

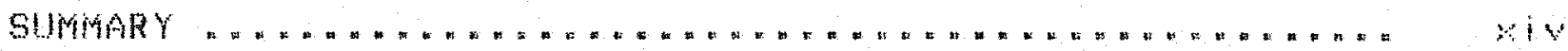

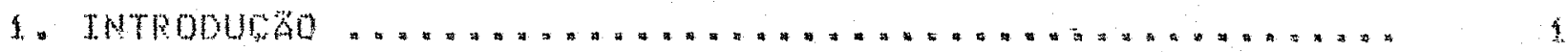

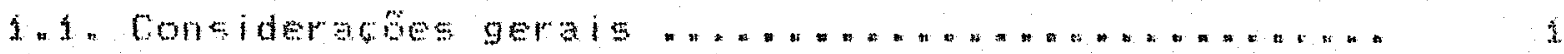

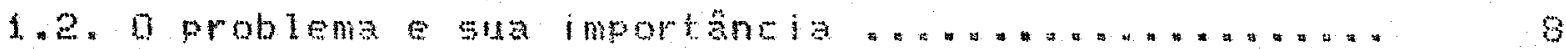

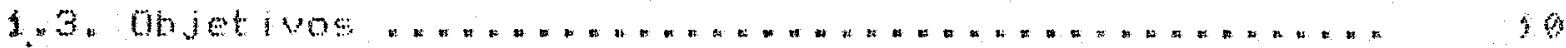

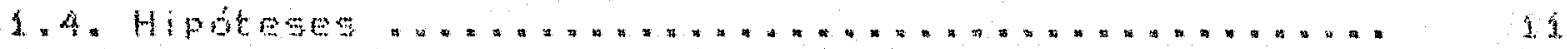

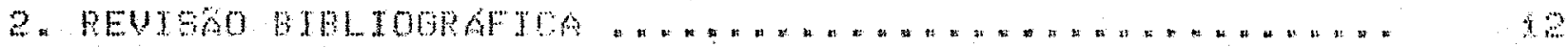

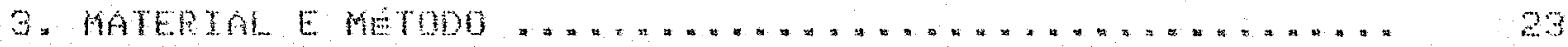

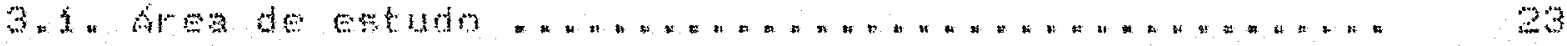

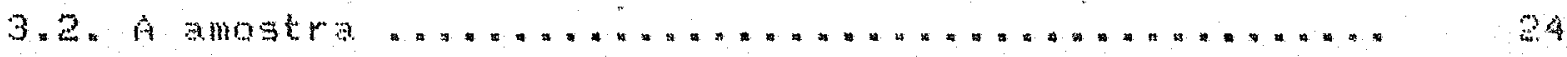

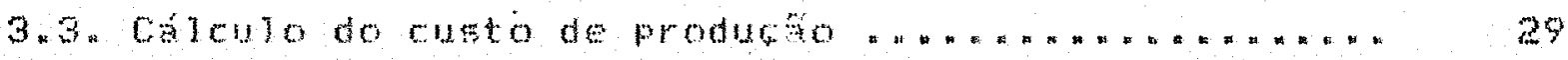

3.3.1. Anmalizaco dos custos de investimento ede

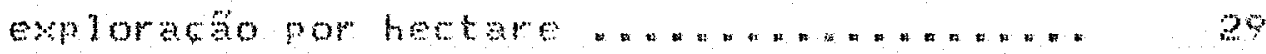

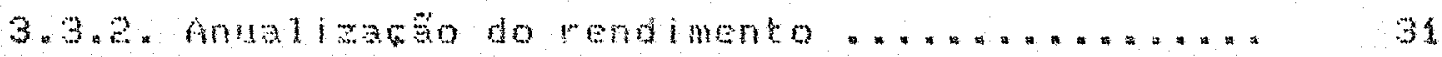

3.3. Cáleulo do custo total medio ...........

3.3 .4 Receitg totat e custo fotal .......... 33

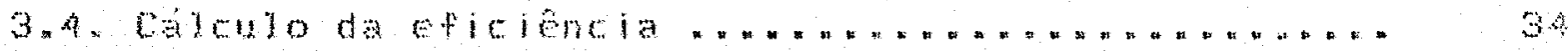

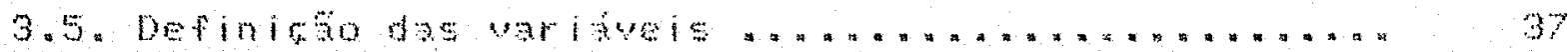

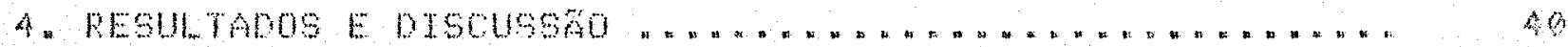




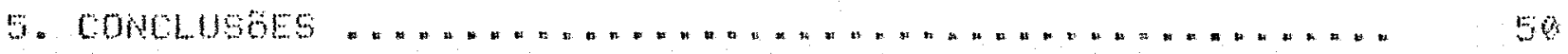

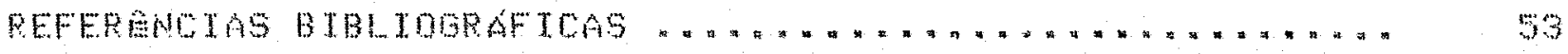

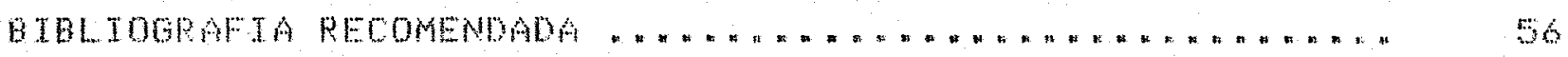

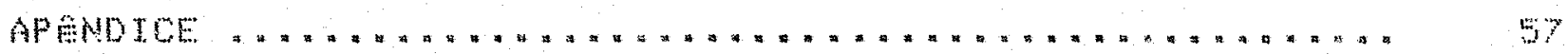




\section{LISA DE TABELA}

Paging

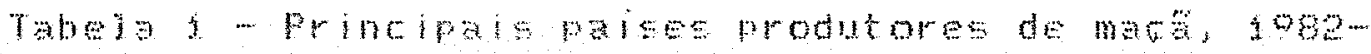

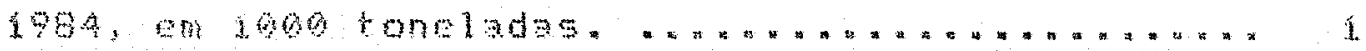

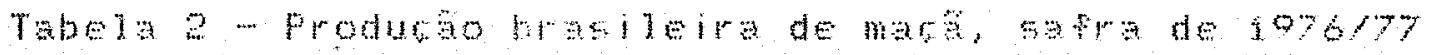

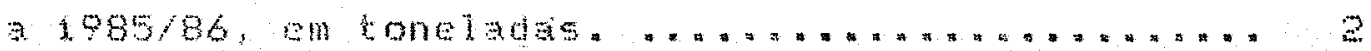

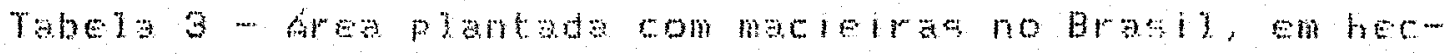

tarea, por Egtado, de 1975 a $1985, \ldots \ldots \ldots \ldots$

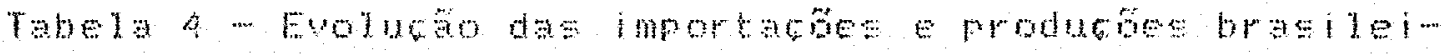

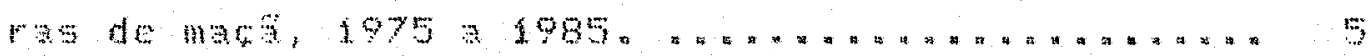

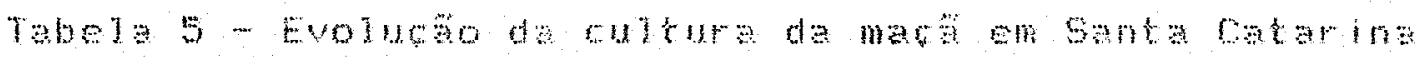

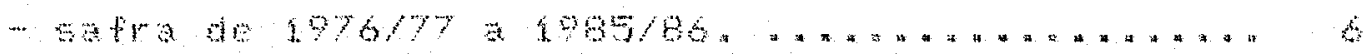

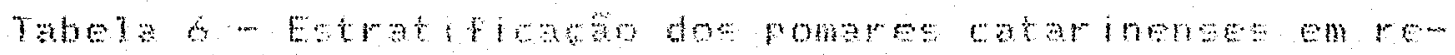
136 a

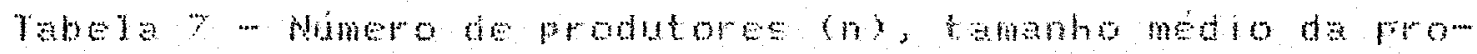
priedade(xil, tamanho modio do pomar $(x)$, área

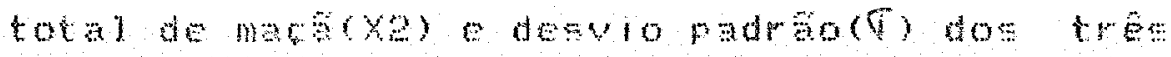
estratose da populagon $\ldots \ldots \ldots \ldots \ldots \ldots \ldots \ldots \ldots$.

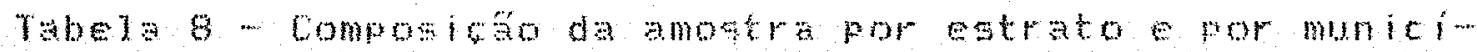
pio, total por estrato tosal por munifipio. . . a

Tabela a - cueto total por hewtare, custo total medio por quilo ereceita por hectare parbo estrato I (peguenos produtores). valores en orne ved e

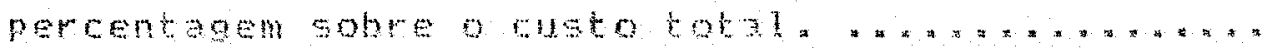

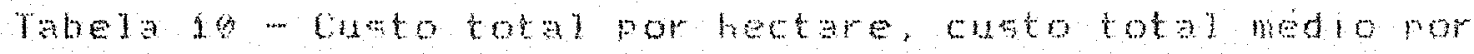

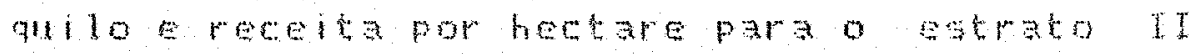


(medios produtores. Ua ores em oTN e USd e rer...

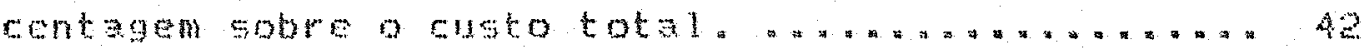

Tabel +1 - Custo total por hectare, cueto total medio por allo ereceite por hectare parao setrato II Grandes produtores?, Ualores an oTN e Ust e per

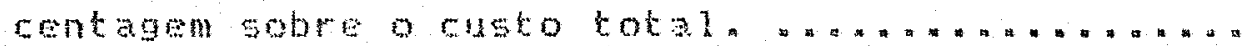

Tabela 12 - Partipipaso parcentual dos diversos itons no custo total para o grupo de fruticultores malsew ficientes e para os menos eficientes. Media dos

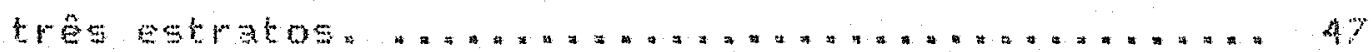

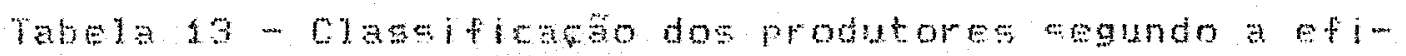

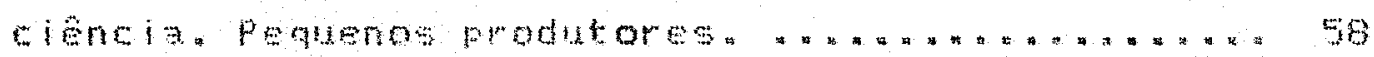

Tabela 10 - Claselfitato dos produtores segundo a efi-

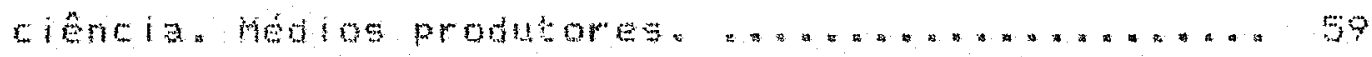

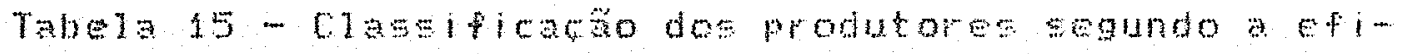

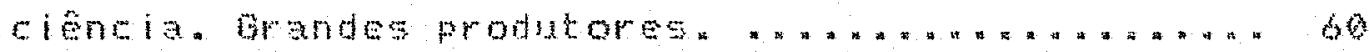

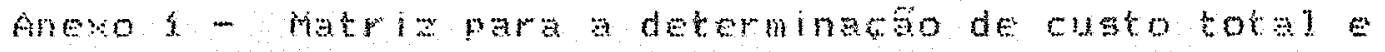
cueto opergeional de mats, yidatil de 22 anos, estabilizacto aos 10 anos, fectrato I.

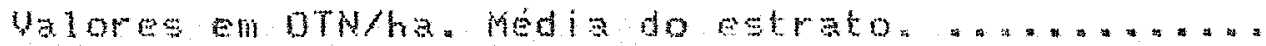

Anexo 2 - Matriz para determinabo de custo total e custo operaclonal de mas, vida iftil de 2 anos, estabilizaso aos to anos, estrato II. Valores em orNha. Media do estrato. a......... be

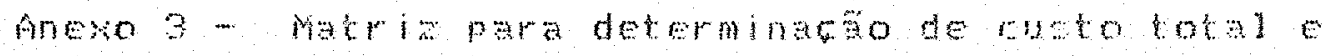
custo operacional de magé, vida ltil de 2 
anos, extabilizatao aos 10 anos, extato ITI.

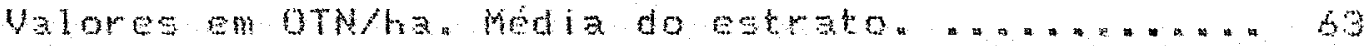

Anevo a -.. Drientabses para a impresso do reitato

"COMPARAGEO COM A MEDIA DO ESTRATO" .......... GA

Anexo 5 - Matriz de coetiolentes tecnicos para a producto

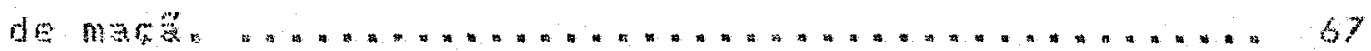




\section{"CURR ICULUH GITAE"}

Nome: Armands bocts.

Data de naseinento: La de novembro de 1945.

Loral de naseimente: Thiruba (PS).

Gradusa: Encenhelro Agronomo pela Un rersidade Fereral de pem

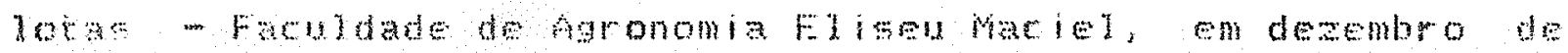
$197 \%$

Athidates protictonats:

- Propesor das disciplinas de Economia Rural do curso de

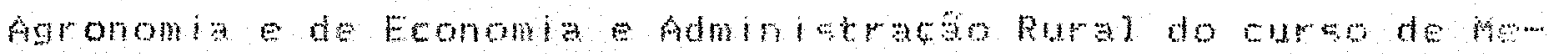

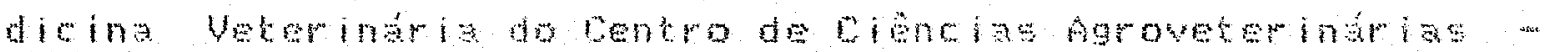

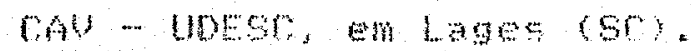

- Integrante do qudro de Engenheiro foronomos da compania Riograndense de fdubos - CPA de outubo de 1972 ats abll de 1979 e Inspetor de Uendas na mesma empresa de abril de 1979 . $\operatorname{agcta} d e 1983$

- Avalador da Curelra de crédito Rural e Induetrial do banco

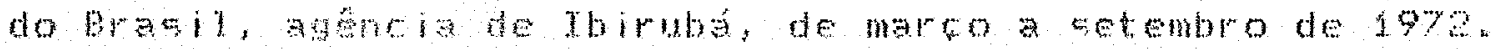

- Protessor da disciplina de Estatistirana Escola Ternica de

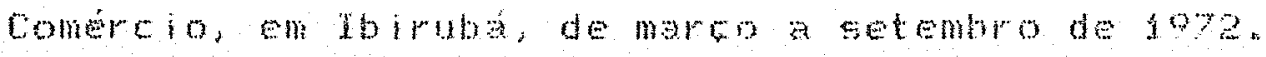




\section{EFTCENCTA E CUSTOS DA PRODUERO DE MACH MA REOTHO \\ CAMPOS DE LAGES. ESTADO DE SANTA CATARTMA}

Autor: ArMando boms

Orientador: PROF = DR. PEDRO UALENTTM MARQUES

\section{RESUMD}

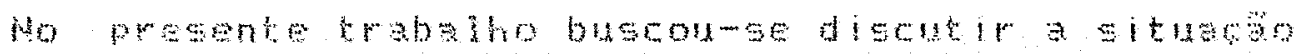

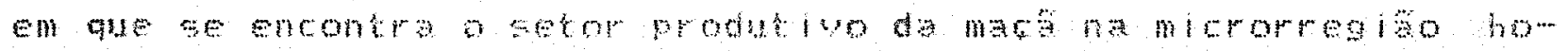

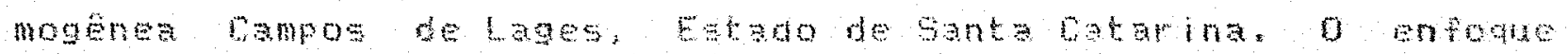

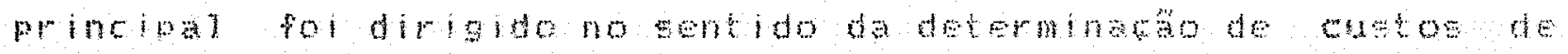

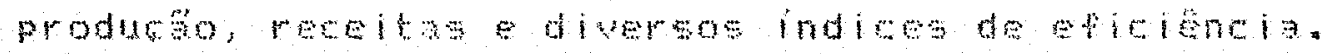

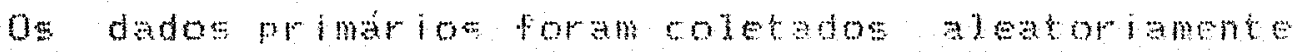

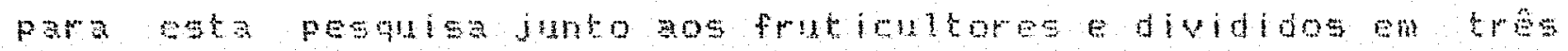

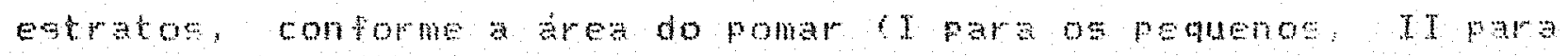

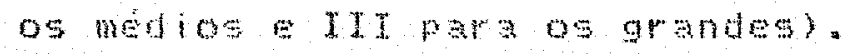

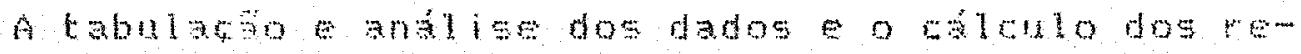

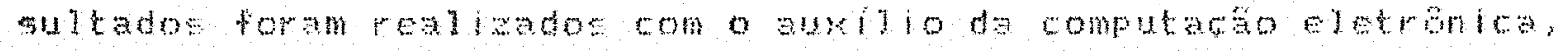
por melo doprograme 10713 1-2-3.

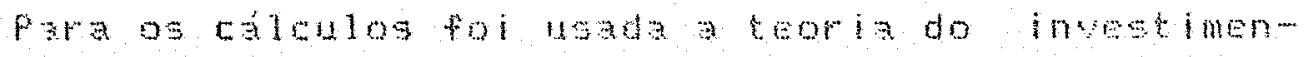

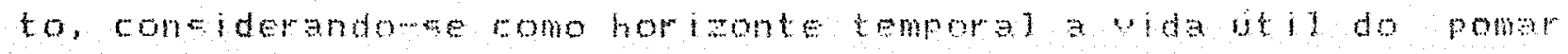

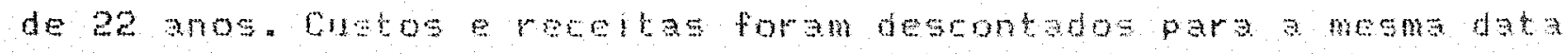
base ama taxa de $6 \%$ an ano. 


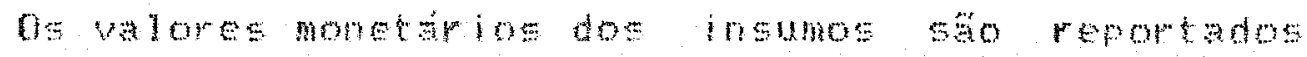
para janeiro de 2980 e preco da mas representa a medio de ma seriehistorica que postariormente foram tranctormados em orn Cobrigarose do Tesono Nactonal) e Usa (dolar).

Determinou-se o custo tolal/ha, custo fotal mediol kg, as receitas bruta e liquidpor hectaree os indices de

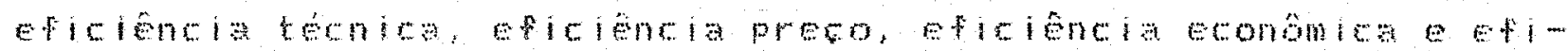
ciêneia da explotaso.

Eetatisticamente, ao nivel de g\% de signiticanein.

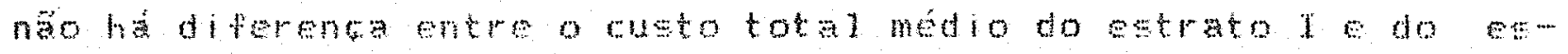
trato TI nen entre a receita lianda dos mesmos estratos.

Utilizando on dados medtoe de wada merato, arma-

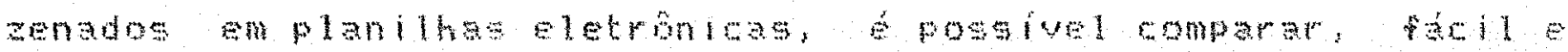

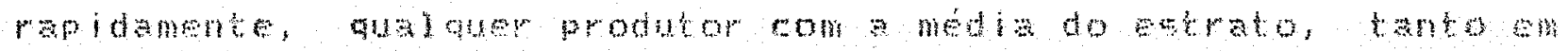

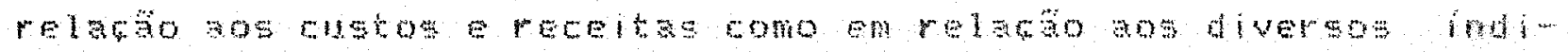
ces de eficiencia.

0 menor wusto da mara é obtido no estratoly. depols no estrato l finalments no estrato II.

Na tomposibo do rugto total obsernase que as

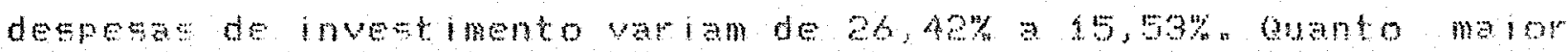
o pomar, menor a sua participacto

Nas despesas operacionais, que yriande $79,58 \%$ a

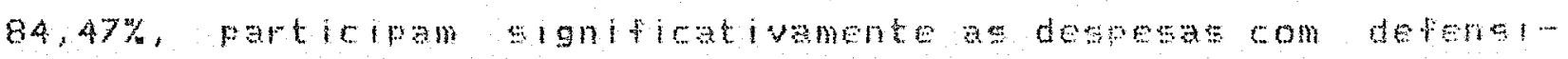
vos, combustiveis e lubeificantese momamoln aue conjuntamente

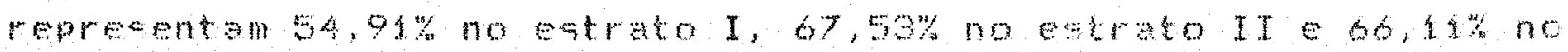
estrato III. 
A receita liquida media some valores positivos nos tres estratos, sendo que o melhor resulta es apesentado pow

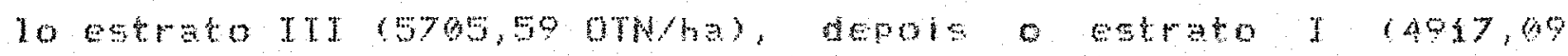

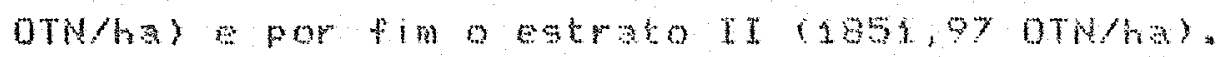

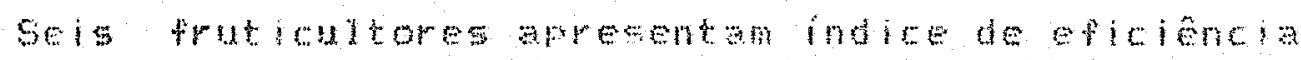

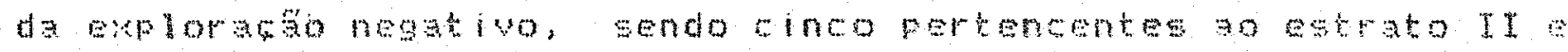
um to setrato 1

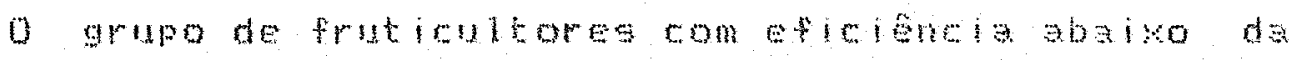

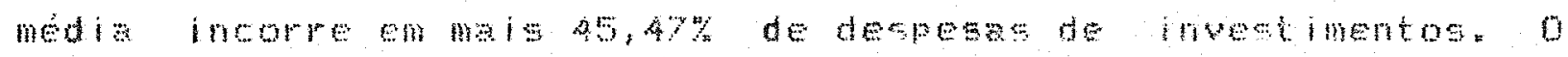

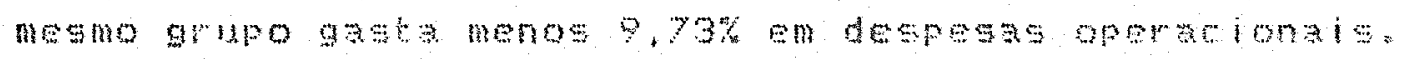

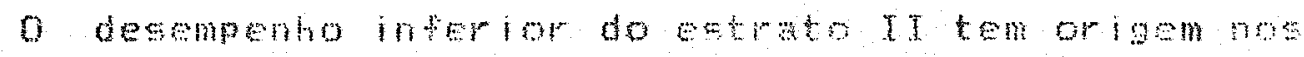

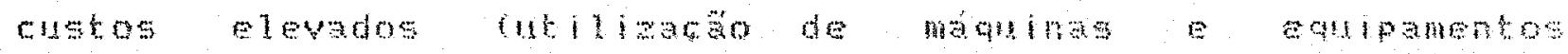

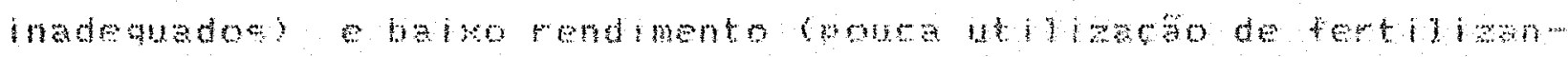

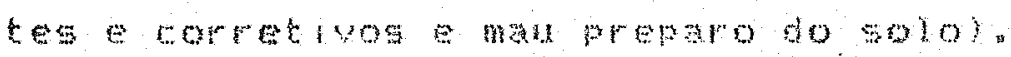

o. autor auger me ontras pesmisas sejam

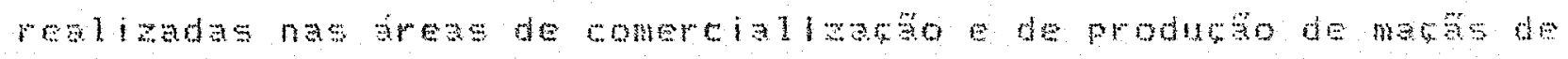
mator somatho melhor apesentabo, 
EFFICIENCY AND APPLE PROUUTION COSTS IN THE CAMPOS DE LAGES REOION, STATE OF SAMTA CATARINA

\author{
Author: Armando bogks \\ Adwiser: Prof. Dr. Pedro Unentim marase
}

\title{
SUMMARY
}

\begin{abstract}
This disertation discussed the sple poductive

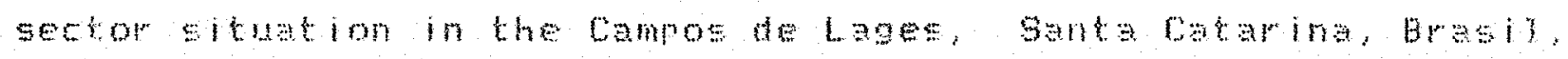
homogeneous micro reginn. The ma in objective ans to determinato the production costs. movnue and several efficioncy inderes.

The data for this rasearch was randomly rollected with trut producer and divided intothree clasese acoramsu

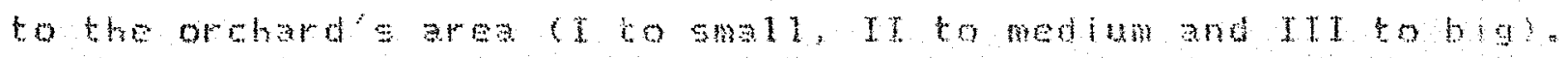

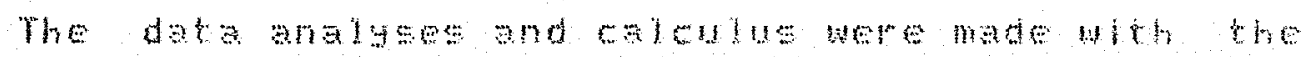
help of the Lotus $1-3-3$ program.

The investment theory was used and it was considered as time horlantal the orchard moductive lite of 22 years. cost and revenue vere discombed to the same dats at the interest rate of ow per year.

The monetary values of infut were calculated at the Janurs 1980 basis and the congldered apple price was the men ot a historical egries which was thentranelaged both in National

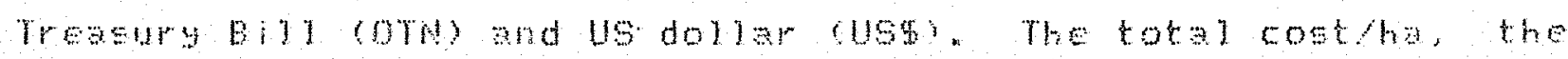
averag costra, the oros and net revente/ha and the inderes of technicalefficiency, price efficiency, economic etficiencs and exploitation efficiency were then calculated. 
There was no statistical diference, at the gin level, neither betwen the mean total cost for the farmers in the I clase and in the III class nor for the net revenue for the same $\cos 25$

Using the man data por axh class, stored in the

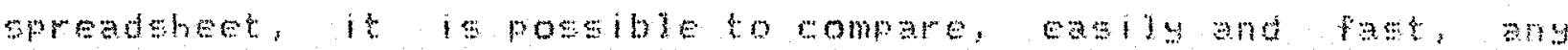
producer with the mean of the his elase, both in relation to roet and revenue and in relation to several etpiciency indexes.

The smallest apple cost obtalned was in clas TH, after in elase 1 and finally, in class II.

Looking at the tosal cost moposition, it can be

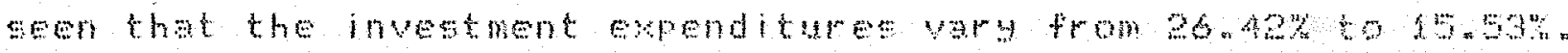

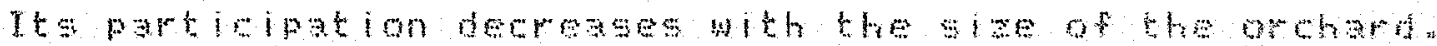

In the operational expendives, which ury from

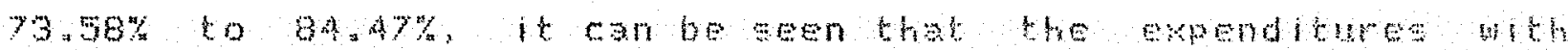
agriculural deteneises, fum and lubronts and labor are the

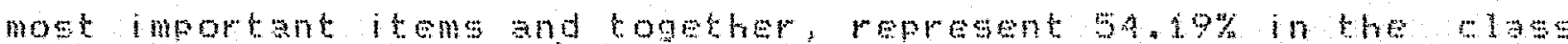

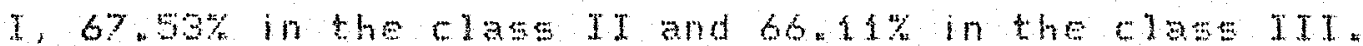

The net revenue was positive in the three classos,

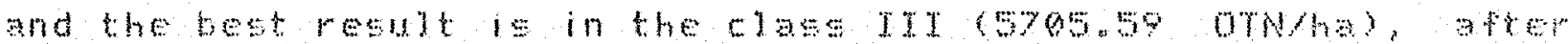

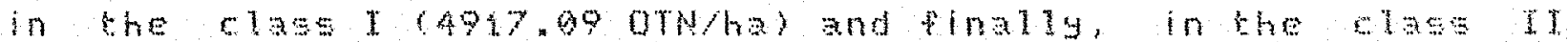

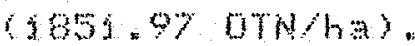

Six growers presented negative IEEx, five in the clare IT and one in the elase I.

The group of the arouers with efficienes bellom the

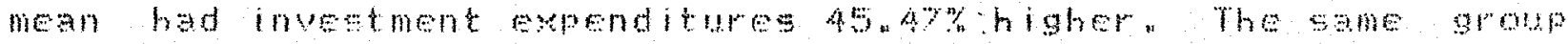




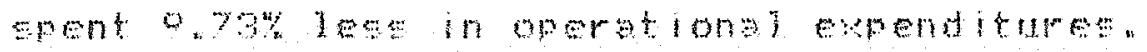

The inferior performance of the farmers in the II

clase was due to the high cost resulting from machires and equipment not afequate and low yield due to low input utilization and bad soil prenaring.

This auhor wugests that other researchos should be done in the marketing and produetion of bleger and better looking apples. 


\section{INTPODUESO}

\subsection{Coneideracoses aerais}

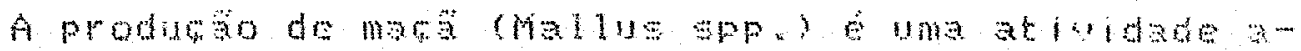

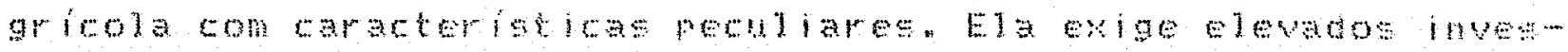

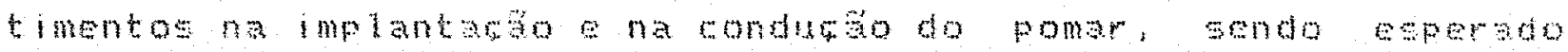
un retorno Emente a molo prazo. Hé anda a neceseidado de ir...

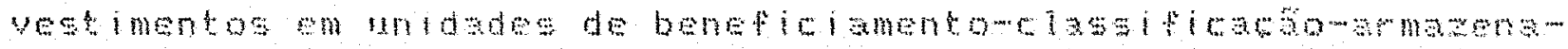
mento para completar o c icto modut 190

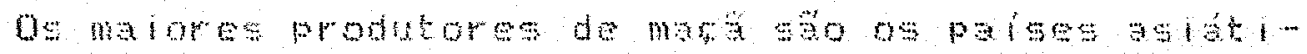

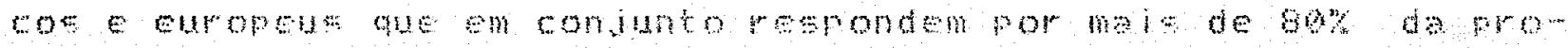

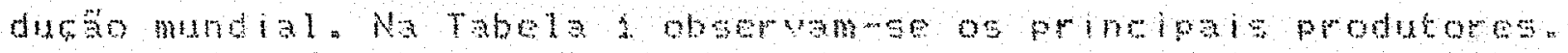

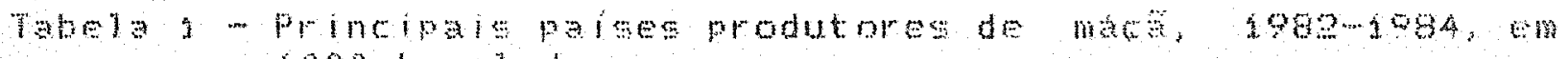
topotoneladas.

\begin{tabular}{|c|c|c|c|}
\hline$p+1 \leq 0$ & 1902 & 1983 & 1934 \\
\hline Uniso sonterio & $y \cdot d \cos$ & $7.8 \%$ & 7.500 \\
\hline Ghina & $2 . A A$ & 3.51 & $3 ., 10$ \\
\hline Eetados Unidos & $3.6 \%$ & 3.76 & 3.729 \\
\hline Frants & 3.149 & 1.963 & 2.935 \\
\hline $1+311$ & 2.603 & 2.31 & 2,650 \\
\hline Tur aula & 1.500 & 1.750 & 1.900 \\
\hline Alemanh boidental & 2.637 & 1.313 & 1.732 \\
\hline Polonia & $2 \cdot 1 \cdot b$ & 1,729 & 1.560 \\
\hline Hisngrio & 1.20 & $3 \times 34$ & 1.144 \\
\hline Eamha & 89 & 1.96 & 1,019 \\
\hline Outros & $13.62 \%$ & 13.477 & 12.973 \\
\hline Total mundial & 41.440 & 30.340 & 40.378 \\
\hline
\end{tabular}

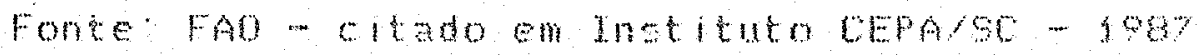




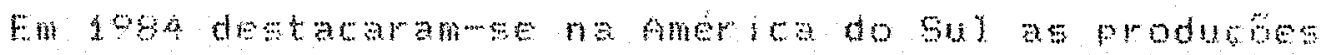
dargentina (934.000 ty a do fhile (110.090 t? "

A produca brasileira de mata duranta decada do 1960 foi liderada pelo Eutado de 590 Palo seguido pelo Rio Grande do sul santa Catarina, apresentando nma cwoluco meda anual calculada en $4,1 \%$ entre 1957 e 1967. (NEYEs, 1969$)$

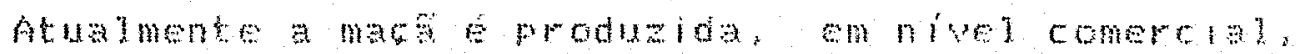
en apenas cinco Estados brasileiros, CTabela 2).

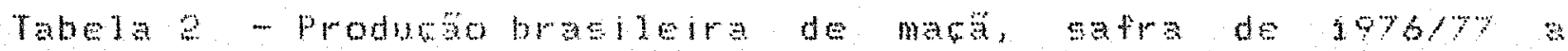
1985,86, en tonelatas.

\begin{tabular}{|c|c|c|c|c|c|c|}
\hline \multirow{2}{*}{$5 a b a$} & \multicolumn{5}{|c|}{ Estado produtor } & \\
\hline & PS & 50 & $P R$ & $s$ & $\mathrm{MB}$ & BRASL \\
\hline 2976177 & 1.953 & 2.355 & 256 & $\cdots$ & - & 14.56 \\
\hline $1977 / 78$ & 3.340 & $10 \cdot 35$ & $y$ & $-m$ & $\cdots$ & $f, 2, y$ \\
\hline $19787 \%$ & 3.600 & $21 \cdot 410$ & rot & $1+000$ & 200 & 30,90 \\
\hline 1979180 & 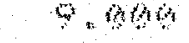 & $28 \times 29$ & $2 \cdot 356$ & $.90 \%$ & 53 & 49.13 \\
\hline $1960 / 8$ & 13.500 & $39+179$ & 4000 & 11.600 & 947 & 69.2 \\
\hline $1081 / 82$ & 25.900 & 76,664 & 7.710 & 17.000 & 1.300 & $127=0$ \\
\hline $1962 / 83$ & 21.000 & $57 \cdot 39$ & 8.000 & 13.200 & $1-100$ & $100 \times 698$ \\
\hline $1083 / 84$ & 32.000 & 190,609 & $13.88 \%$ & 7.20 & $=200$ & 162,89 \\
\hline $198 \mathrm{~A} / \mathrm{s}$ & 50.060 & 138.096 & 17.300 & 8.000 & 1.200 & 218.96 \\
\hline $1035 / 86$ & 65,80 & $106 \times 997$ & $10.72 \%$ & 7.716 & 1 of 830 & 247,160 \\
\hline
\end{tabular}

Fonte: Instidu OEFASC 1997 (adaptada?

A possibilidade de aplicaso de incentinos pingas

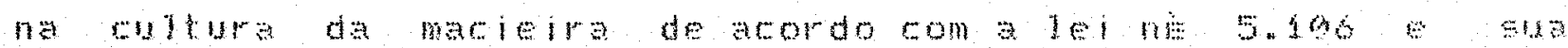

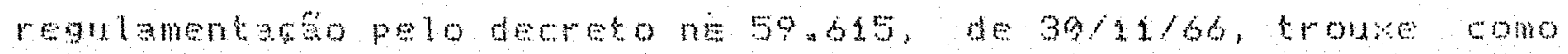
objetuo fundamental o amento da area cultrada com macira ja que por multo samo o mercado brasilaro fol obasecido basicam mente pela mas importada, endo a nacional produsda emparena 
guancidade com qualidade multo infer for am 1970 , segundo dados da Food and Agriculture Organization (FAO), o Brasil absoryiad 5 a $6 \%$ do volums mundlal de mara, constibundo-se no mator mpor

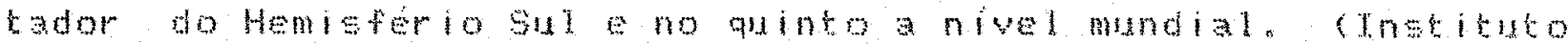
$\operatorname{CEPAOC}, 1986$

En 1968, com a criago do Projeto de Fricionluma

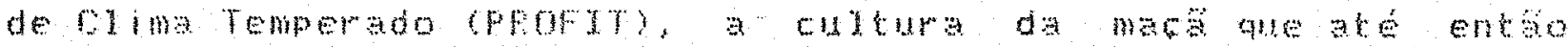
era realizada de forma empirica, tomon outros rmos, sendo vieta

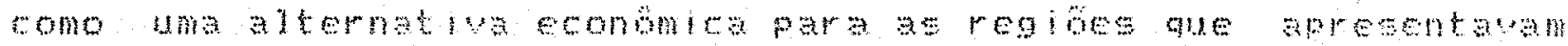

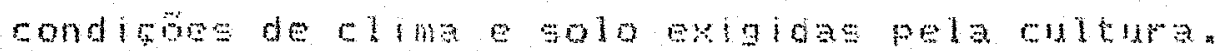

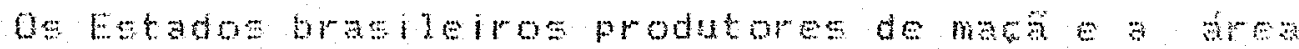
plantada estarepresentados na Tabela 3

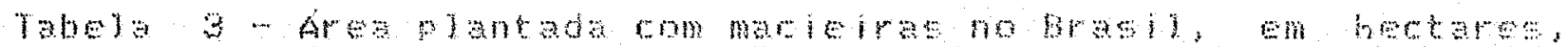
por Eado, de $1973 \Rightarrow 1985$

\begin{tabular}{|c|c|c|c|c|c|c|}
\hline Ano & Ps & $5 \%$ & $P Q$ & $s p$ & $M S$ & Bras \\
\hline $19 \%$ & 54 & 2.668 & 380 & $\ldots$ & ... & 3.59 \\
\hline 1976 & $1 . \pm 18$ & 3.916 & 69 &.- & $\ldots$ & 5.629 \\
\hline 1977 & 1.674 & 5.287 & 1.136 & - & $m$ & $8,1 d 7$ \\
\hline 1998 & 2.70 & $6.39 \%$ & $1=6 \mathrm{~b}$ & - & 150 & 10,87 \\
\hline 1979 & 3.185 & $7,5 a$ & 2.256 & 2.000 & 157 & $1 A, 72$ \\
\hline 198 & $4 \times 424$ & $\beta_{2}+1$ & $2, \beta$ & $24 \Delta 8$ & eno & 18,4 \\
\hline $198 \mathrm{t}$ & $5.49 \%$ & 9.93 & 3.690 & 2.600 & 220 & 20,915 \\
\hline 1908 & 6.96 & 10,09 & 4.100 & $2.9 A 9$ & 220 & 28,218 \\
\hline 1983 & 6.640 & 10,608 & 4.27 & 3.900 & 280 & 24,911 \\
\hline 1904 & $7.4 A G$ & 11,96 & 4.49 & 3.400 & 280 & 27,160 \\
\hline 1985 & 7.949 & $12=821$ & 4.538 & 3.00 & 280 & 28.680 \\
\hline
\end{tabular}

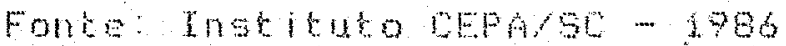

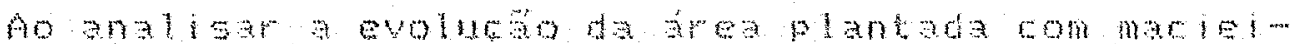

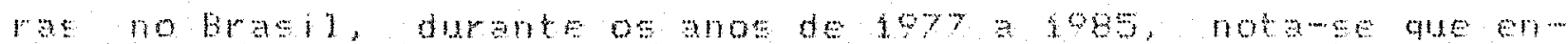




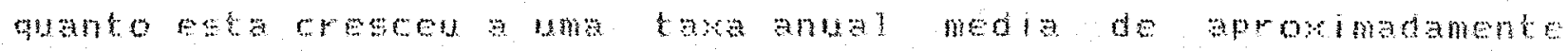

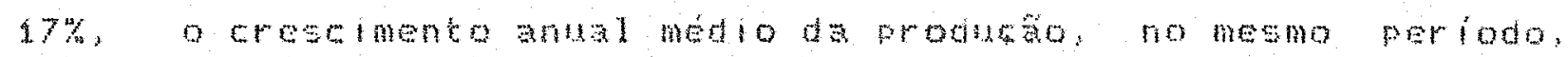

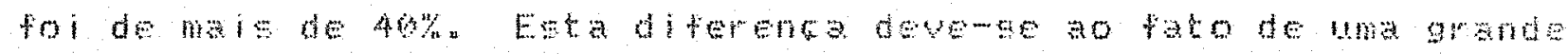

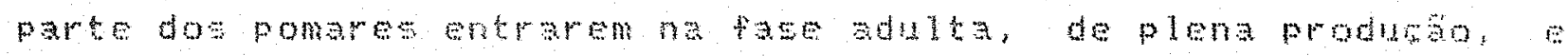

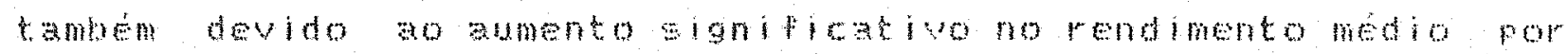
hetents

No Brasil, o conamo de nag por habitantaranotan

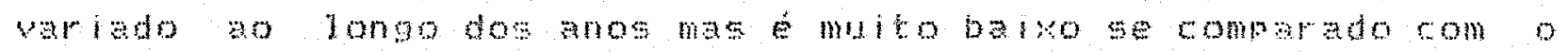

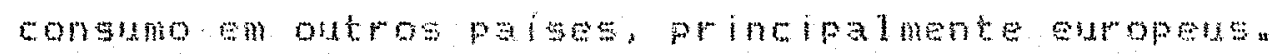

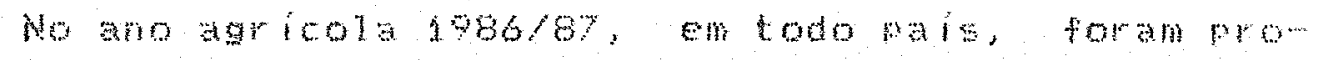

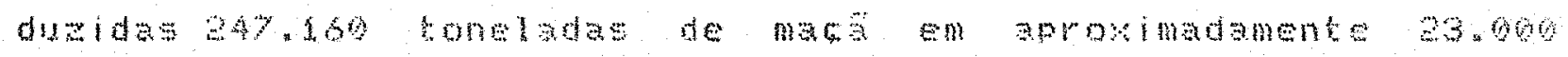

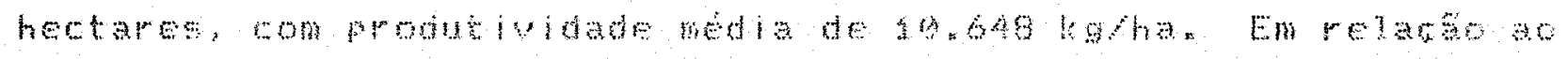

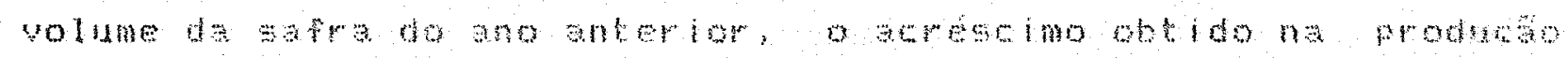

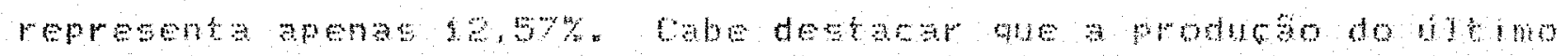

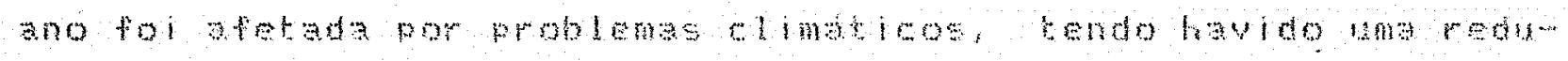

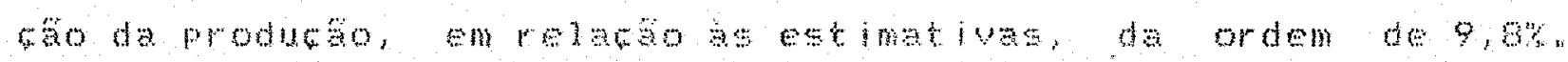

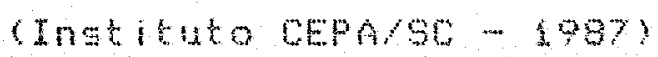

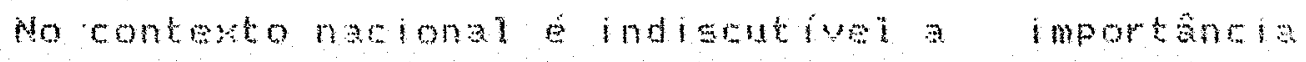

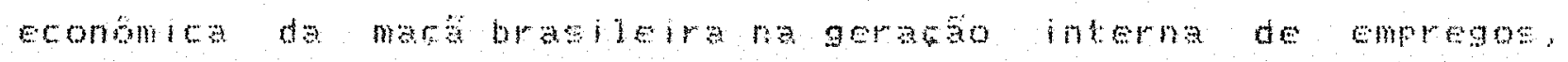

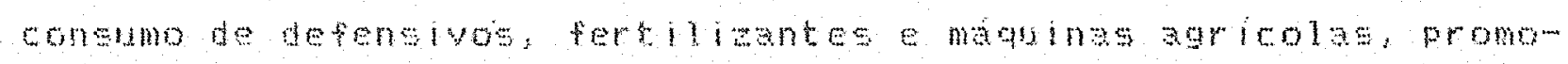

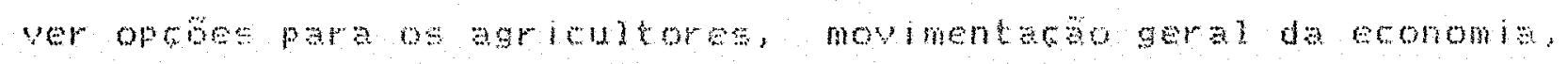

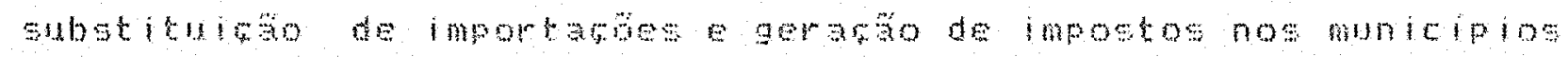

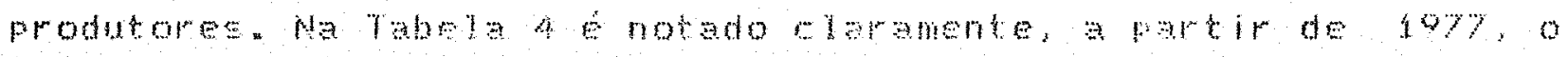

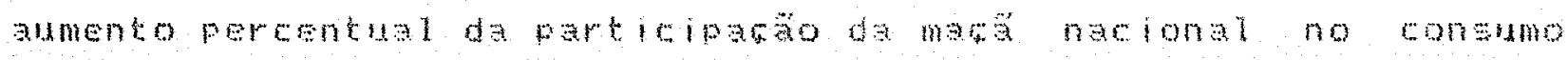

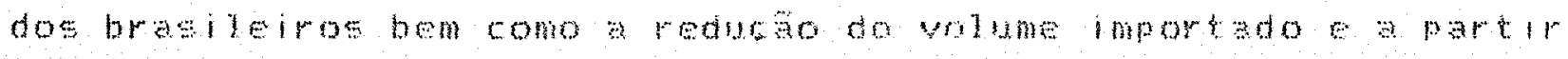

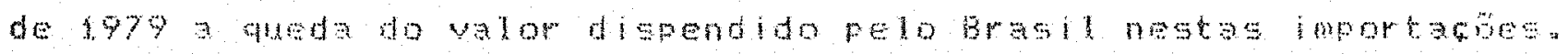




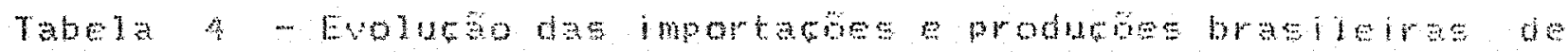
$\operatorname{mac}, \quad 1979298$

\begin{tabular}{|c|c|c|c|c|c|c|}
\hline Ano & 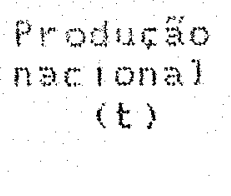 & $\begin{array}{c}\text { Uolume } \\
\text { importado } \\
\text { ts }\end{array}$ & $\begin{array}{c}\text { Yolume } \\
\text { cotal } \\
\text { (t) }\end{array}$ & 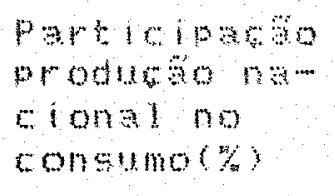 & $\begin{array}{l}\text { Consumo } \\
\text { narional } \\
\text { clobabs } \\
\text { ano }\end{array}$ & 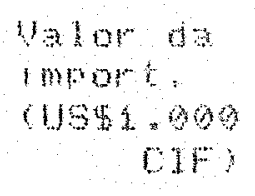 \\
\hline 197 & $27 \cdot 312$ & 143,59 & 170.607 & 15,83 & 1,6 & $62,8 r^{2}$ \\
\hline 1976 & 23.303 & $18 \% .996$ & $212.69 \%$ & 10.96 & 2,0 & 78.89 \\
\hline $197 \%$ & 14 $3 \mathrm{wg}$ & 202,668 & $217-123$ & 6,70 & 20 & 88.996 \\
\hline 1978 & 14.793 & 190.217 & 204.920 & 7,17 & 1,8 & 97.78 \\
\hline 1979 & 38.96 & 183,117 & 22,867 & 17,54 & 1,9 & 101.882 \\
\hline 1980 & $49 \cdot 13$ & 135,420 & $18 \Delta, y A d$ & $2 b, 62$ & 1,6 & 77.206 \\
\hline 1981 & $69 \times 202$ & 112,569 & 181.785 & 39,09 & 1.5 & $68,42 A$ \\
\hline $190 \%$ & 227,874 & 127,631 & 255.605 & $30,0 \%$ & 2,0 & $67-128$ \\
\hline $108 \%$ & $100^{\prime} 690$ & 115,984 & 36.62 & 48,59 & 1,7 & 42660 \\
\hline 1984 & 162,780 & 89.233 & $25 \mathrm{an}$ & 64,4 & 1,9 & 20.65 \\
\hline 1985 & 219458 & 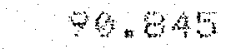 & $316.46 \%$ & 70,73 & 2,3 & $26, A 84$ \\
\hline
\end{tabular}

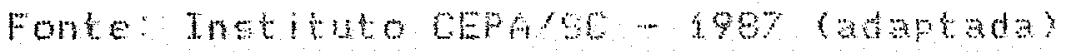

0 Eatado dz sama Catarina fem apresentado mm

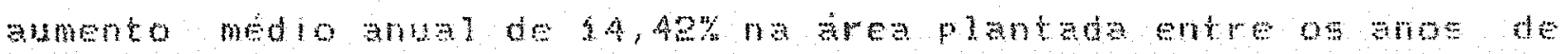
1977 e $966=32,63 \%$ ne poduso Como ow demale Estadosprodu

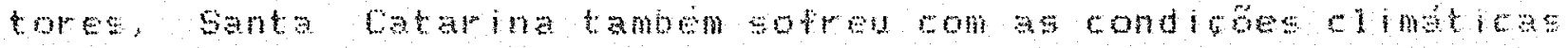
advergas ocom idae durante o ano de tobs aue reduziram arodubo

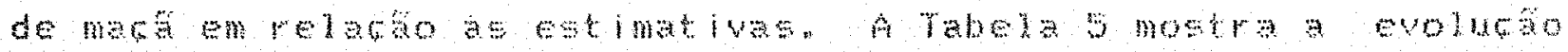
da culdura da mara no Estado de santa batarina no per fodo de 1977 $\Rightarrow \operatorname{seg}$ 


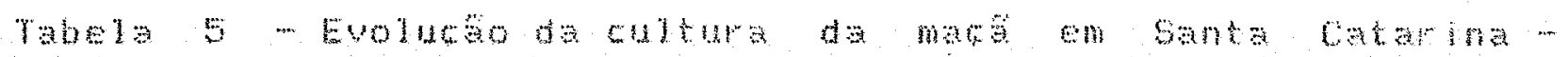

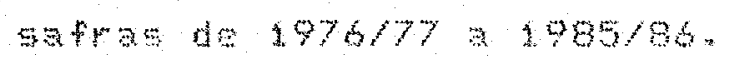

\begin{tabular}{|c|c|c|c|c|c|}
\hline $9 a+r a$ & $\begin{array}{l}\text { Area } \\
\text { flantada } \\
(h a)\end{array}$ & $\begin{array}{l}\text { Area } \\
\text { wothlds } \\
\text { (ha) }\end{array}$ & $\begin{array}{l}\text { Produso } \\
\text { of ida } \\
(t)\end{array}$ & $\begin{array}{l}\text { Particlpaso } \\
\text { na produsao } \\
\text { nactonalo }\end{array}$ & $\begin{array}{l}\text { Pendimeno } \\
\text { modio } \\
\text { (kolnas }\end{array}$ \\
\hline $1976 / 77$ & 3.815 & 1.37 & 12.355 & 8,87 & 8.90 \\
\hline 1977,70 & $5,28 \%$ & 1.06 & 0.04 & 73,52 & 5.32 \\
\hline 1978779 & 6.337 & $2.6 b 8$ & 21.410 & 64,97 & 8,8 \\
\hline $1979 / \theta 0$ & $y .150$ & 3.94 & 23,25 & $57,4 d$ & 7.398 \\
\hline $18 \Theta \curvearrowleft / 81$ & 8.91 & s. $29 \%$ & 30.175 & 56,59 & 7.410 \\
\hline $18818=$ & 9.96 & $6,33 \%$ & 76.664 & 59.9 & 12.098 \\
\hline $196 \%, 83$ & $10, n 3$ & $7 \times 16$ & 7,338 & 66,97 & 9.95 \\
\hline 1983,8 & $\Delta \mathrm{w}_{2} \mathrm{~g} g$ & 602 & 108.600 & 66,72 & 3,5 \\
\hline $103 A / 8$ & 11.946 & 9.036 & 138.059 & 62.87 & +9.278 \\
\hline $1005 / 86$ & 12,821 & 10.36 & 156,987 & 6348 & $13.63 \mathrm{~A}$ \\
\hline
\end{tabular}

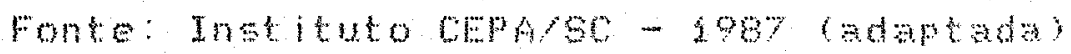

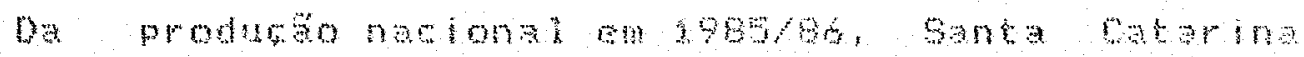

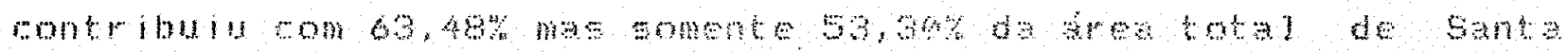

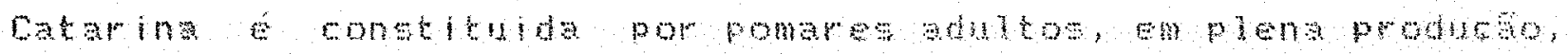
contorme pode ser vieto na Tabela 6

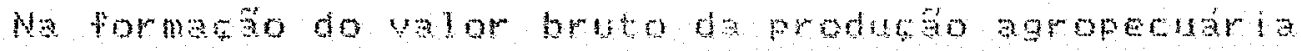

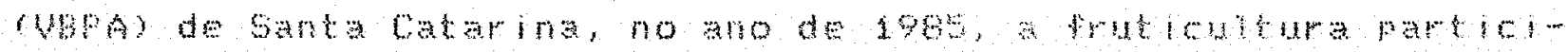

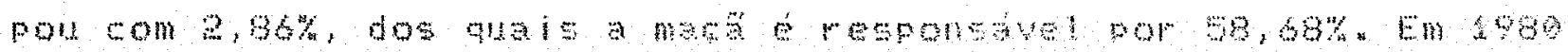

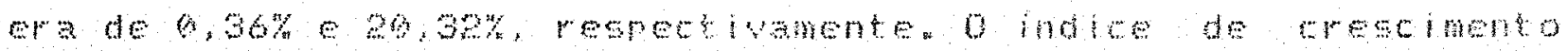
do valor brutade produga de mag cresceu de sog em 1909 para 507 em 198 anresentando o maiom crescimento entre os principals produtos agropecuarios anstituto CEPAs - 1985)

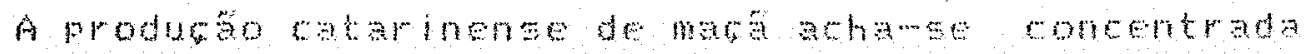

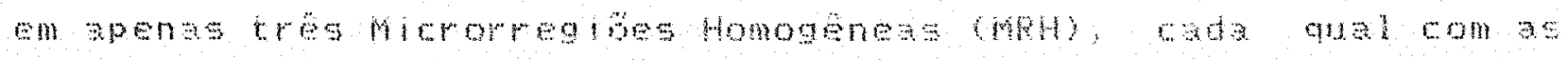

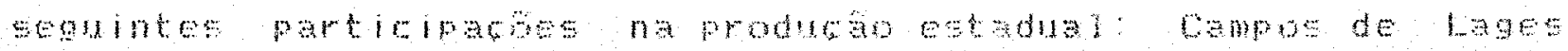




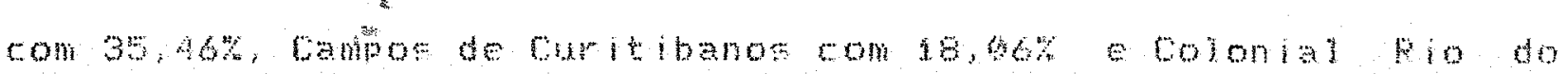

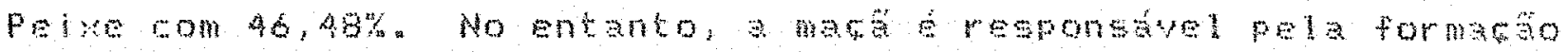
do Uppa, em cada um dectas MH, respectivanente em $19,90 \%$,

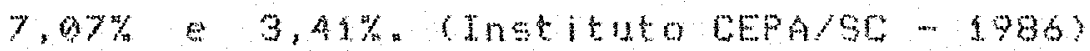

rodos os municipios que compon a MH Campos do Lags so considerados monciplos preferenoials no proorama da

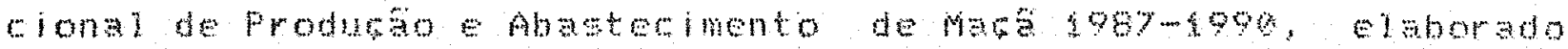
pelo hinigerio da Agr hultura.

Diantedos dados apesentados das perpectias do

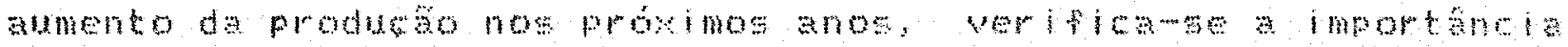

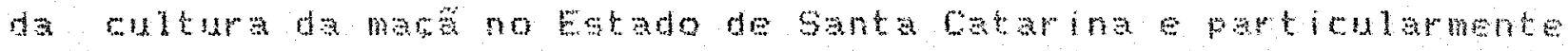
na MH Cempos de Lages.

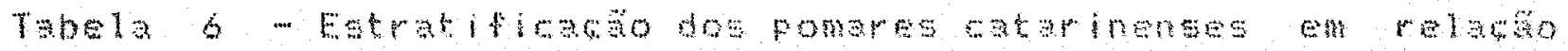
\& idade das plantas, 5970 a 1906

\begin{tabular}{|c|c|c|c|}
\hline \multirow[t]{2}{*}{ foora de plantio } & \multirow[t]{2}{*}{ macteristoses } & \multicolumn{2}{|c|}{ Aroporad } \\
\hline & & ha & $\%$ \\
\hline $\begin{array}{l}\text { Plantios ofetuados } \\
\text { ato 1970 }\end{array}$ & $\begin{array}{l}\text { Pomares adnltos, em } \\
\text { idade de plena prom } \\
\text { duga }\end{array}$ & $7 \cdot 1.4$ & 53,30 \\
\hline $\begin{array}{l}\text { Pantios etethados } \\
\text { de } 1980 \text { a } 1983\end{array}$ & $\begin{array}{l}\text { Pomares en crescimento } \\
\text { em idade de produmb } \\
\text { initial }\end{array}$ & 3.65 & 27,23 \\
\hline $\begin{array}{l}\text { Plantios efettados } \\
\text { de } 1984 \Rightarrow 1986\end{array}$ & $\begin{array}{l}\text { Pomares em tase de for } \\
\text { macio, ainda improduti } \\
\text { vos }\end{array}$ & 2.613 & 19,87 \\
\hline Totalo & & 13.421 & 100,00 \\
\hline
\end{tabular}




\section{2. o problema e. su importancia}

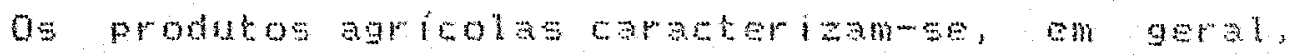

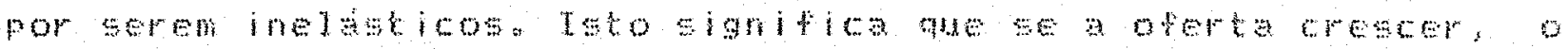

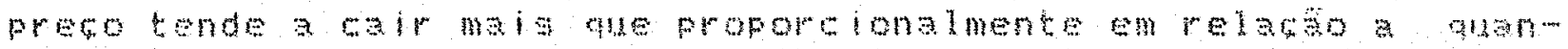

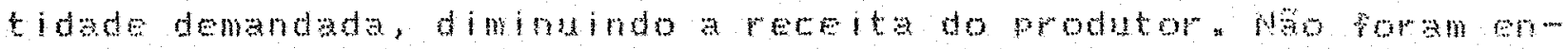
contrados trabaloo one quantifinem a elastieidade da denanda da $\operatorname{man} 2$

$$
\text { Diante de diversos patos, ta como expanso da }
$$

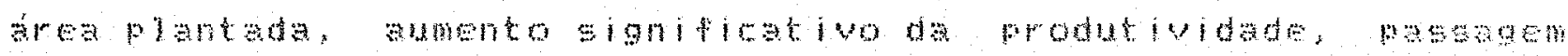
de pomars sinda improdutivos ou en fase lnicial de produmo

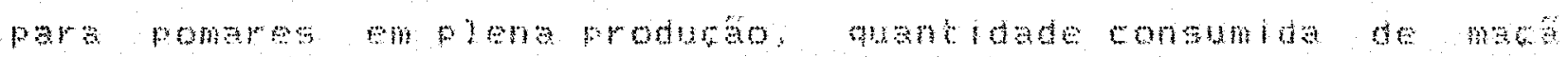

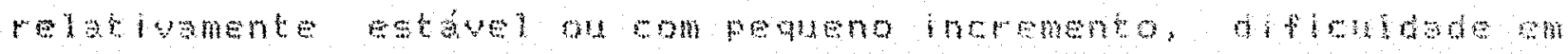

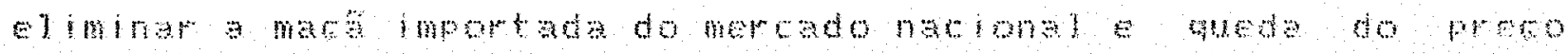
real da mas imporada o de se esperar unamesto no senta

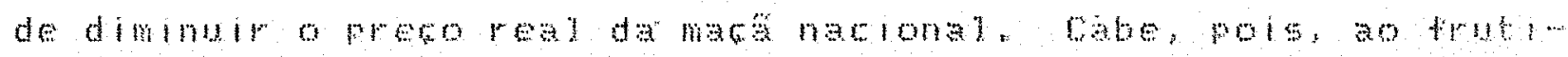
cultor viablingr aterba de seu produto a um preso menot o que serapos ivel somente com o amento na efletenciaterntere

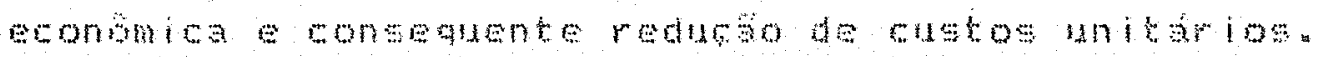

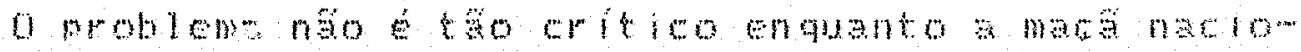

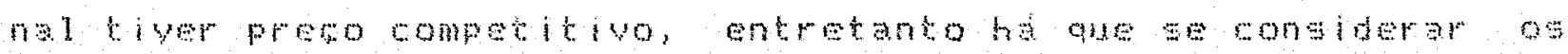

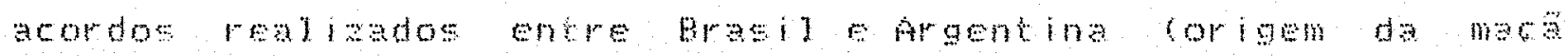
impotada) an podem tavorecer oproduto imporado alem de se

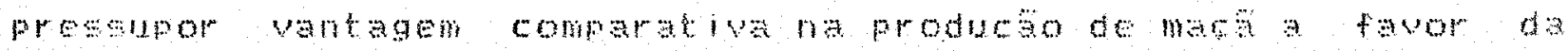
argentina e queda do precorealda mas imortada como rem acontecendo desde 1082 (CEPA/SC - 1966). 


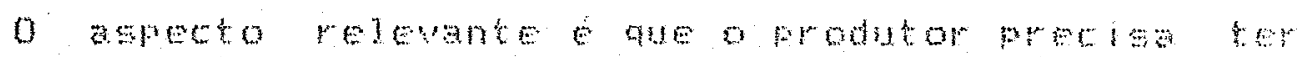

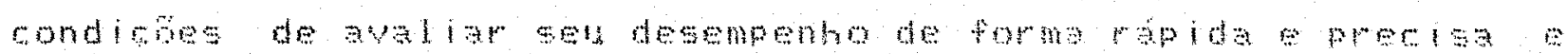

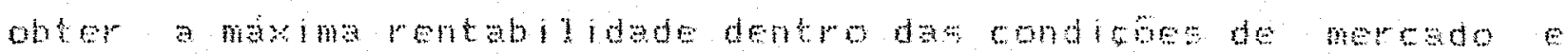

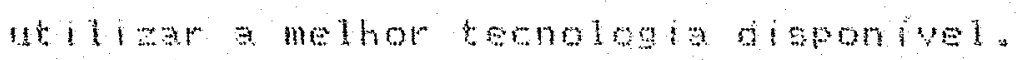

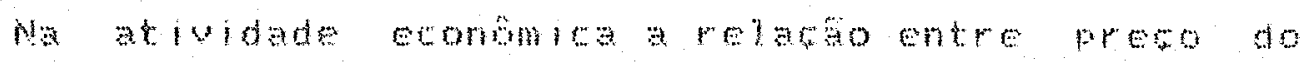

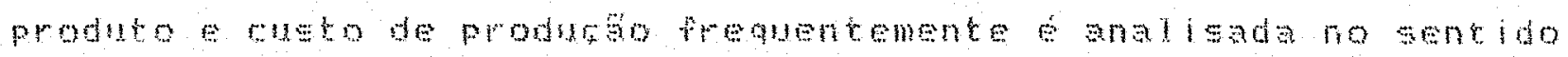
de majiar a ficlancia da atridade.

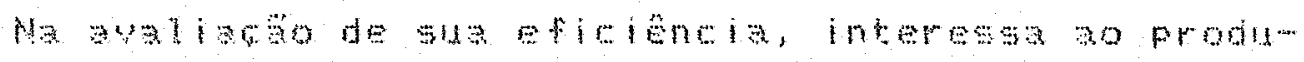

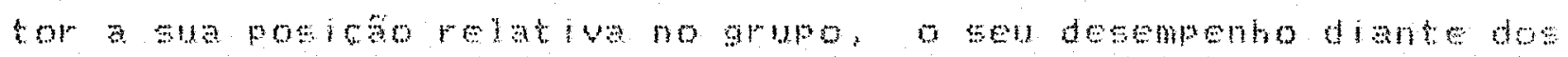

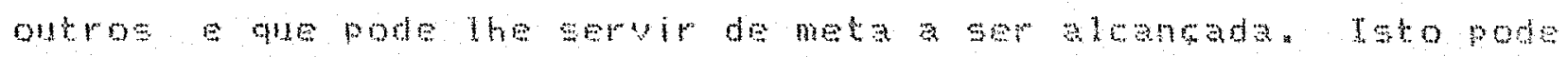

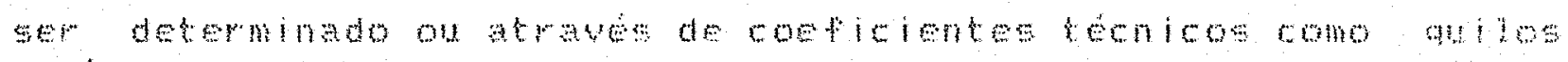

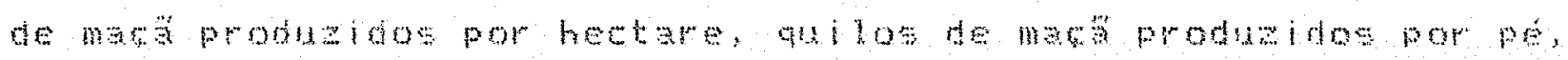

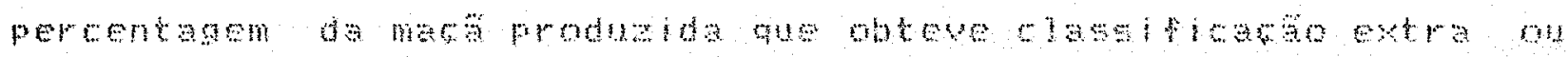

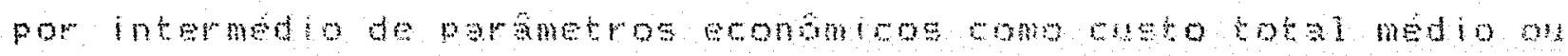

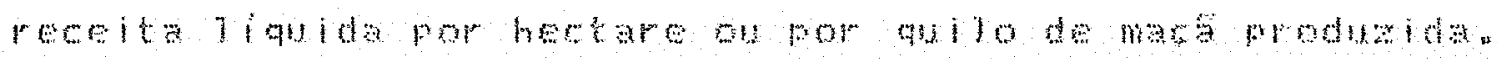

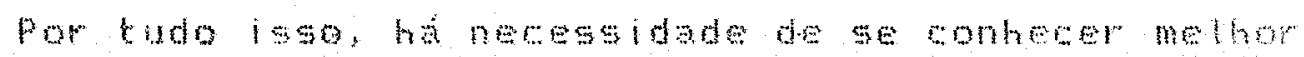

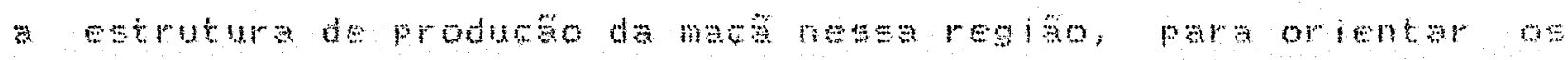

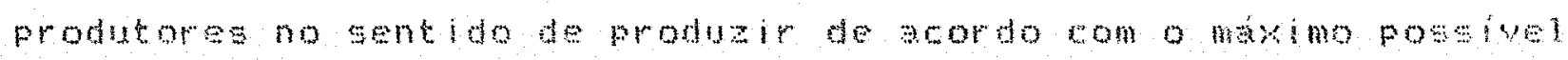

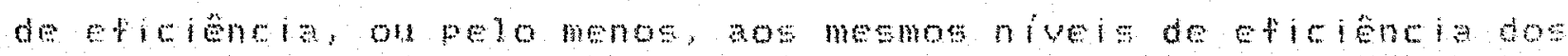
demas integrates do sen arato

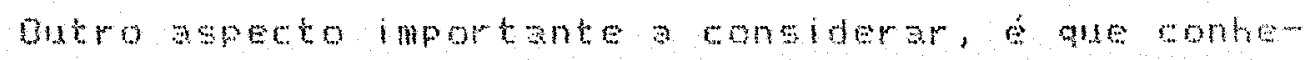

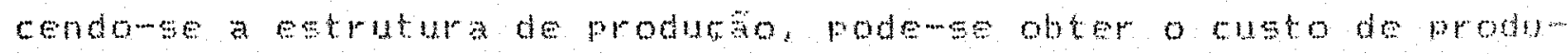

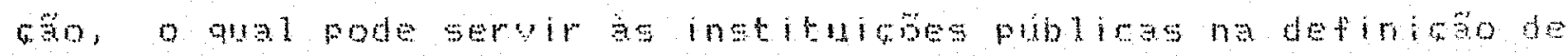

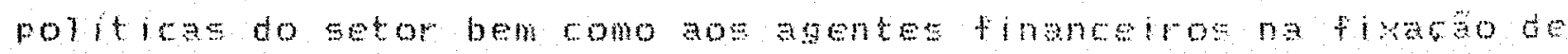

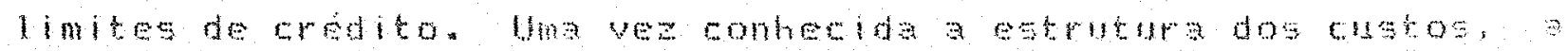

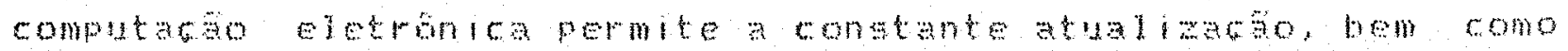




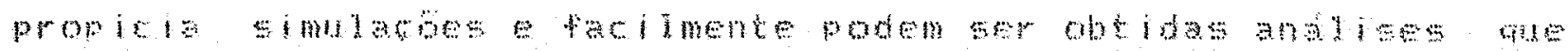
or ienten o pronutar em susa tomadas de decinos.

\section{3. objerivos}

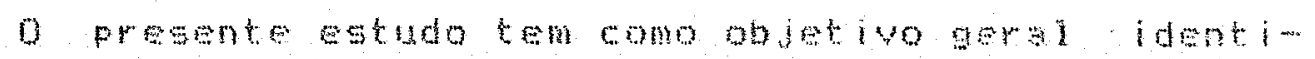

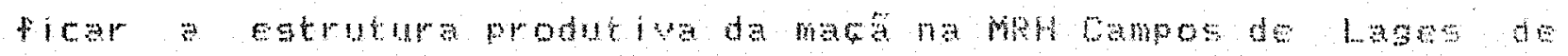

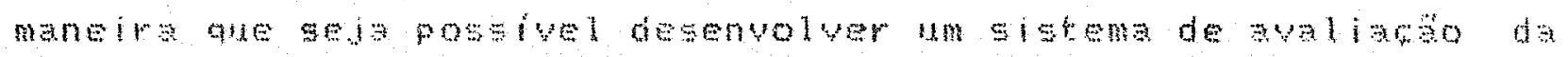

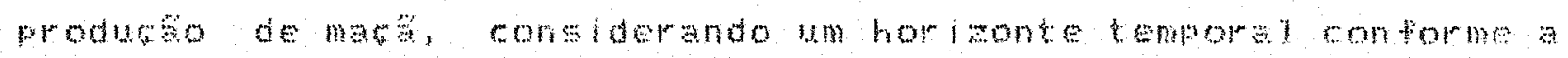

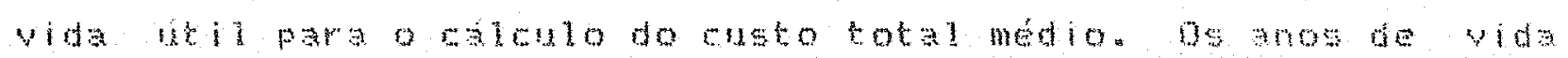

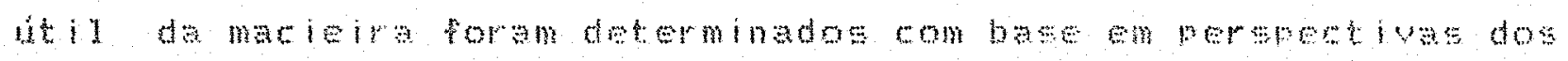

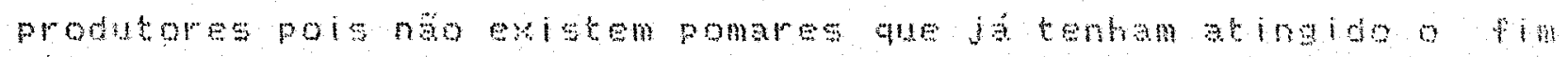

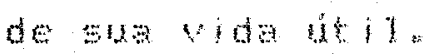

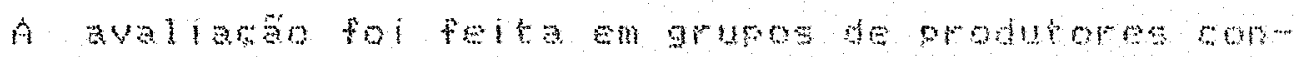

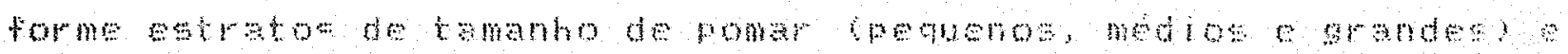
depois individualmenta.

\section{Esperticamentepretende 50 :}

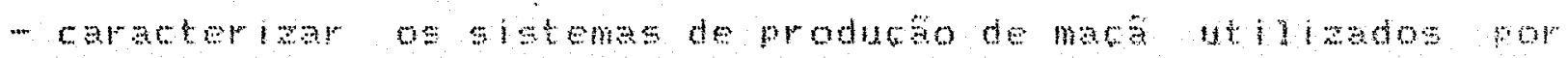
diterentes grupos de produtores;

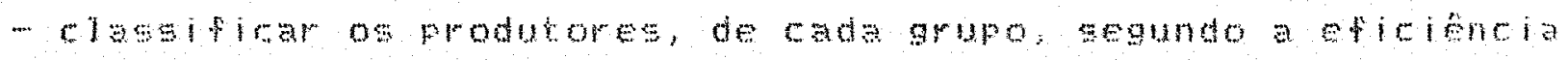

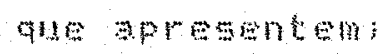

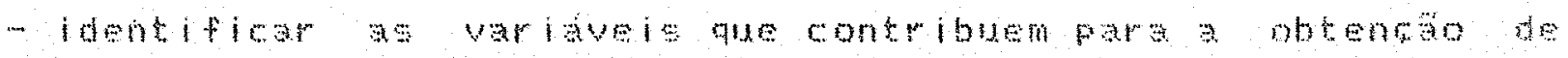
mator eficioncia da exploracas 


\subsection{Hipostas}

Mesmo rom a utilizaga de recnologia semelhante.

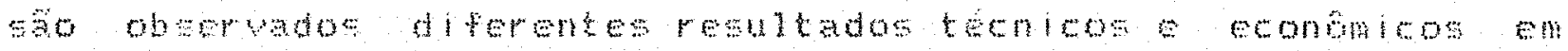
determada atiuidade agricola

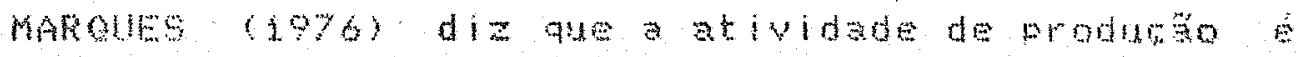
atetada por tatores "tisicon"e "népo fisicos" Entre os tatores fisicos estarianterra, semente, fertilizantes, capibal empresado

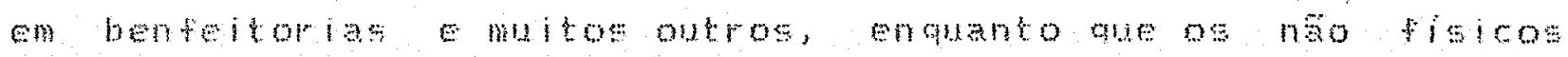

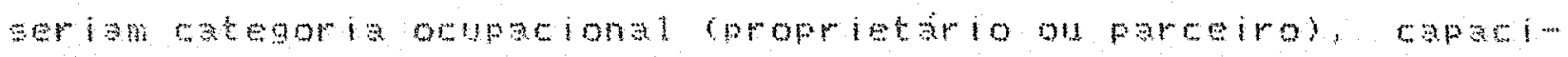
dade de leivra, idade, distácia a sede domuncipio niue de vida, comopolitimo. exposica a melos de commicano do masa exposica me mos do commicato temica.

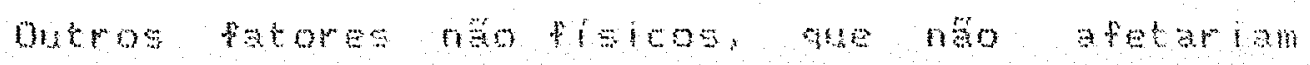

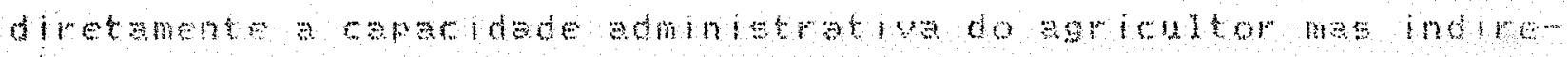
tamente o resultadoternico e econfmico da atividade, tambom

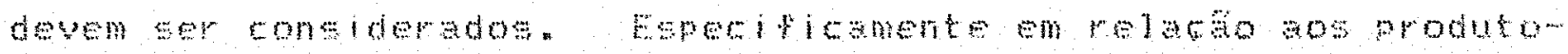
res de mas a mersos destane o tamanto do pomar.

As hipoteses do presente trabalho so:

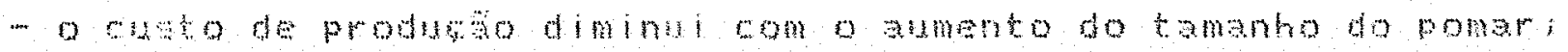

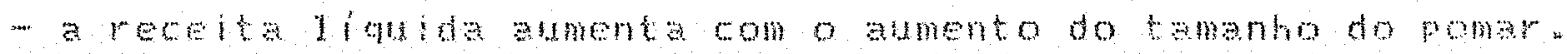


2. REVTSO BIBLIOSPAFTCA

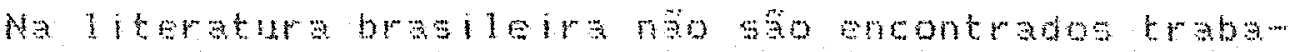

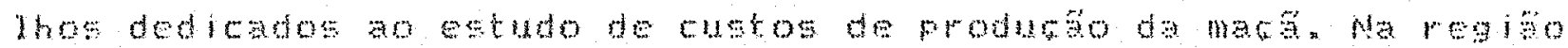

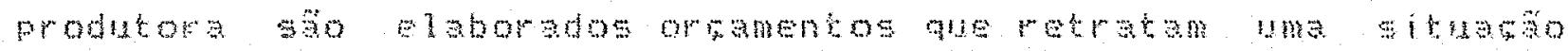

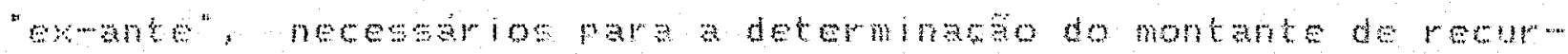

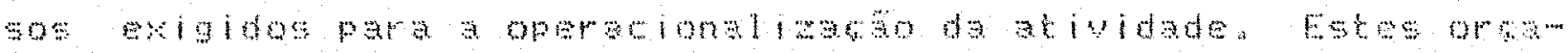

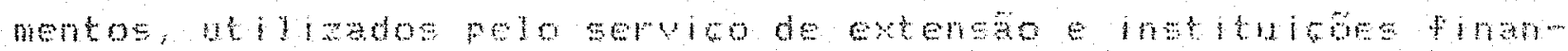

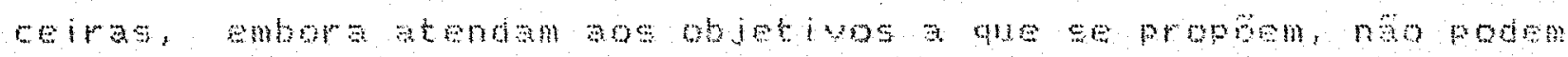

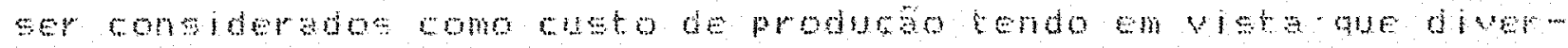

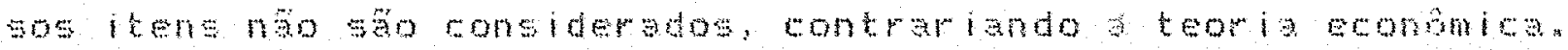

Nas determinabes de custos de producto das ativi dades aropecuarias no estse uma metodologla linica consagan

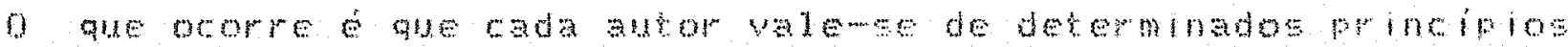

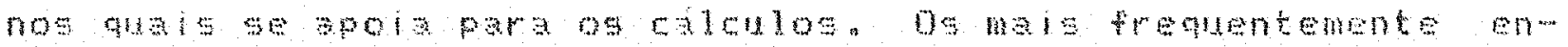
contrados valem-se dos principlos abordados na biblospata a

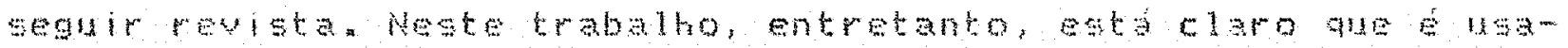
da una motodologia que considera o longoprazo apolawe na teor ta do investimento.

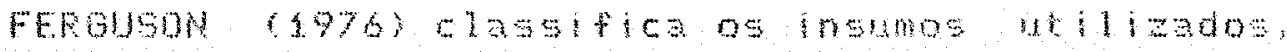

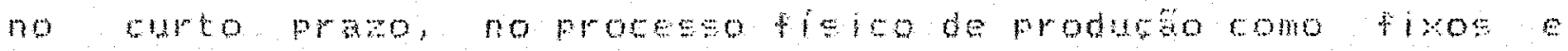




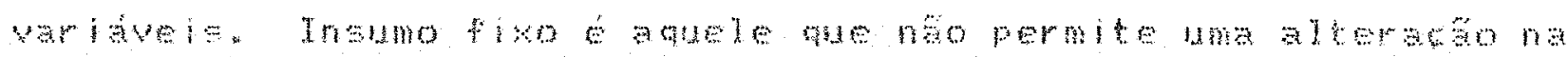

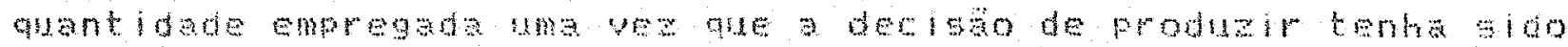

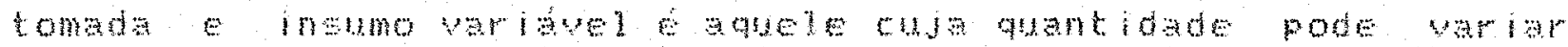

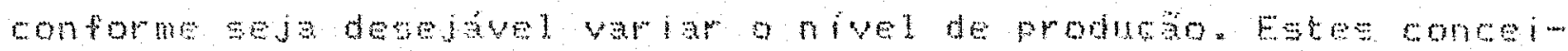

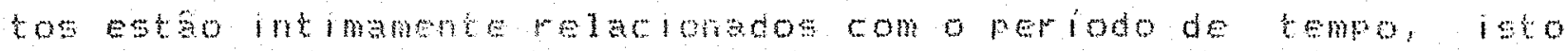
6. o curto a longo prazos wo curto prazo seria possiral variar a quatodade moregada de alans insumos porem, no minimo um

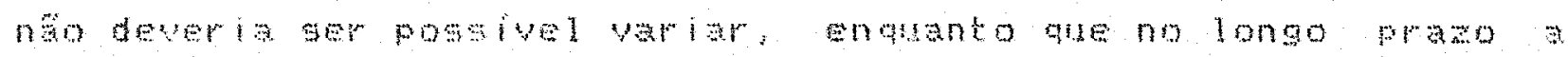
puantidade de rodos os insumos e variavel. A cada un desses

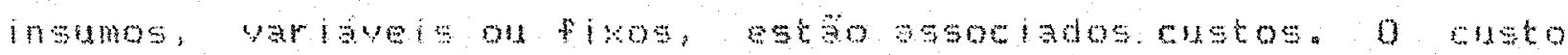

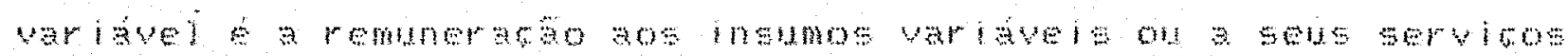

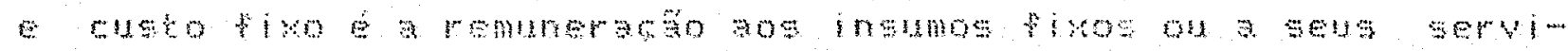

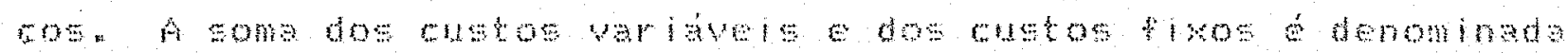
susto totsin

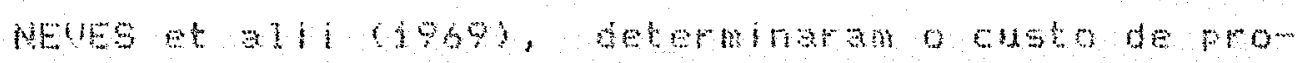

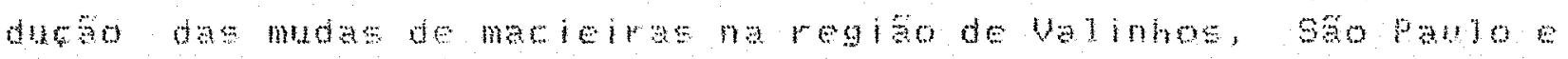
tombem degerevem as caracteristicas das propladades produtora

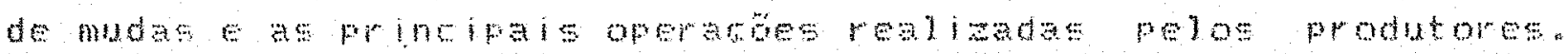

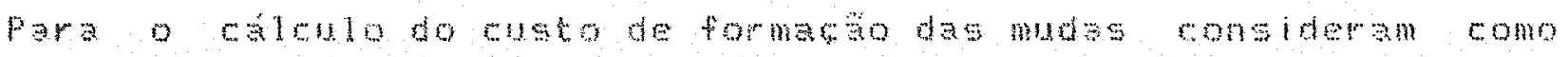

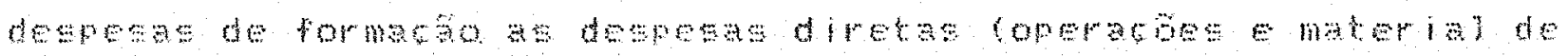
consume ag daspesa indiratas diversos, conservaro de ins...

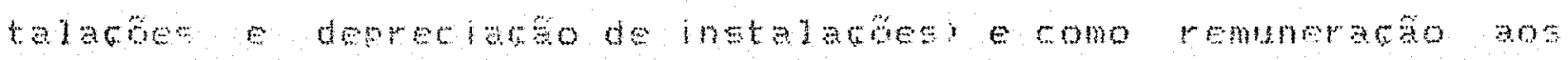

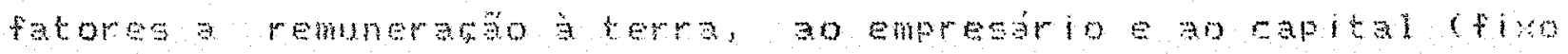

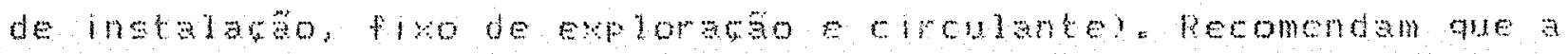

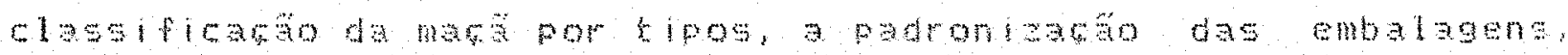
o Hoo de camaras frias a e etrutura de mercado deven ser estuda- 
das par que a aldidade posen creser e mpresentar methores resultanos

schut (496), em trabatho onde aboda diveroo

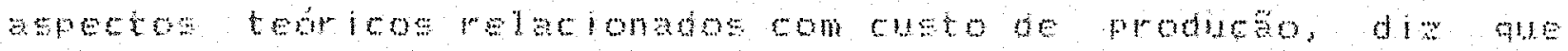

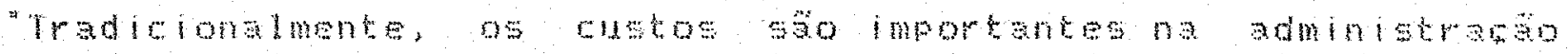

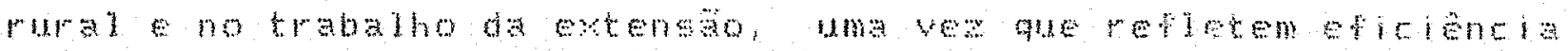

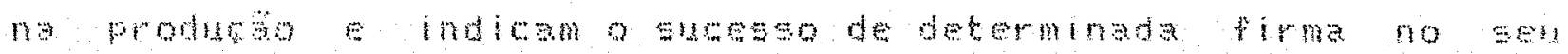

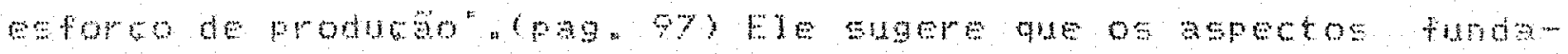

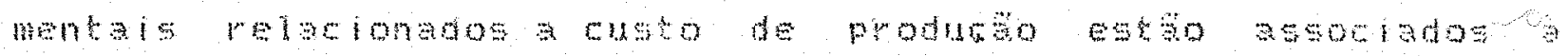

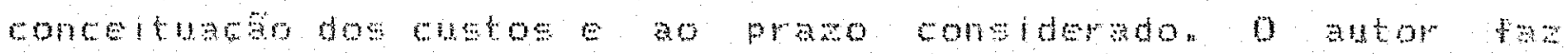

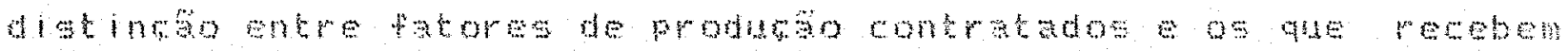

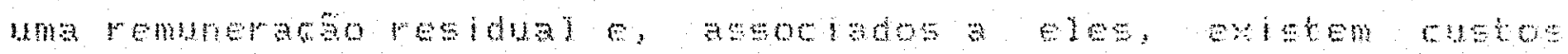

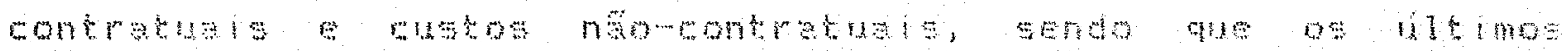

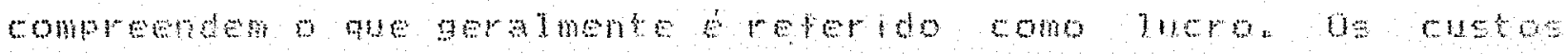

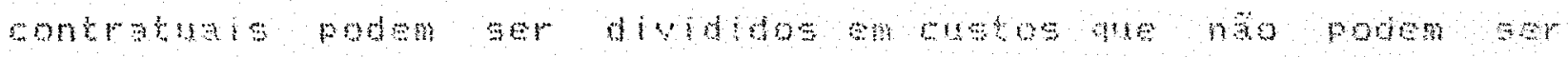

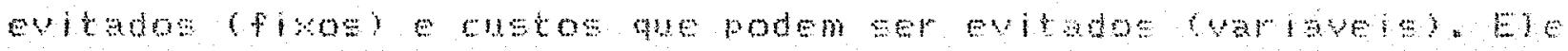

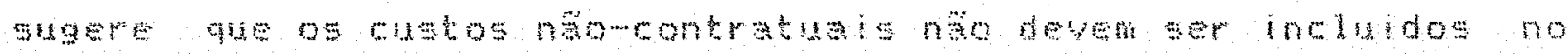

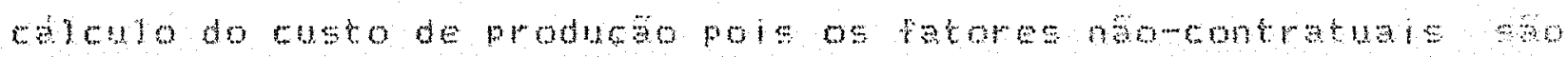
prebendentes a renda residul.

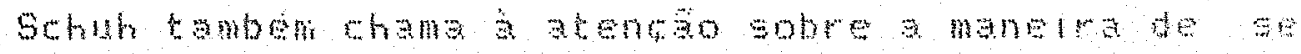

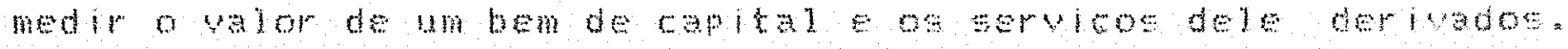
o bem de eapital deve ser avaliado pelo cuaro de reposiga.

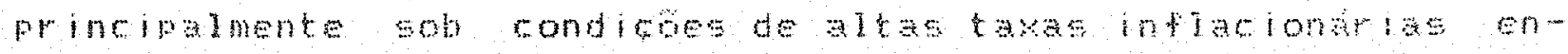
quanto que o prego de seve serviros e entandido, nsuabente.

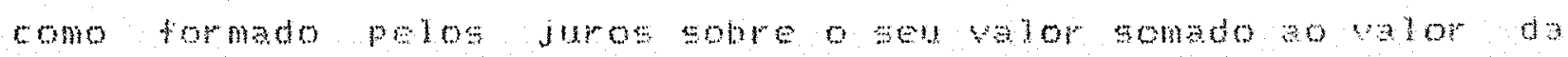
depres labo por unidade de tempo e ao custo de qua buser reparos 


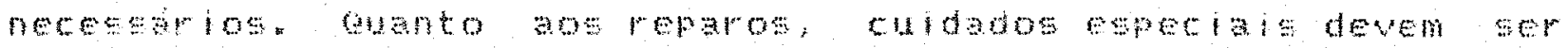

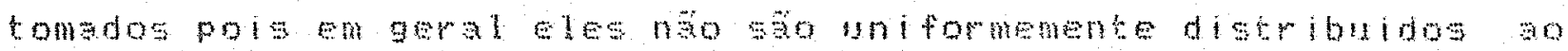

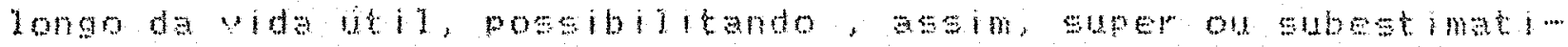

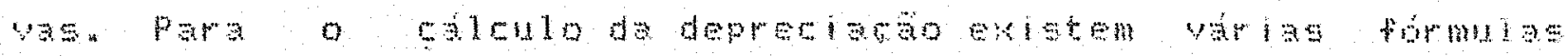

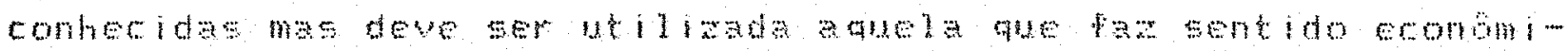

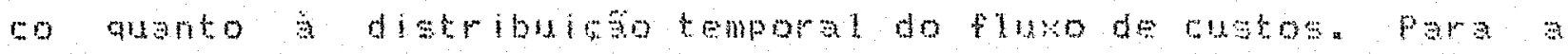

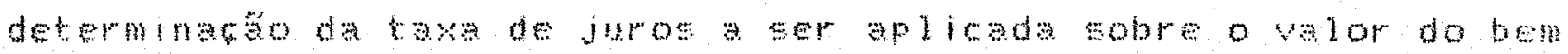

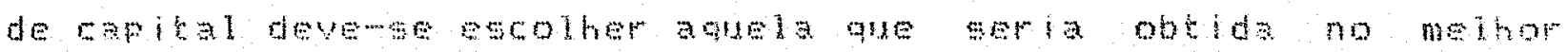

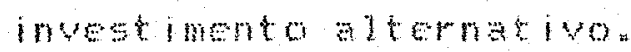

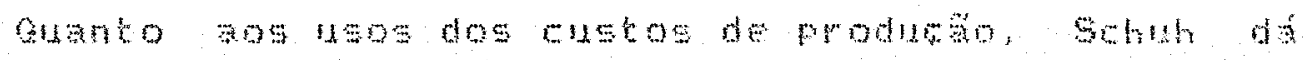

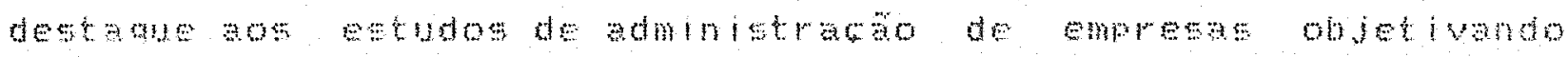

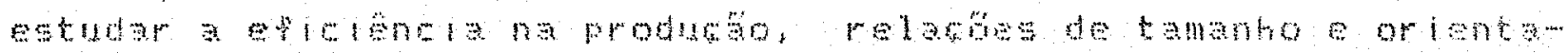

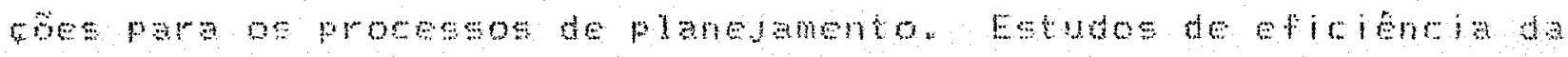

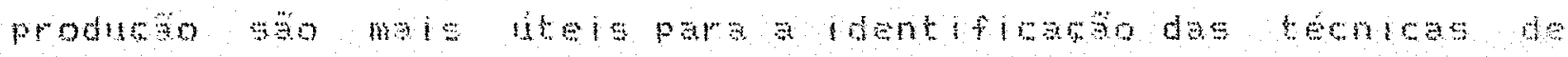

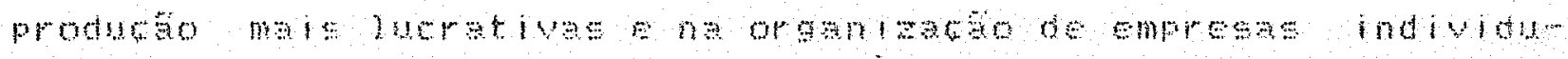
अ

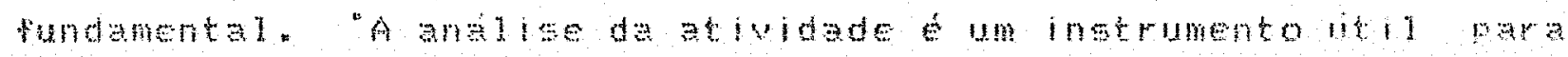

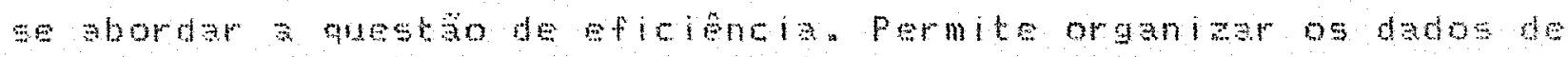

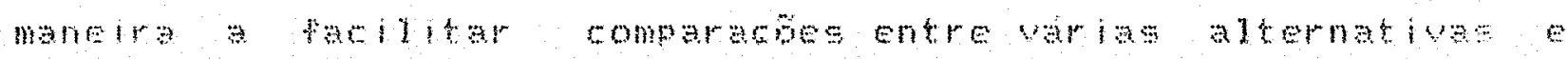

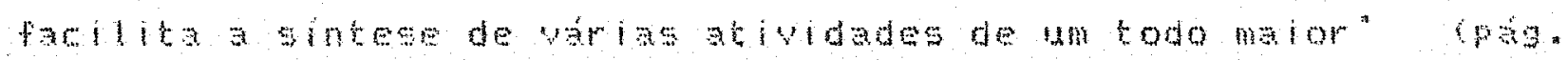

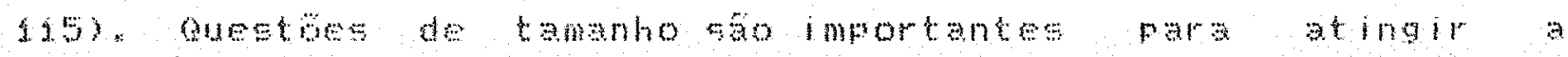

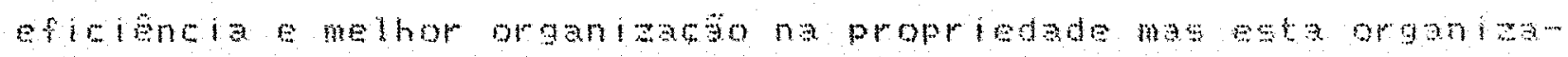
so termos de planejamento, custo de produrage una intormajo

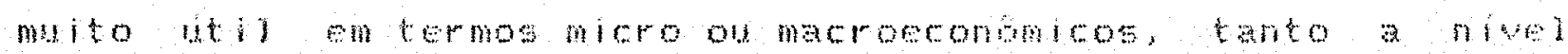
setorial wno alobal. 
MATSUNAG et a i i (1976) propuseram un procedimento alternarivo no mécodo de chllo das estimativas de custos,

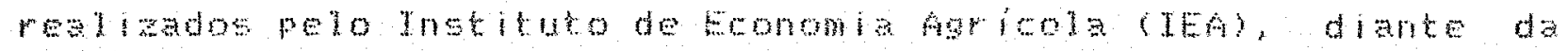

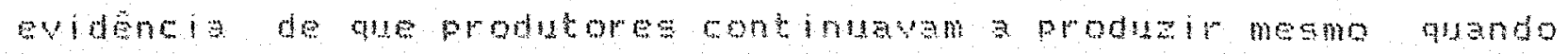
os precos ram interiores aos rustos chtoo calculados. Acrediten

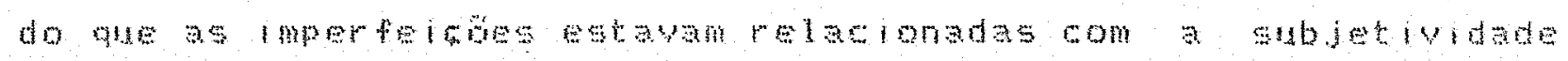

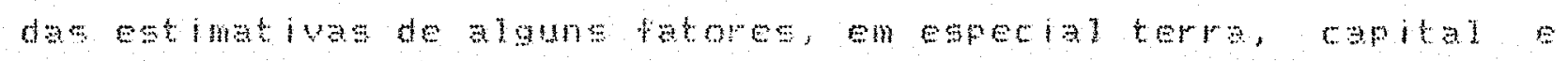

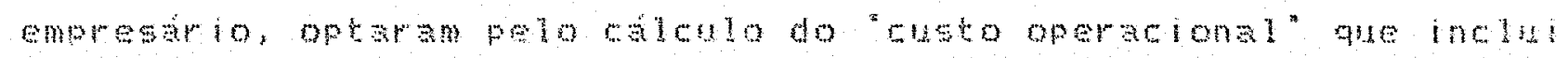

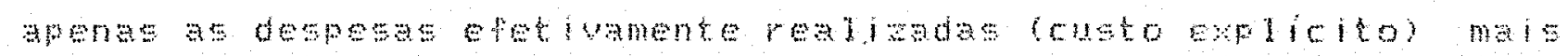

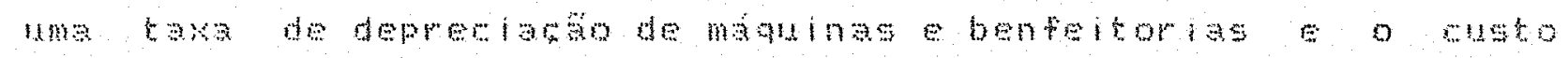

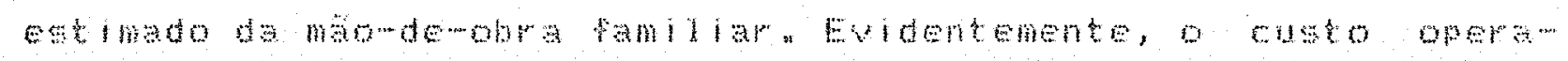

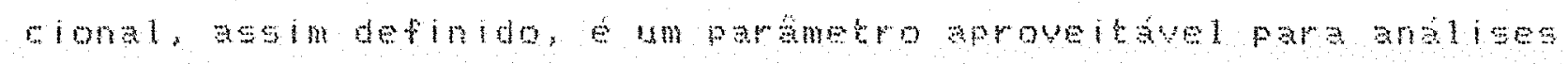

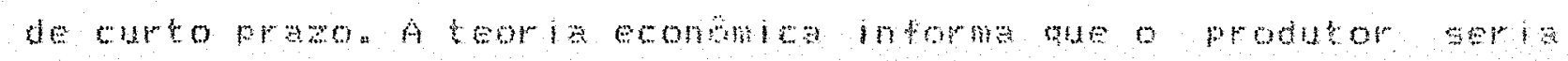

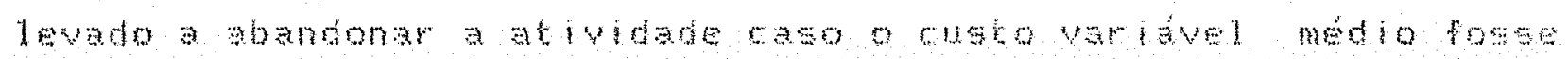

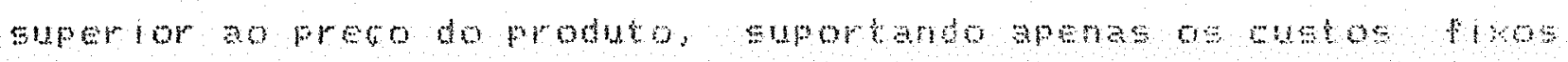
duranto periodo desfayoravel, estando apto reiniciar a ativi-

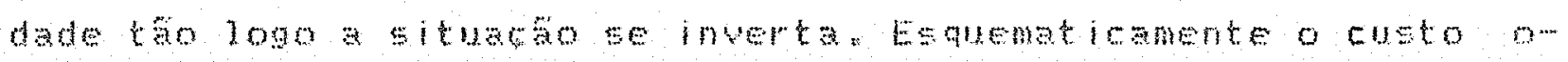
peracional compomse de codos os itens de custoconsiderados ya

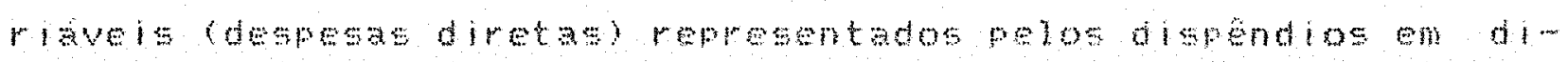
nheiro en momowobra, sementes, fertiliantes, defensivos, comm bustred, repros, al imentatyo, warinas, nedramentos e juros

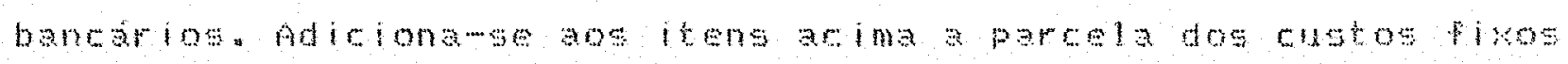
(indiretos) representados pela depreciano dos bers duravels em.

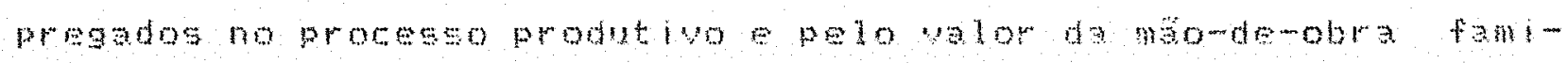
liar que apesar de noo remunerada realize cervaos bastoos am prescindiseis ao desenvolymento a acivida ramben sao aprom 


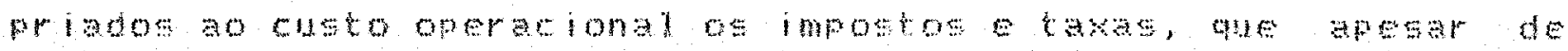

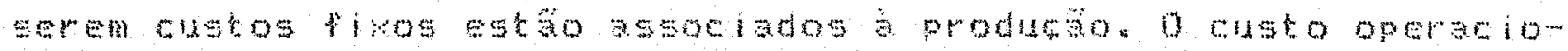

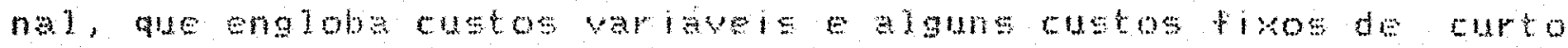

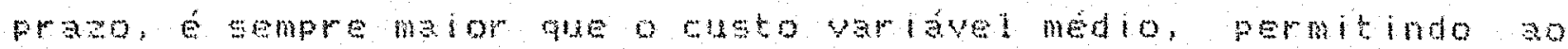

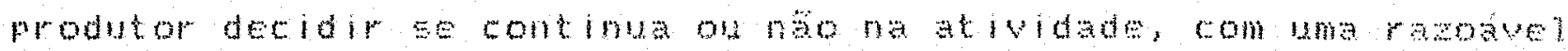

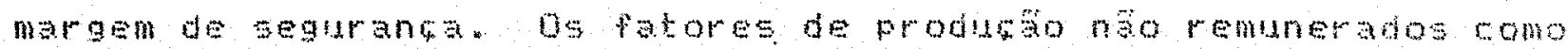

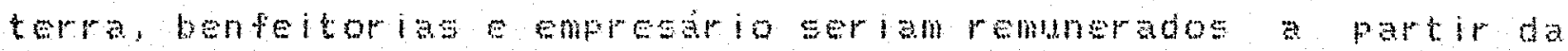
renda residual, com percentageng prowdeterminadas, de acomorom

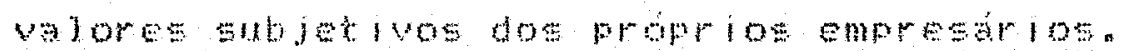

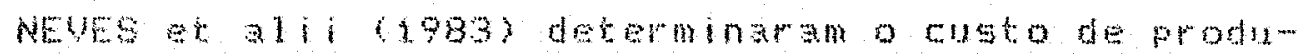

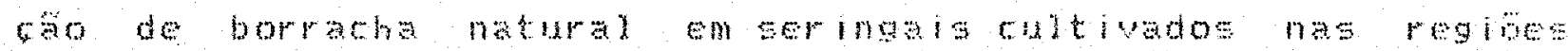

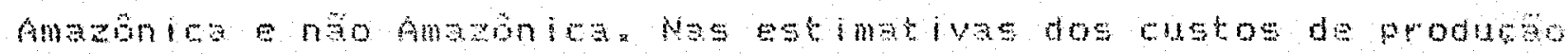

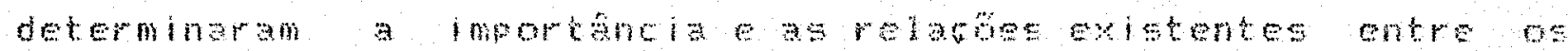

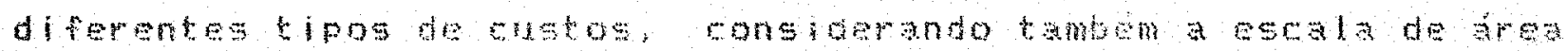

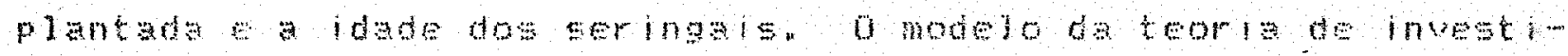

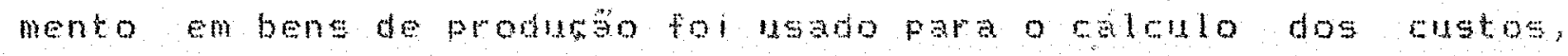

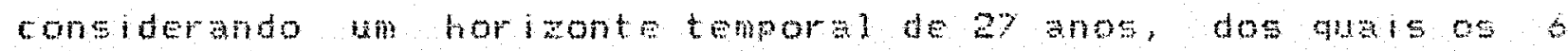
primoiros represantam a fase de investimento os 2x restantes a

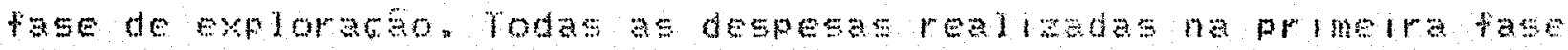
soo custos de inuesimentos posteriormente intelam as despesas

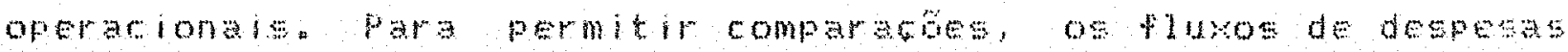

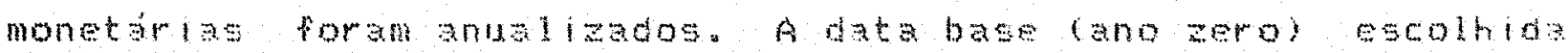

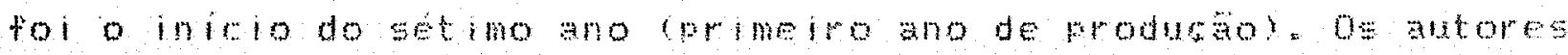

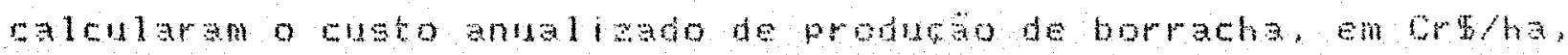

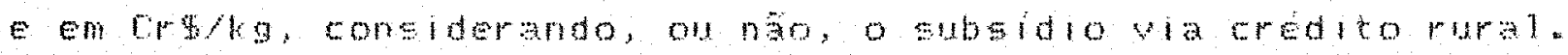

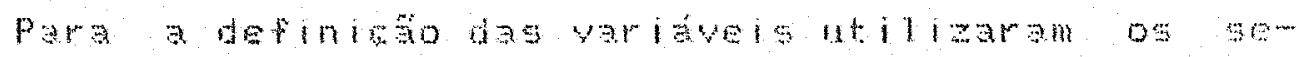


gutntes corterios:

- moromobra: o ses valor ra novento de sqe? de acordo com os contrientes tenteos

- Inomos: as daspesas com muas fertilizantes o outros materias de acordo com as exigencias en fatores of produca

- equpamentos: o var decomprafol distribudopelos anos de vida bil do mesmo. o criterio foi utilizado quando da necessidade de reposiza do equipamento

- máninas implementos mesmo criterio adotado para os equajmentos, incluindo anda os custos de monutengo

- administracalo considerado o valor do salario do acministradom thetarerano no caso de proprledade eapecializada na producas de borrath ou considerando apenas um percentual

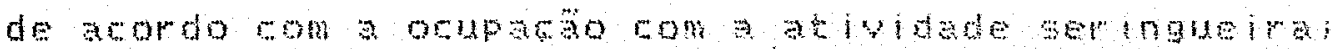

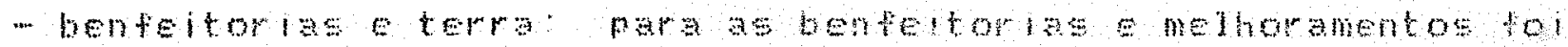
considerado s\% sobre o ylor novo, ano a ano. Ho caso de noyos investimentos durante oforizonte temporal tol utilizado o nes mo eriterio. Para a terra fol considerado $3 \%$ sobre o valor de compra na regito tendo como referencia o mes de novembo de 1982. Para a deteminabo do custo pom hectare utilizaram

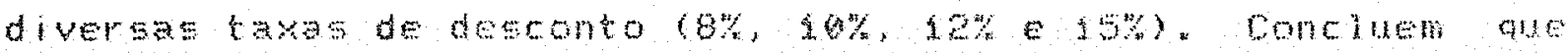
na regian Amasnica, para aud auer Estado, taka de desconto ou

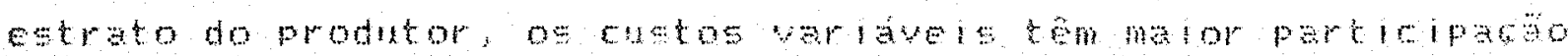

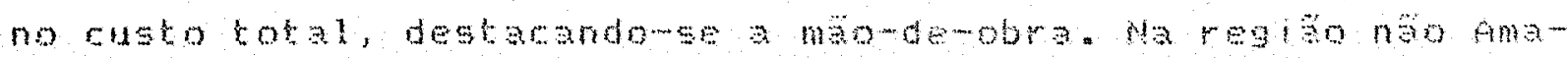

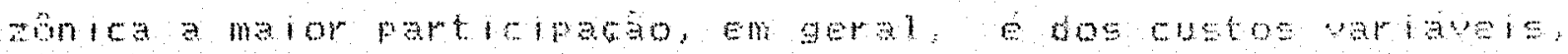

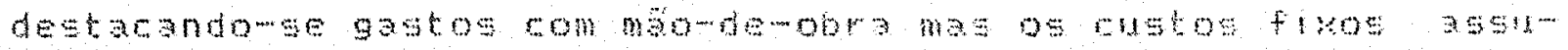




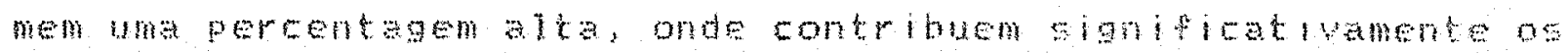
gatos com malumas equipantos.

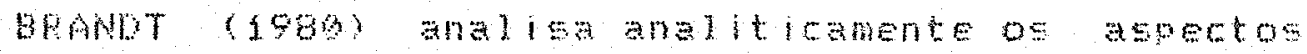

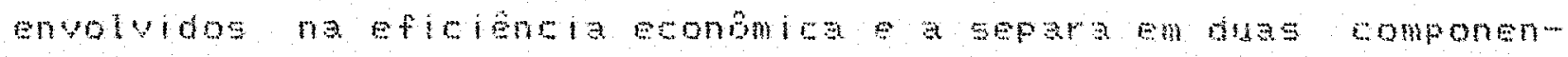

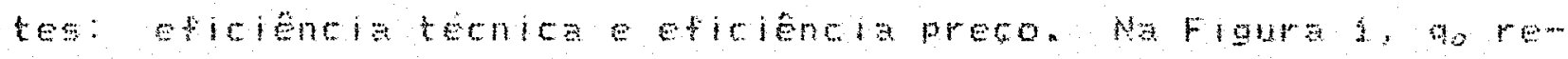

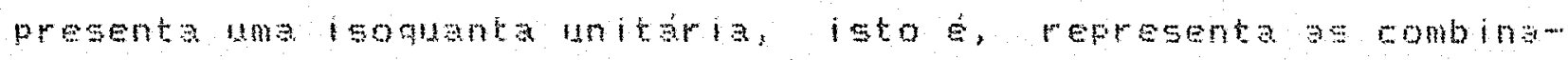
Whe dos insumos xa exzeom as quale é posslvel obtor una

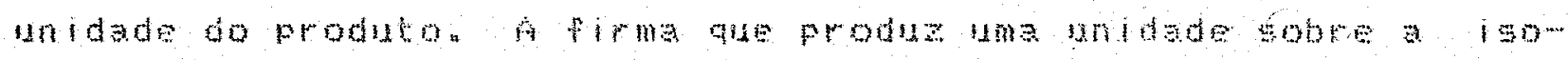

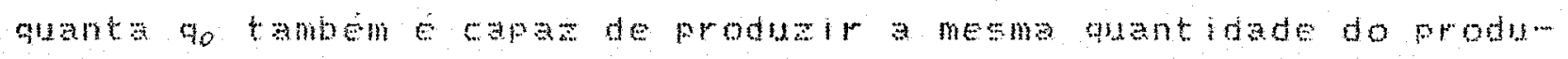

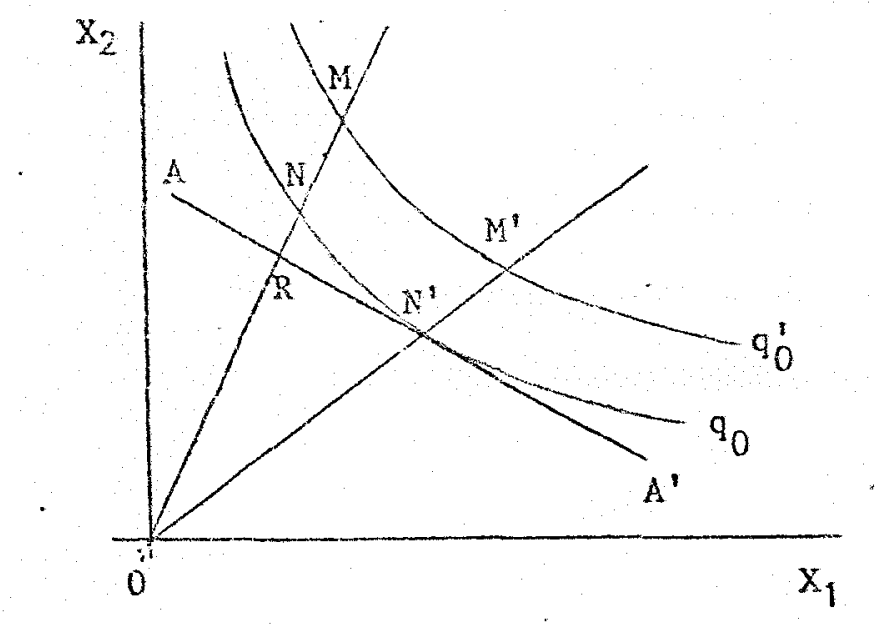

Figura a - Eficlencia Economica: ilustrasoda diferenga entre componentes de efiriencia techica eficloncia prego

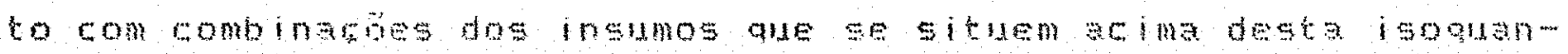

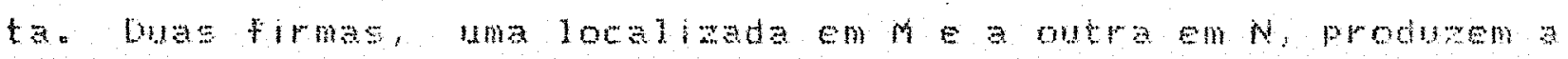
méma quantidade de produto e, embora ubilizando mesmapopor-

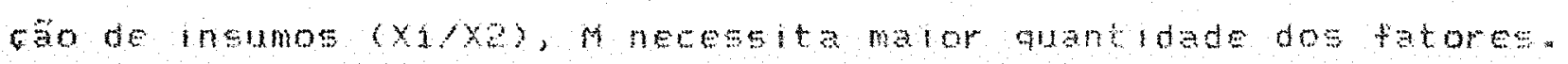

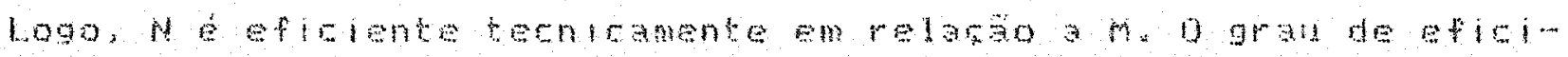

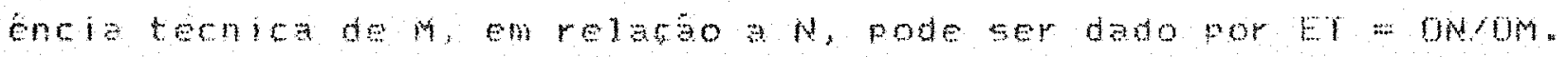




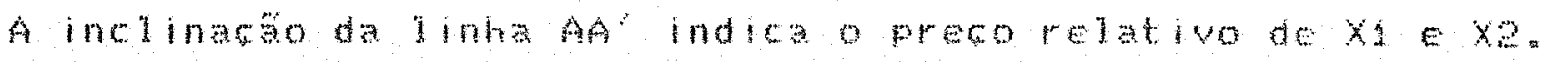
A eficiencia prero b obtida pela comparara dos

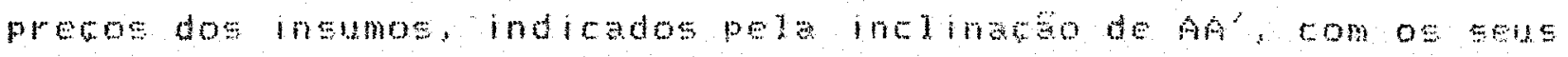

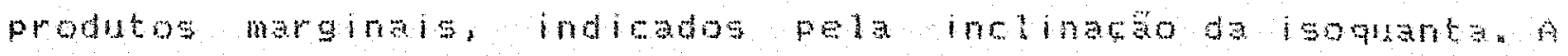
firma localiagda em é preco eticiente ja que a razodo produto marginal do ingumo $x+e$ produto marabal do insumo $x e$ e

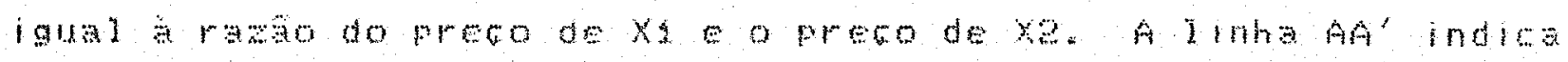

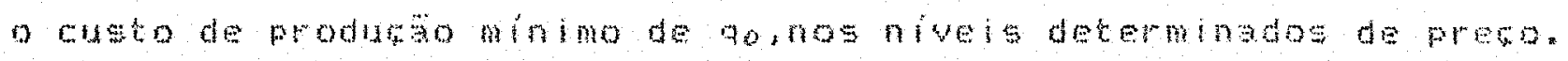

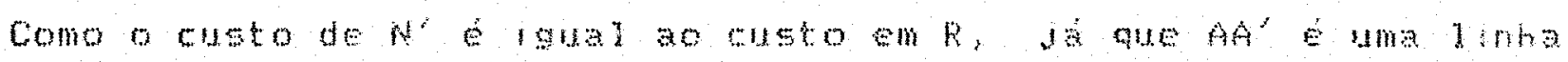
de isocusto. a eficiencia preco da firma localizada en N pode ger expressa por PF :-: OF $/$ ON.

0 autor informa que exise uma relargo simples

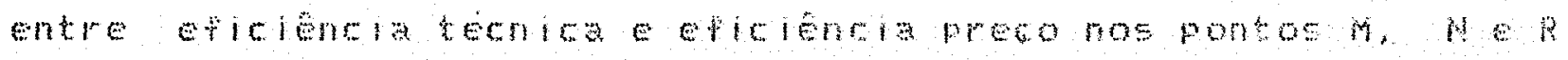

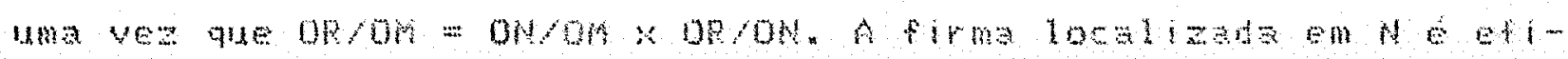
ciente tecnicamente pole esta localizada sobe a leogunta que produz 90 com o minimo poseivel de recursos mas é prexometin.

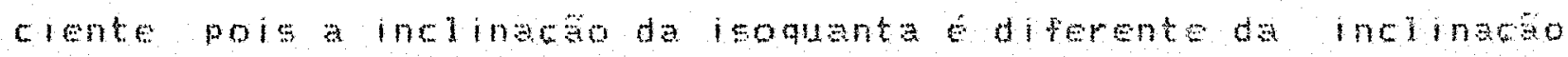

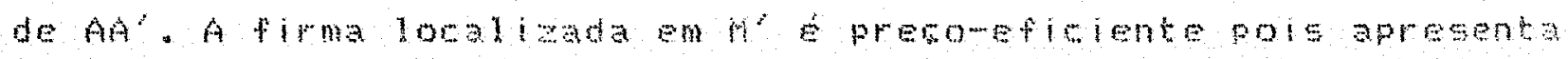

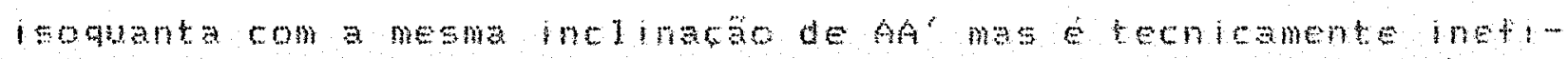
clente já me utiliza maj recurgos ane o minimo poseivel para produsir 90

Erand afirma somente a firma localizada em w é

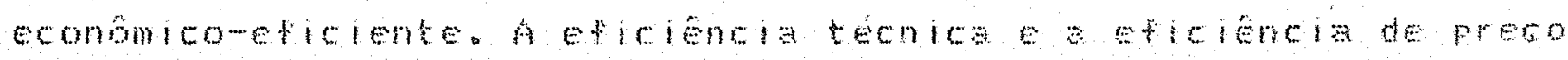
So condloses necesearias, e abando oortem coniuntamence, sao

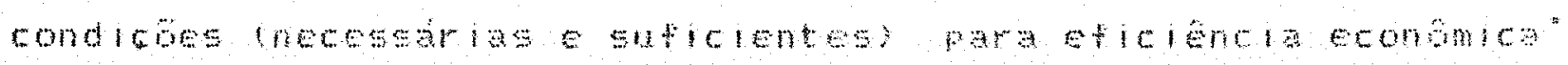
$(p \operatorname{sg} 28)$ 


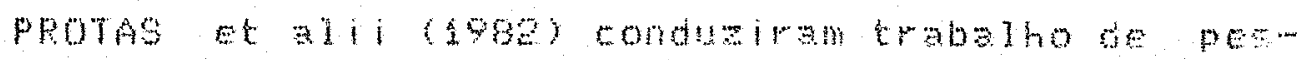
quisa com o objetivo de verificar a existencia de diferentes resultadostecnicose econmicos e identificar as variduels ane determinam estas diferengas em propredades que sedediram z producto de suinos no bexado de santa lataring considerando tras egcalas de producto (peguena, modia equnde). Ut lizando dados primar ios obtidos por intermedo de levantamentos mensals junto a produtorse de seis mulciplos da regloo do ato Urugua catar nense, as propriedades foran classificadas tom tres grupos a partir do nimero medio de matrizes do rebanho os prinotpais

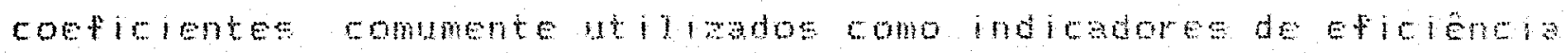
temica foran determinadompra wada grapo A comparabo das marans brutas, definio cono dierengentrea reselta da

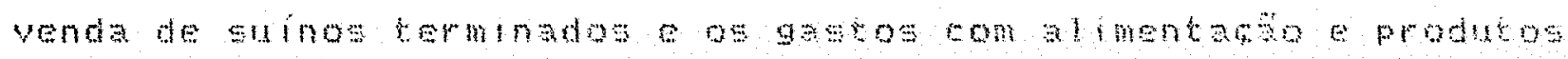

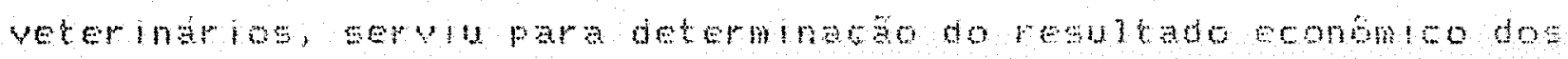
grupos de sulnowltores. As estimativa dos coficientes de tor relaso entre o numer a matrizes, númo de terminadosporcala

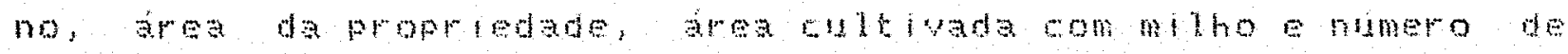
partosporeano nao apresentaranditerenca com sonificancia estatistion.

Aquelos autores concluem ane as propriedades de tamento med 0 , com aproximadanente 17 matr 120 . obtem as malores margens brikta, pringlpalmente deydo ao melhor desempenho zoom tecnico veriticado nestas propredades observam tambem, ane a

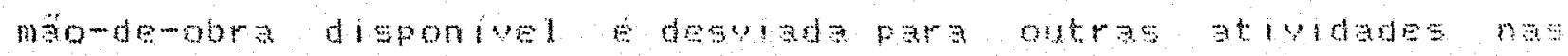
proprlodades pequenas e b insulelente nas arandos "A melnor 


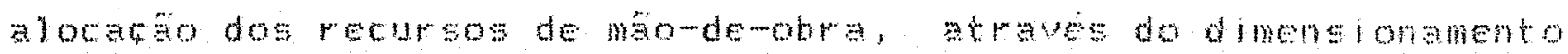
dos plantés em tunço de sua disponibilidade, e responsavel pelos melhores resultados tecnicose economicos obtidoe pelas

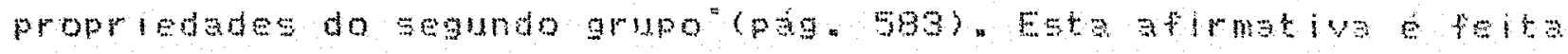
pelos autores alicercada en observabes "in loco", sem uma anslise formal.

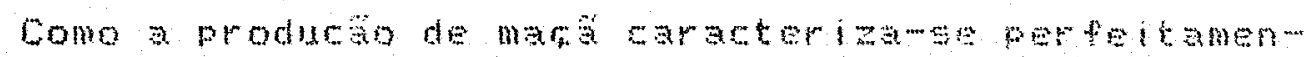
te como umativode com longo periodo de maturatoo coldur o custo de produmo baseado a teoria do inyectimento parece ser a melhor alternativa No entanto, entersestre sob diversos as pectos, eaber o wusto operacional. Neste trabaho será detembaw do, tamben o custo operacional, entendido como o monante de recursos necessarios operacional izaco da atividade.

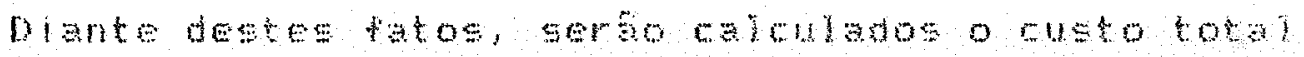
medio considerando todo o horizonte temporal e tamba 0 custo operacional, tanto na media do estrato como indiuidalmente para cada frodutor.

Para a avaliaco da eficiencia serbo determinados o

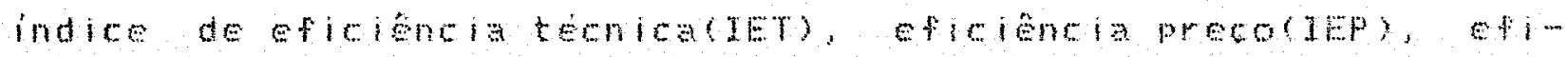
ciencia economica(TEE) e eficiencia da explorago(TEEx. 


\section{MATERTAL E METODO}

Esta pesanisa wrilizon dados frimarios obtidos, por amostragem, pelometodo da entrevista direta junto a produtores de maga da MRH Campos de Lages.

\subsection{Area de estido}

A MPH Gampos de Lages compose polos munieipios de Bom Jardim da Sarro, Bom letiro, Comreiaptato, Lases, otacin 110 costa, sedo Joadim e Urubici.

A cultura da motelra evoluid a partir do ano do 2968 com o PROFTT. quando profiseionals coneraram a se dedicar

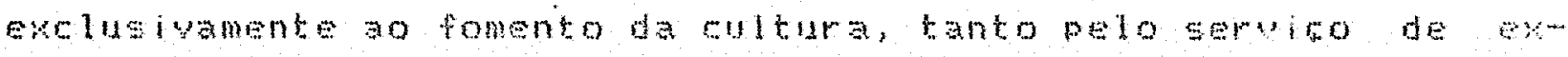

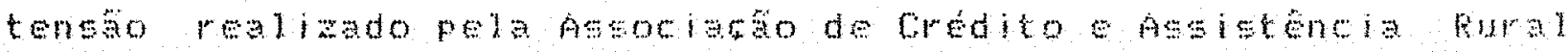
de santa Catarina (ACARSO), como na pesqusa realizada pela

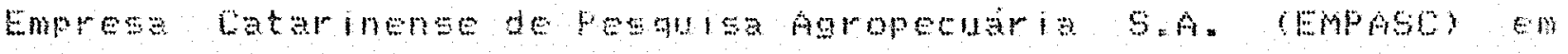
$\operatorname{sing} e \operatorname{tactes}$

Duato ao solo, a regijo apresenta boas rondiries quimicas mas limisecies no preparo devido ao afpramento de

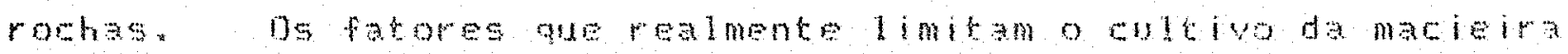
em diferentes areas, principalmente nosul do brasil sag os

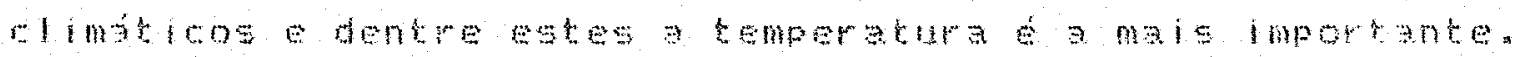


Durante a fase voutatia matelra necosta tenperaturas de $180 \mathrm{O}$ a $230 \mathrm{C}$ e durante o inverno sao newessarias tomperaturas baikes e continuas para que a planta reinicie um novo cielo vegetativo com brotacyo flomaro nommis. para qua ocora a qubra de dormenela naturalnente, a temperatura nao deve ultrapasar os 20 c. devendo as balkas temperaturas permane-

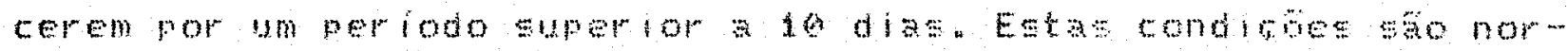

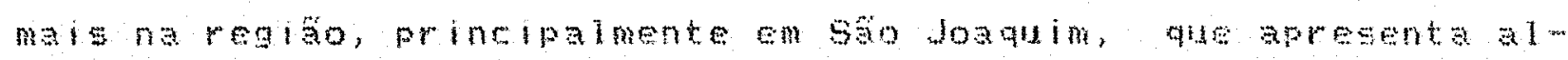
titudes superiores 1200 metrose a temperatura mima durante

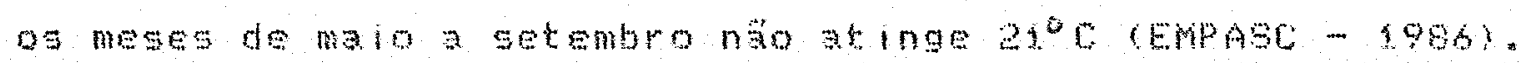

ounto aos aspectos de escutura fundiaria poses daterra, a reaso tamben apresenta caractoristios peculiares. En numero de propriededes prebominam en todos as muniolplos

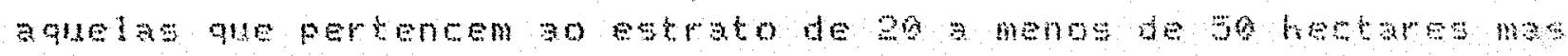
o tamano medio da propriedade fe tag, so ha coneldarando condicio legal das teras, 13, $14 \%$ do numero das propriedades so arrendadas e correspondem a b.71\% da area total (TBOE 2983 .

\subsection{A amostim}

Utilizado a tenica de entreyiga direta dos pro dutores, os dados primár los foram coletados por amostragem toman do por base o unverso de produtores de mas conforme informacies da ACAPES .

A coleta dos coeficientes tecricos fol procedida pelo autor durante os meses de janewro fovereuro de abs sendo

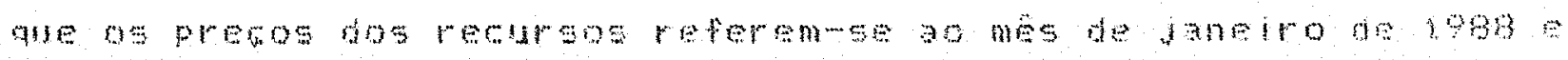


representam a modia dos pretos praticados na region

Para opreso da naz pol conslaerado o prero nedio mensal obtido no atacado pelo produtor na Compania de Entrepostos e Abaterimento berais do Estado de 9 a pallo ceAGEs, de Janeiro de 1980 ate outubro de 1987 dInstituto CEPASC 1988* Este freco medio foi egrolhido por representar a tendencia do preco já aue janciro um més toico de precobalvo este preno deve ser visto com muto cuidado pois nele esta embutidos os custos de comercializaco frete, taxa de descara e comisebes que representam aprokimadamente $25 \%$. portanto, o prea ná reflem te a remunerafo dp produtor.

Como a media da amostra eusda como estimativa dos parametros da populato, edesencial que a amostra represente populató Como a universo a pesquear apresente caracteristicas que diferem entre sle paro que se tenta uma amosta representativa, tornou-se necessaria e estatificaco da amosta. Ao distribuir a populaco em intervalos de 0.5 ho.

foi observado que hayiam tres grupos ben definldos. pentro de cad arupo os diferentes tamanhos de fomar apresentavan frequancia semelhante. Assim, a popularas compota por 700 produtores, foi dividida em tres estratos conforme a jrea cult vada com mara. O estrato $x$, ou de pequenos produtores, composto pelas propriedades aue cultivan mas ato, sha (inclusiver o estratoll, ou de medios produtores lol compotopelos produtores

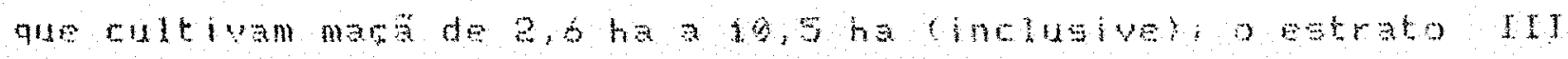

(1) conforme levantamento lealizado pela ACAPESC. 
on de arandes produtorse foi composto pelos produtors aue cutivam mais de 10,5 hectares de maran

A Tabela fornece algumasestatisticas dos tres ectratos bem como da populacán.

Tabela 7 - Numero de produtores(n), Samanho medio da propriedide (xi), tamenho medto do pomartes, area total de mas (xe) e desvio fadrog) dos tres estratos e da popu1 a 630 .

\begin{tabular}{|c|c|c|c|c|}
\hline \multicolumn{4}{|c|}{ Estratos } & \multirow{2}{*}{ Popul $3 \% 30$} \\
\hline & I & II & III & \\
\hline$n$ & 374 & 279 & 83 & 706 \\
\hline$x+$ ha & 68,55 & 120 & 137.97 & 99,40 \\
\hline$x \geq(h a)$ & $1,299 \%$ & 5.4423 & 20,9560 & 4,8629 \\
\hline$\times 2(h a)$ & 486,1 & 1518,4 & 1428,7 & 3433,2 \\
\hline$\pi$ & 0,6901 & 2,3491 & 25,4710 & 9,7288 \\
\hline
\end{tabular}

Fonte: calculados a partir dos dados fornecidos pela ACARESC.

TOMPKTN (1967) sugere que o tamanto da amotra pode ser determinado em 50 mais $2 \%$ da populacio no caso dela ser inferior a 500\%. Seguindo esta metodologia a amosta poderia ser composa por 64 fruticultores. Na pratica, prequentemente, a amostra corresfonde a $10 \%$ da populata.

Este percentual foi aplicado para os estratos I e 11 mas para o estrato III, por apresentar variancla maior e pela

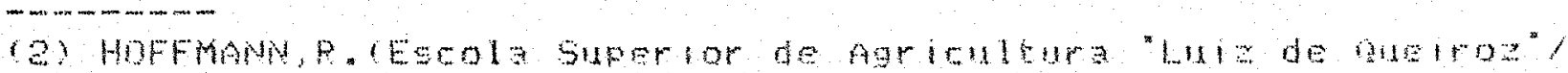

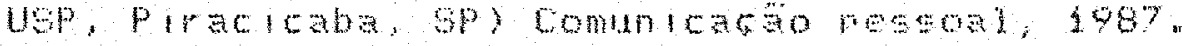


neceseidade de dispor de dados de bn pomar, no mínimo, para cada ano devidalit, fol aplicado zom sobre a populasa do estrato. Como adistribulas dos fruticutorese conhecida por estrato e por municipio, amostragem fol froporeional am cada municifio os ob produtores foram escolbidos aleator amente respeitsndo cada estrato e cada munimio.

A Tabela 8 fornece o mumero de questionarios aplicados por estrato en Eada municipio.

Tabela 8 - Composiano da amostra por estrato e por municipio. total por setrato e total por muncipio.

\begin{tabular}{|c|c|c|c|c|}
\hline \multirow[b]{2}{*}{ Municiplos } & \multicolumn{3}{|c|}{ Estratos } & \multirow{2}{*}{$\begin{array}{l}\text { rotal } \\
\text { por } \\
\text { munitipio }\end{array}$} \\
\hline & 1 & II & IIT & \\
\hline Bom dardem da serra & 8 & 5 & 1 & $1+3$ \\
\hline Bom testro & 2 & 1 & 2 & 5 \\
\hline Correia Pinto & 0 & 9 & 0 & 9 \\
\hline $\operatorname{Lag} 5$ & 4 & 2 & 1 & 7 \\
\hline otacilio costa & 1 & 0 & 1 & 2 \\
\hline 530 josquim & 15 & 17 & 8 & $A 0$ \\
\hline Urubici & 7 & 3 & 2 & 12 \\
\hline Total por estrato & 37 & 28 & 13 & 80 \\
\hline
\end{tabular}

Fonte: calculados a partir dos dados fornecidos fela ACARESC.

Oe alores monetarios correspondentes aos coeficientes tecnicos for an arupados, fara cada estrato, en planilhos

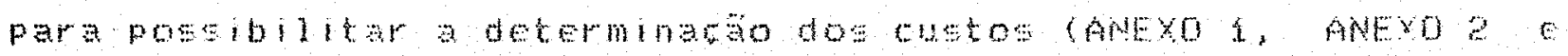

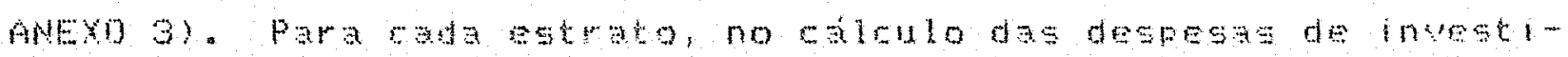
mento. constoroumes a media dos balores de todos os trut tulto-

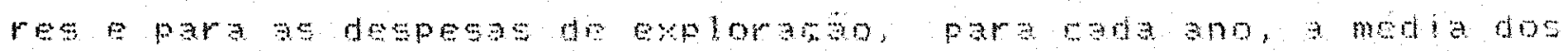




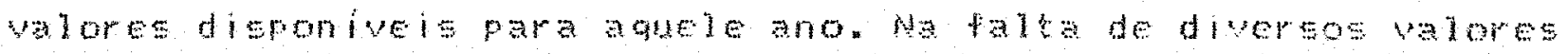
para calcular a media, utilizou-se apenas in romases induiduas para aguele ano.

Para a determinaco da idade do pomar a sor coneiderada no presente trabatho. fol calculada a media ponderada pela área da cada talla no caso do frut icultor fossur diversos talhoes com idades diprentrs.

A vids dil provale e a estabilizato decusos a produt ividades do ponar foram obtidos junto aos fruticultores que acusaram uma medie de 22 anos de vida util e estailizaço de cutos e produtividade no decimo ano. A wida lit il provavel realmente e una estativa ja que natoxistem pomares que fentam atingido fim de sya vida.

Tendo en vista que os coeficientes tecnieos de

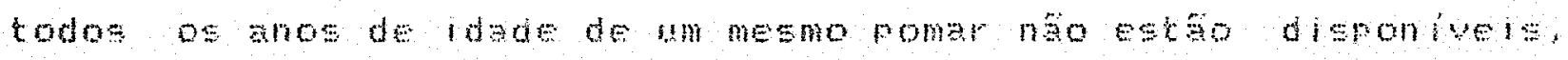
para o coldo dos custos e receitas individuats de cada pomar utilizou-se as medias do setrato correspondente nos diversos anos de vid lit a so no ano correspondente lisde do pomar for am ut llizados dados deste pomar A adocadesteprocedinento tax fom que os resultados individuas costos, peceitas e coeficien tes sejam vistos com cudado pois trazem conslob yalores corresFondentes a coeficientes tecnicos de outros pomares.

09 wares monetar los, inicialmente conelderados em cruzados, foram convertidos em obrigabos no Tesmur Necional

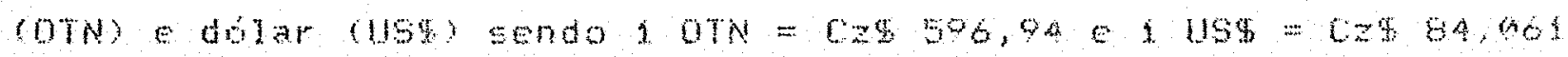
Para oraloulo dos resultados foi ut lizado opro 
grama lotus i-2-3 da Lotus hevelopment corp - versoo 2

\subsection{Cálculo do custo de producáo}

Para determinaráo do custo total de produsa foi utilizado o modelo da teoria do investimento em bens de produsto uma vez que a culbura da mag e um investimento de longo per iodo de maturacio. No inicio da atividade sao teitos os investimentos e posteriormente tem-se as despesas operacionais. As despesas gao consideradas antecipadas, como se ocorressen no iniciodo ano.

Para possibilitar a comparaca dos flukos de despesas monetarlas no tenpo foi utilizado o calculo do custo de prom

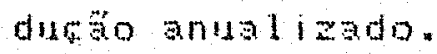

A raxa de desconto esclhida fol de d\% a ano for representar a remuneraco de un investimento alternat vo e seguro que e a caderneta de poupana.

o custo operacional representa a remunerano aos diferentes fatores de produrio utilizados no processo produtivo, pressupondo que os investimentos já tenham sido realizados.

3.3.1. Anus izacáo dos custos de investimento de exploracáo. por hectare.

Todas as despesae ralizadas na implantara do pomar foram consideradas despesas de investimento incluindo a

(3) Malores informabes sobre a montagen e pperacionaliagáadestas matrizes podem ser obtidas com o autor. 
infraestrutura. As despess de investimento foram caritalizadas para o inicio do $3^{\circ}$ ano beste modo o inicio do ano $\mathrm{B}$ será considerado como data base. o valor obtidonestecalculo é "Valor presente das despesas de Investimento" ou

$\operatorname{lp} I=\sum_{t=0}^{B} \operatorname{lt}(1+r)^{B-t} \operatorname{con}$

$t=0,1, \ldots, B, \ldots, T ; B=2$ e T representa os anos de vida it il do pomar, onde

UPI = yalor presente daj despesas de investimento no inio io do ano B, a taxa de capitalizactore

DIt = vlor das despesas de investimento realizadas em cada anot As despese realiadas do ano B en diante, ate $T$. foram consideradas despesas de exoloraco da macieira deseonta das para a mesma dab base, obtendo-se o valor presente das bespesas de Exploramo" on

$U P E=\sum_{t=B}^{T} D E t(1+r)^{B-t}$ onde

UPE = valor presente das despesas de explorario no inicio do ano B, a taxa descontore

DEt = valor das despesas de exploracáo realizadas en cada anot. 0. Wor presente ou atualizado de todas as despesas do pomar, for hertare, nesta data e a soma destes dois yalores ou $U P P=U P I+U P E=\sum_{t=0}^{B} D T(1+r)^{B-t}+\sum_{t=B}^{T} D E t(1+r)^{B-C}=\sum_{t=0}^{T} D P(1+r)^{B-C}(3)$ onde upp = valor presente das desesos do pomer, calculado a taka $r$ e 


$$
\begin{aligned}
& \text { mp = valor das degpeas do pomar realizadas em cada ano } \\
& \text { representa, para cada ano, ataxar, o valor presentedas despem }
\end{aligned}
$$

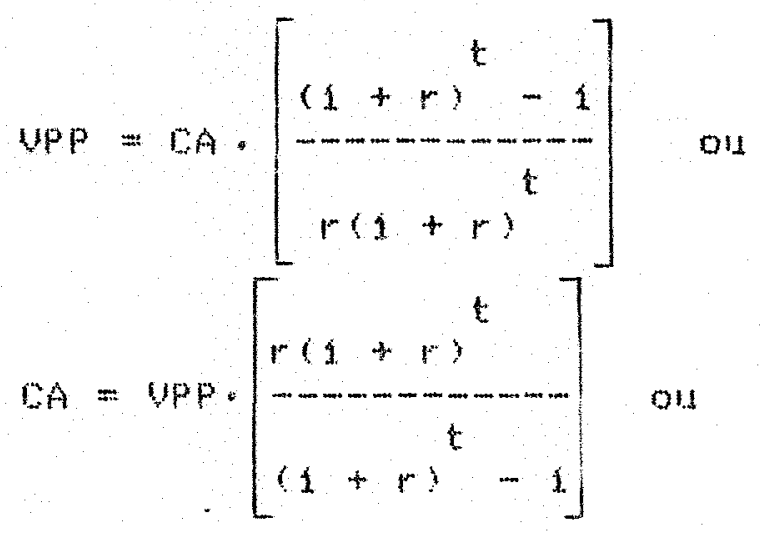$$
0 \text { custo anulizado(CA) vem a ser o montanta que }
$$

onde a expresto entre colohetes e ofator de recuperara do cotal

Subetituindo upp obtido em (3) temos:

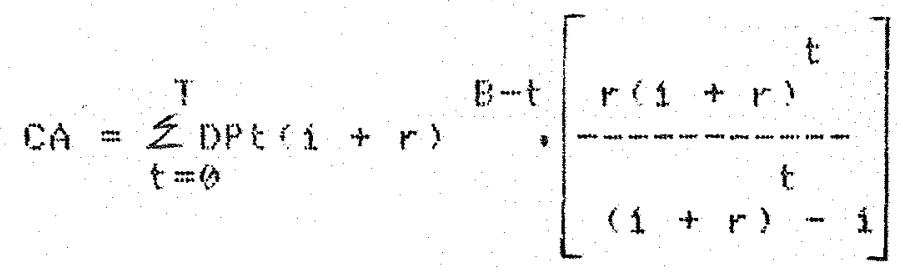

\subsubsection{Anualizacto do rendimento.}

Da mesma forma que os flukos monetarios sas capitalizadom ou descontados para uma determinada data base, as quantidades fisicas (produciojtambem devem ser descontadas para a mesma daca base, permitindo, desca forma, posteriores comparacirs de rustose receitas.

seja pt o rendimento em tolha do mara en rada ano t. "Valor presente dog Rendimentos" (R) E: 
$R=\sum_{t=0}^{\gamma} \theta t(1+r)^{B-t}$

o rendimento andaliado (PA) representa, para cada ano considerado. a taka de desconto r o valor presentedos rendimentos. Assim,

$R=\operatorname{RA}\left[\frac{(1+r)^{t}-1}{r(1+r)^{t}}\right]$ on

$R A=R \cdot\left[\begin{array}{c}r(1+r)^{t} \\ (1+r)^{t}-1\end{array}\right]$

Substituindo p for seu ralor obtido em $(7)$, temos

$P A=\sum_{t=0}^{T} R+(1+r)^{B-t}\left[\frac{r(1+r)^{t}}{(1+r-t-1}\right]$

\subsubsection{Calculo do custo total medio}

0 custo total medio (ctme) pepresenta o custo total por unidade produzlda oividindo o custo total anualizado pelo rendimento anulizado obtem-se o custo total modio por unidade do

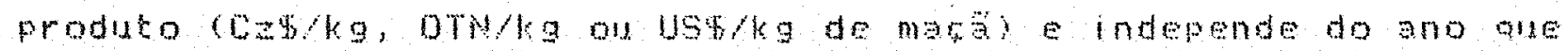
e utilizado como pontode referencia para acumular custos e rendimentos. Logo, CTMe = CAPA. Substituindo OA de (b) e RA de (10) tenos: 


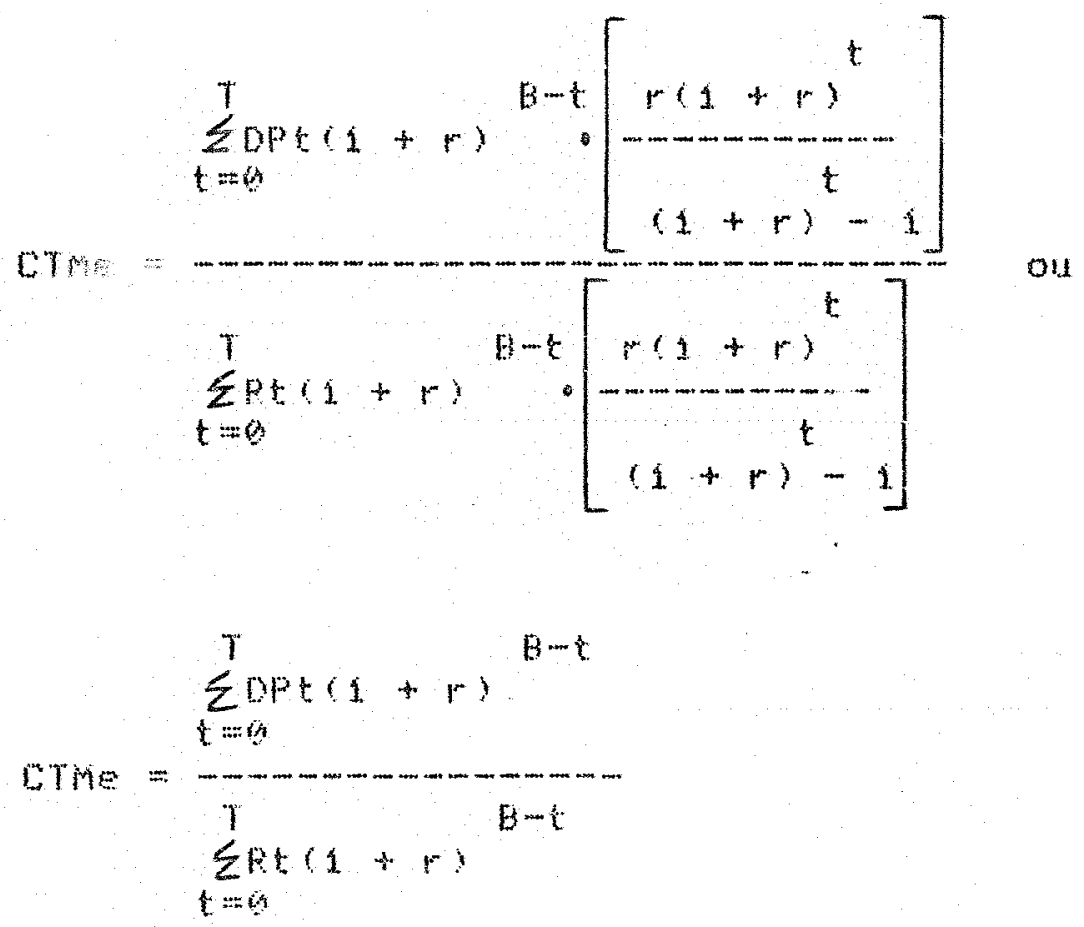

(1)

(12)

\subsubsection{Receita total cueto total}

A receite bruta (RQ? ó obtida pela multiplicacódo rendimento anualizado pelo preco (P) da mace ou seja.

$P B=\sum_{t=0 t}^{r}(1+r) \operatorname{B-t}\left[\frac{r(1+r)^{t}}{(1+r)^{t}-1}\right] \cdot p$

Se a receita bruta for igualada ao custo anualiagdo tem-es que oprecop é loual ao minimo necessirio fara cobrir tom dos os custos considerados, on seja:

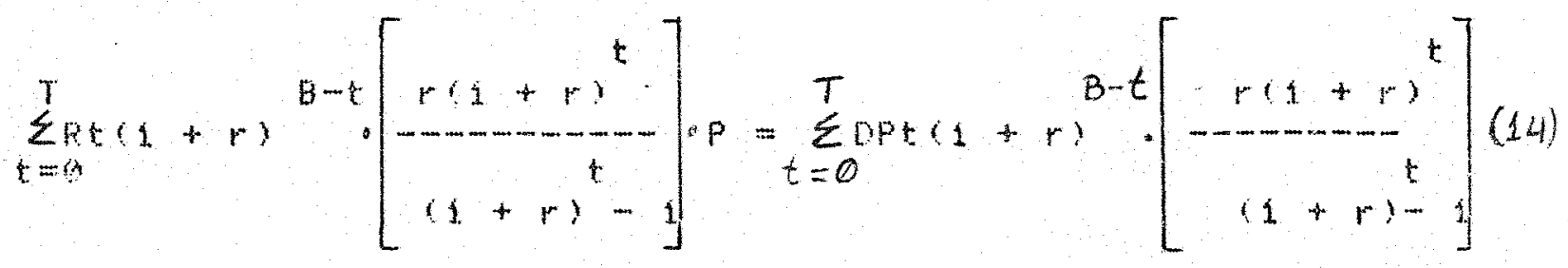




$$
\begin{aligned}
& \left.\sum_{t=0}^{T} p_{t}+r+r\right)\left[\begin{array}{c}
r(1+r)^{t} \\
(1+r)^{t}-1
\end{array}\right] \\
& P=\sum_{t=b}^{T} R(1+r)^{B-t}\left[\begin{array}{c}
r(1+r)^{t} \\
(1+r)^{-}
\end{array}\right]
\end{aligned}
$$

3.4. Cálculo da eficiêtia

A eficiencia da producto do mas fol anpessa pelos seguintes indices: indice de eficiencia tecnica rifr. indice de eficiencla preco (IEP), indice de eficiencia economica (IEE) e indice de efieiencia da explorata (TEEx).

Para a determinaco da eficiencia tonica da produ Go de maca em cada propriedade foi anallsada a sua produtividade en relazo a media das produtividades dos frutieultores do egtrato em la/ha, on peja,

$$
\text { IETI = RAXIRRAK, onde: }
$$

IETi = indice de eficiencia tenica da i-esima propriedade

RÁi = rendimento anualizado obtido, por hectare, pela i-ésima propriedade

RAX = media do rendimento anualizado obtido, por hectare, pelos 
fruticulores do respectivo estrato.

E considerado ficiente cemicamente o produtor que

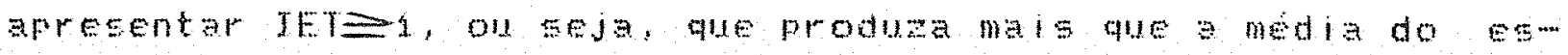
trato, edeconsiderado ineficiente aquele que apresenta IET< 1 , isto é, que produza menos aue a média do estrato.

0 indice de eficiencia tecnica assume valore

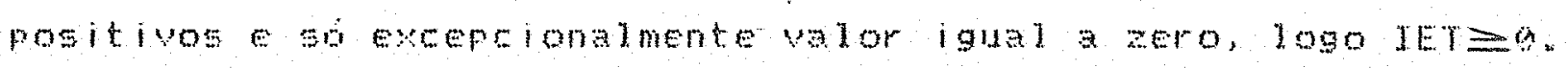
Sera zero somente na ituara extrema en que o rendimento analizado do fruticulor for igual a zero. Embora esa gituaco geja muto dificil de ocorrer napritica, quase impossivel ocorrer o Pato da media do estrato ser zero, o que alteraria a posica inicial.

A eficiencia preco da producáo de mas am cada prom priedade toi determinad pela diviag oa media dos cuetos anualizados de todos os fruticultores do estrato pelo custo anualizado de cada propriadade, orlainalmente calculados en bathate depols transformatos en orwha e US\$/ha, ou seja,

$$
\text { IEPI }=\text { CANACAXI }
$$

onde

IEPi = indice de eficiencia premo da i-emima propriedade.

CAK = media do custo anualizado dos fruticultores do recpectivo $\operatorname{esctat} e$

CAxi = rusto anualizado da i-sedma propriedade.

0 indire de eficlencla preco aecume somente valores postlios pols alam custo sempre ha, sendo conslopado eficlence

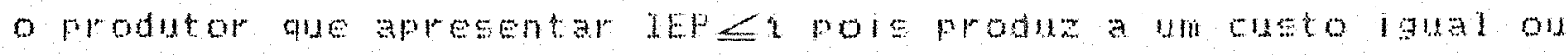


menar que a media do estrato e e ineficiente o produtor com IEP > 1 pois produz an custo maior que a media do estrato.

o indics de eficiencia conomica (TEE i) da producto de mag en cada propriedade, que engloba a eficiencia tecnica a eficincia preco, obtidopelo produto destes dois indices ou $3 \mathrm{ja}$

$$
\text { IEE }=\text { IET } \times \text { IEP }
$$

o indice de eficiencta economica asume nomalmente viores fositivos a so no caso em gue IET $a$ a temme IEE $=0$. É coneiderado eficiente orodutor que apresentar IEE $\Rightarrow$ f e ineficiente aquele com TEE 1 .

o indice de eficlencia da explorago de cads

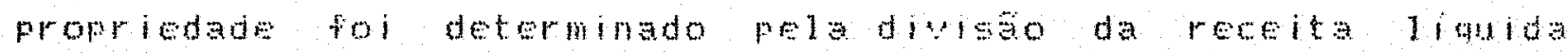
obtida a partir da prodirio de mas de cada propriedade pela média da recelta limuda dos produtores de mata de cada cotrato. ouseja,

$$
\text { IEEKI = RLYI/RLE. }
$$

ond

IEExi = indice de eficienciada explorago de maga da i-sima proprledade,

RLKi = receita liquida obtida com a magela i-esima propriedade. RLe mediada recelts lianda dos producores de mas dacado estrato.

0 indice de efiriencia da explorabo podr assumir valores post wos on negativosera negativo se os snats de Rlxi a Ph forem diferentes, isto of um posituo e o outro negativo. 
IEEx? asianifica aue os dols sinals sa ignais.

Se RLXi, RLX, a entro TEExDt significa eficien-

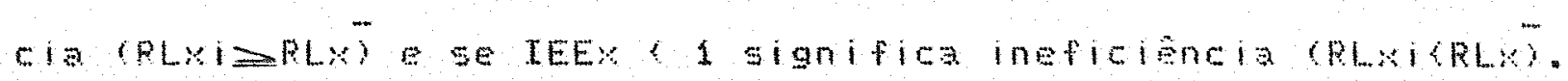

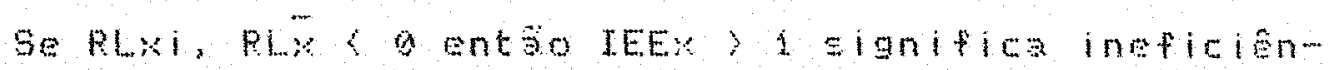

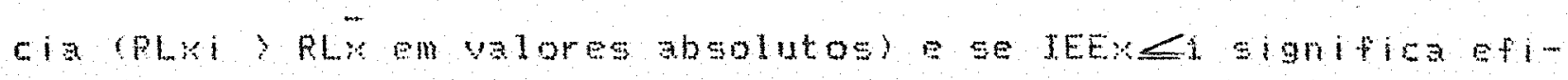
ciencia (RLXIERLe en valores mosolutost.

Se RLxi RLX forem de sinais diferentes tem-se dob casoe. Se Rlxi y a entao qual quer valor negativo do IEEx expressa eficiencise ester, a, entä qual quer yalor negativo do IEE representa ineticianeia para o produtor.

\subsection{Definicäo das varidveis}

Ao conceituar custo total de froducto como o conjunto degastos, implitos eeplicitos, necessios at realizaron da producso con areseruaco da capacidade de producao inctalada, tem-se cm nente a remuneracáde todos os fatores de producso on de seus detentores.

Na composiono do custo total foram considerados:

- despasas de investimento : o valor de

(xi) tera nuat

(xa) benteitorias melhoramentos,

(x) mánas e equipanentós.

(xa) materialse utensilios.

(xs) preparo do solo elantio indas, insumos náde-obra. horas-matouai;

- despesas operacionais o yalor efetiamente gato com 
(xo) conservacto e reparos de benteitorlas e melhoramentos.

(x7) conservaso e reparos de mánins e equipamentos,

(XB) combustiveis o lubpificantes.

(x9) defensivos cherbicides, formicidas inseticidas fungi(dias)

(xio) woretivose fertilizantes le outros materiaig que perdem a forma ao serem utilizedos?,

(xi1) mädemobra contratada

(xiz) mäondemoba familiar.

(X13) seguros (PRogbro e seguros sobre bens de capital ou da production,

(x14) gastos diversos (112, telefone, impostos, takas arpendanento de terme outros pamentos näo esecinicados)

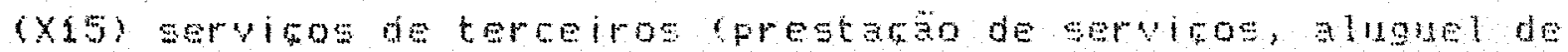

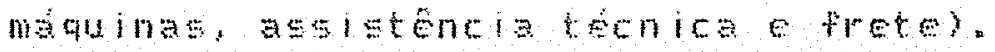

Para a mónemobra contratada foi considerado o va lor efetivamente pago emsalariose encargos sociais o valor imputado a ontras vantagens fornecimento de moradia, lenta. lete, efe.). Na móde-obrafamiliar fol considerado o valor efotivante pago o yalor imputado pela prestara de servicos na produga de mán por membro da familia.

0 montante dos custos com terra, momemora. seguros, defeneloge, fertilazantes e corretivos, preparodo solo e plantio e servicos de terceiros foram considerados contoma a participacto reletiva desces custos no processo produtivo da mate. o valor dos custos com benteltorias mellomanom 
tos: máqunas e equpmentos, materiais e utensilios conservaso e reparos do bentelcortas, conservacio e reparos de maninas equipamentos, gastos diversos e combustiveis e lubrificantes fom ram distribudos proporclonalmente conforme a participaro da renda bruta da mata na renda bruta de cada propriedade, tendo em yeta que os frodutores nó dispom destes glores isoladamente para macä.

A receita bruta botida pela soma dos ingressos provententes da venda da produgo da mara acrescida pelo ylor da terra com os melhoramentos fundiar ios realizados por ocasiando arepro do solo e plantio tais como desmatamento, destoca, retrada de pedras, abertur de estras teraceamento. ra procedimento fazse necessario tendo en usta que nateoria do

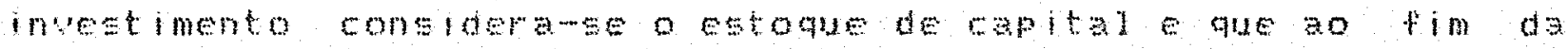

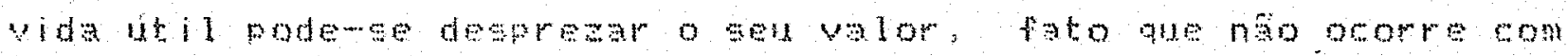
o fator de producio terra pois nao perde o valor antes pelo contrário, o valor inicial foi anesoido pelos melhomamentos fundisrios realizados fara a cultura da mas

Como receita líguda é considerada a diferensa entre a receita bruta cuto total. A peceita liguida assindefinida, remunera o emprestrio. 


\section{RESULTADOS E DISCUSSÄO.}

Ds custos e as receita sio mostrados, para cada estrato, nae Tabelas 9, a

Dbserva-se que a participacoo das despesas de in vestimento diminuem com o aumento do tamanho do pomar. participando con 26, 42\% no estrato $1,16,90 \%$ no estrato 11 e $15,53 \%$ no estrato TIT. Eeta tendencia nfo é manifestada pelo valor da terra gastos com preparo do solo e plantio.

Observame que as propriedades malores aplical

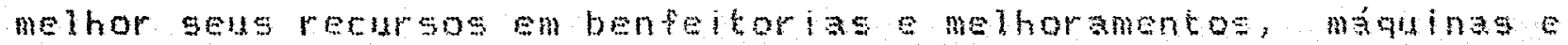
equipamentos e materials utenefiros. partirularmente, chamos atencäo no levantamento a existencia doconstructes, tratorese outros equipamentos super dimensionados em relatá as necessidam des dos pequenos, produtores.

Quanto ao valor da terra fol observado durante o levantamento dos coeficientes tecnicos auestevaria mas em funca da distancia a sede do municipio (en media $20 \mathrm{~km}$ ) ausencia de pedras do que a tamanho da propriedade ou do pomar. Este pto pode expliear a falta de tendencia definida do valor da terra en relacáo ao tamanho do pomar. observa-se tambem que c mar o valor do heetare de terra para os pequenos pomares. 
Tabela - Cuto total por hectare, cueto total medio por quilo e receita por hectar para o estrato I cpequenos produm toren). Ualores en oTN USg e percentagem sobre o custo total.

\begin{tabular}{|c|c|c|c|c|}
\hline & & ornha & USthis & $\begin{array}{l}\text { \% sobre } \\
\text { custo total }\end{array}$ \\
\hline$(1)$ & $\begin{array}{l}\text { DESPESAS DE INUESTIMENTO } \\
\text { Terr } \\
\text { Bent. e melhoranentos } \\
\text { Maq. equipamentos } \\
\text { Mat. e utensilios } \\
\text { Prep. solo e plantio }\end{array}$ & $\begin{array}{l}1857,61 \\
169,85 \\
851,20 \\
498,48 \\
77,59 \\
260,55\end{array}$ & $\begin{array}{r}13191,40 \\
1206,15 \\
604,60 \\
3500,42 \\
550,90 \\
1850,24\end{array}$ & $\begin{array}{r}26,42 \\
2,42 \\
12,11 \\
7,09 \\
1,10 \\
3,71\end{array}$ \\
\hline (2) & 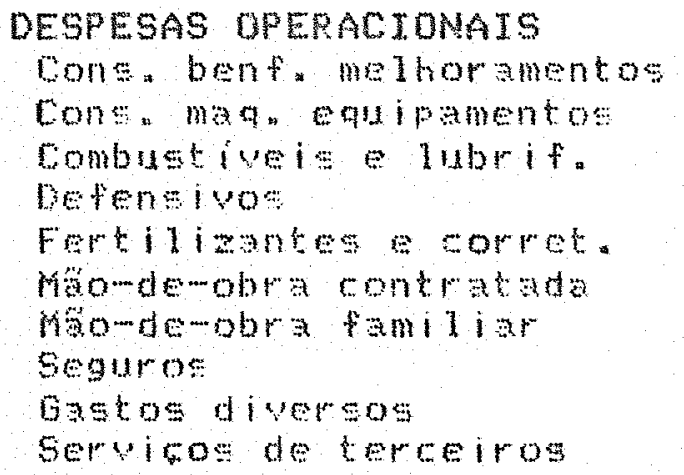 & $\begin{array}{r}513,40 \\
61,21 \\
240,64 \\
094,66 \\
1408,02 \\
303,12 \\
805,40 \\
572,63 \\
164,11 \\
403,62 \\
80,90\end{array}$ & $\begin{array}{r}36737,72 \\
434,67 \\
1772,76 \\
763,35 \\
19001,57 \\
215,54 \\
6254,63 \\
4066,40 \\
1165,30 \\
3221,28 \\
575,13\end{array}$ & $\begin{array}{r}73,58 \\
0,87 \\
3,55 \\
14,15 \\
20,93 \\
4,31 \\
12,59 \\
8,14 \\
2,33 \\
6,45 \\
1,15\end{array}$ \\
\hline$(3)$ & CUSTO TOTAL $(1+2)$ & 7031,01 & 49029,12 & \\
\hline (a) & RECEITA DA TERRA & 62,25 & 42,95 & \\
\hline$(5)$ & RENDIMENTO ( $\mathrm{kg} / \mathrm{ha})$ & 131027 & & \\
\hline & CUSTO TOTAL MEDTO $(3 / 5)$ & 0,053660 & 0,301060 & \\
\hline 67 & PRECO DA MAQR/K9 & 0,090713 & 6,644175 & \\
\hline$(8)$ & RECEITA BRUTA $(4+5 \times 7)$ & 11948,10 & 84846,37 & \\
\hline (9) & RECEITA LIOUTDA $(8-3)$ & 4917,09 & 34917.25 & \\
\hline
\end{tabular}

Fonte Dedos da pesqisa. 
Tabela 10 - Custototal for hectare, custo total medio por quilo e recelta por hectare para o estrato II medios from dutores? vadores em oTh e USA e percentagem sobre o custo total.

\begin{tabular}{|c|c|c|c|c|}
\hline & & orNine & Usalha & $\begin{array}{l}\text { \% Eohre } \\
\text { custotatal }\end{array}$ \\
\hline (1) & $\begin{array}{l}\text { DESPESAS OE TNUESTIMENTO } \\
\text { Terra } \\
\text { Benf. melhoramentos } \\
\text { Man e guipamentos } \\
\text { Mat e ntencilos } \\
\text { Prep solo e plantio }\end{array}$ & $\begin{array}{r}1263,98 \\
110,35 \\
479,86 \\
365,34 \\
63,25 \\
24,16\end{array}$ & $\begin{array}{r}8975,88 \\
789,63 \\
3407,76 \\
259,38 \\
449,16 \\
1749,95\end{array}$ & $\begin{array}{r}16,90 \\
1,48 \\
6,49 \\
1,88 \\
0,83 \\
3,28\end{array}$ \\
\hline (2) & 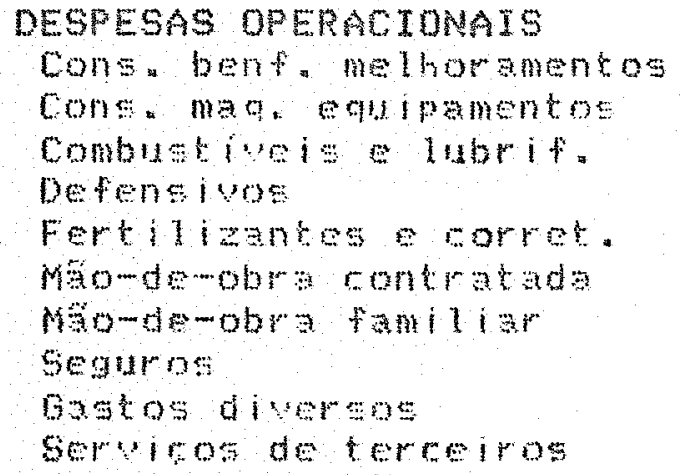 & $\begin{array}{r}6215,08 \\
89,96 \\
27,23 \\
2974,27 \\
1723,31 \\
196,37 \\
967,74 \\
295,56 \\
210,99 \\
233,07 \\
110,46\end{array}$ & $\begin{array}{r}4434,98 \\
632,44 \\
1947,38 \\
1479,10 \\
19237,69 \\
1394,48 \\
6872,10 \\
2027,84 \\
1406,30 \\
=910,16 \\
784,41\end{array}$ & $\begin{array}{r}03,10 \\
1,10 \\
3,67 \\
27,72 \\
23,04 \\
2,63 \\
12,94 \\
3,82 \\
2,82 \\
3,70 \\
1,48\end{array}$ \\
\hline$(3)$ & CUSTO TOTAL $(1+2)$ & 7479,06 & 53110,86 & \\
\hline (A) & PECEITA DA TERRA & 43,56 & 309,33 & \\
\hline$(5)$ & RENDTMENTO (kg/ha) & 102383 & & \\
\hline (6) & CUSTO TOTAL MEDTO $(3 / 5)$ & 0,073949 & 0,518747 & \\
\hline$(7)$ & PRECO DA MACA/Kg & 0.090713 & 0,644175 & \\
\hline$(8)$ & RECEITA BRUTA $(4+5 \times 7)$ & 9331.03 & 66261,90 & \\
\hline$(9)$ & RECETTA LIOUTDA $(B-3)$ & 1851,97 & 13191,04 & \\
\hline
\end{tabular}

Fonte: Dodos do posulsa. 
Tabela 1 - Custo total por hectare, custo total medio por guilo e receita por hectare para o estrato III carandez produtores? Valores en OTN USw e percentagen sobre o custo total.

\begin{tabular}{|c|c|c|c|c|}
\hline & & ordih & Us:ha & $\begin{array}{l}x \text { sobre } \\
\text { custototal }\end{array}$ \\
\hline$(1)$ & 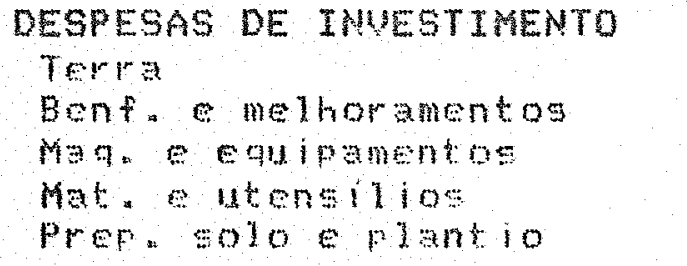 & $\begin{array}{r}1030,76 \\
158,04 \\
239,03 \\
274,63 \\
58,42 \\
300,64\end{array}$ & $\begin{array}{r}7319,72 \\
1120,28 \\
1697,42 \\
1050,28 \\
414,86 \\
2134,93\end{array}$ & $\begin{array}{r}5,53 \\
2,96 \\
3,60 \\
4,14 \\
2,88 \\
1,53\end{array}$ \\
\hline (2) & 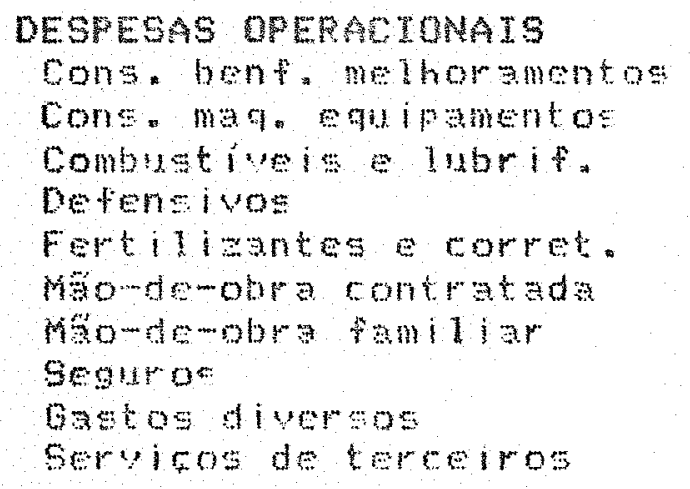 & $\begin{array}{r}5607,90 \\
96,93 \\
231,31 \\
1334,67 \\
1906,80 \\
229,40 \\
1145,27 \\
1,51 \\
295,59 \\
194,92 \\
171,56\end{array}$ & 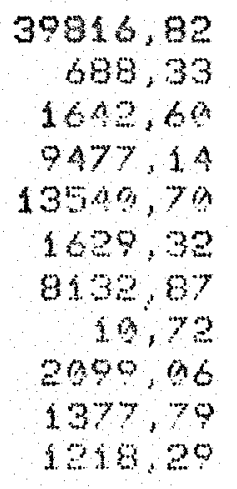 & $\begin{array}{r}0,47 \\
1,46 \\
2,48 \\
20,11 \\
29,73 \\
3,46 \\
2,25 \\
9,02 \\
4,45 \\
2,92 \\
2,58\end{array}$ \\
\hline (3) & CUSTO TOTAL $(1+2)$ & 6637,76 & 4733,53 & \\
\hline (A) & RECEITA DA TERA & 52,83 & 375,16 & \\
\hline & REND IMEMTO (kg/ha) & 135488 & & \\
\hline & CUSTO TOTAL MSOTO (3/5) & 0.048991 & 0,347902 & \\
\hline$(7)$ & PRECO DA MAOK/K & 0,090713 & 0,644175 & \\
\hline$(8)$ & RECEITA BRUTA $(4+5 \times 7)$ & 12343,35 & 87653,14 & \\
\hline (9) & RECEITA LXCUIDA $(8-3)$ & 5705,59 & 40516,61 & \\
\hline
\end{tabular}

Fonte: Dados da punisa 
No itom preparo do molo plantio, o que waysa a maior yariato no seu yalor o tatode haver ou nä nator dispendio ma momde-obra e horas-mánina para a retirada de pedras durante a implantacos do pomer como a presentade pedras na esta relacionada com o tamanho do pomar, elapode justificar a indefiniso do sou alor we relacionado rom a area do pomar. Obaervane, tambem, aue os fruticultores do estrato II, alem de posguirem terras de nenor yalor, investem menos en melhoramentos permanentes desmatamento, destocs, retirada de pedras, abertura de extadase terraceamentol:

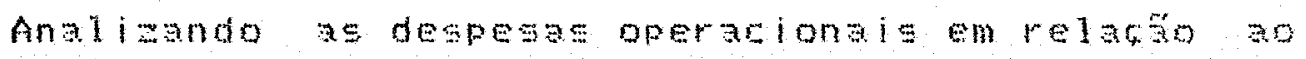
custo total observass que las crercrm com o aumento do tamanho do pomar. Participam com 73,58\% no estrato I, 83, 10\%, no estroto

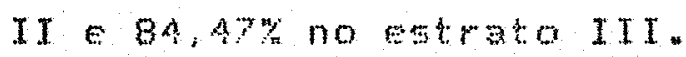

Ds diversos itens que compon as despesas operacionate aprescontan comporkamento di ferente:

a - amentam com o gumento do tamanho do pomar gatos rom conservacto de benteitorias methoramentos, defensivos, mádeobra contratada, seguros a seryicos de terceirosi

b - diminum com o aumento do tananto do pomar: gatos com noode-obra familiar asetos diwersos;

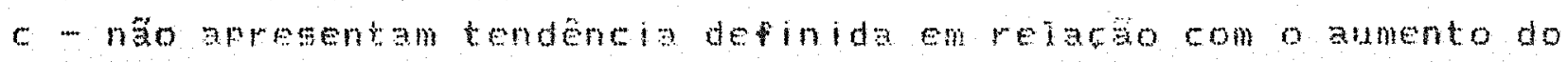

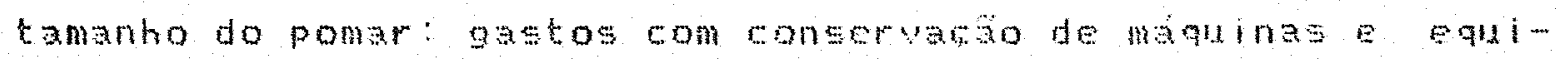
pamentos, combustiveis e lubrificantas fertiliantese ror $r e t 1109$

os itens aue aumentam de valor con o vimento do 
tamano do pomar assin se manifestam pois ha uma utilizacto mals intenge dos diversos fatores de produço, por unidade de área, acarretando entáo a elevarao da participaca relativa destes itens nototal.

Gatos con ma-de-obra familiar e gastos diversos variam em raza inversa a tamanho do pomar. A má-de-obra familiar assim se manifesta poiselo é cada vez menos utilizada quando o pomar aumenta de tamanho, chegando ao extremo em que na maioriz dos pomares grandes ser utilizada apenas näo-de-obra rontratada. Em gastos diversos participam significativamente nos pomares maiorea os gastos com telefone arrendanento, fato raro nos pequenos pomares.

Conseruncro de máquinas e equipamentos, combustim veis e lubrificantes e fertilizantes e corretivos nato aprestam relaço direta nem indireta com o tamanho do pomar.

As maiofe participacies individuais no cueto total sádefensivos, combustiveis e lubrificantes e mäo-de-obra representando 5A, $91 \%(3860,7$ oTNhar no strato I, 67,53\% 0050,00 orNha) no estrato II e 66,11\% (4386, 15 OTM/ha) no estrato III, portanto, mais da netade dos gavos.

Analizando os itens que mats contribuem indluidual mente, obseruane ano os fruticultores do estrato I gastam mals no total dos tres itens. Estes gatos so aignifiativo nos com

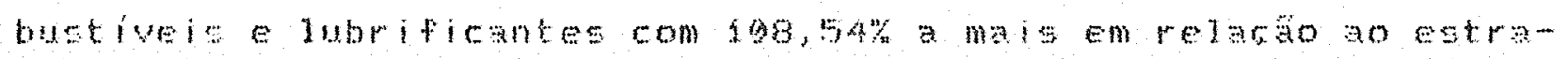
to I e com g5, as\% a maigem relaro ao estrato IIT.

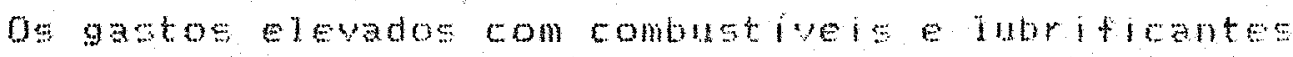


do ectrato Ix orla inam-se do equipamento de pulerizaço ut ilizado pelos fruticultores os grandes fruticultores utilizam pulver izadores aue apresentam trande rendimento, conhecidos por "turbina", logo, o tempo gasto por heckare te reduaddo. os pequenos fruticultores usam, na matoria tratores pequenos cmico tratores) aos quals sa acoplados pulyerizadores com mangueiras a pulverizacio fe manul. Embora levem mais temo por hectare, o consumo de combustuel e menor com o micro trator. Os médios produlores combinam tratores arandes cmator coneunol com pulverizago manul cma is tempol, dai o mator gasto con conbustio veis e lubrificantes.

Separando todos os produtores em duas categorias: numa aueles que apresontam IEEs acima da medis no oura oe que apresentam IEEx abairo da media, observase na Tabela le ane os menos etidientes apresentam hares gasos con inuestimento. Assumen importancia significativa os gastos combenteitorias e me-

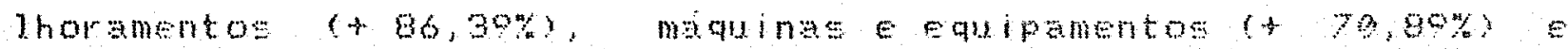
terra (19,05\%) menos $10,39 \%$ ea preparo do solo e plantio.

Nas despesas de exploratso o unico item onde o

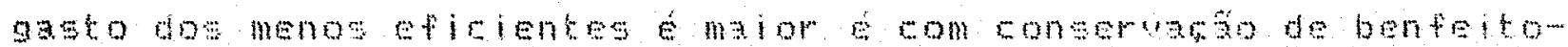

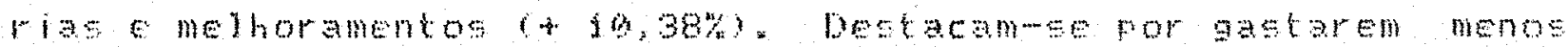

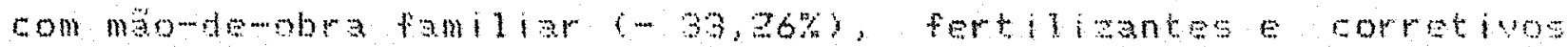
(-23,30\%, conservaro de máninas e equipamentos $(\cdots, 16,2 \% \%$, $9 a t o s$ diversog $\left(-16,26^{m}\right)$ e defensivos $(-11,25 \%$.

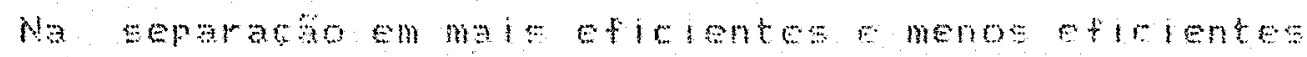
por estrato. oberuawe que os produtores mats elicientes do es. 


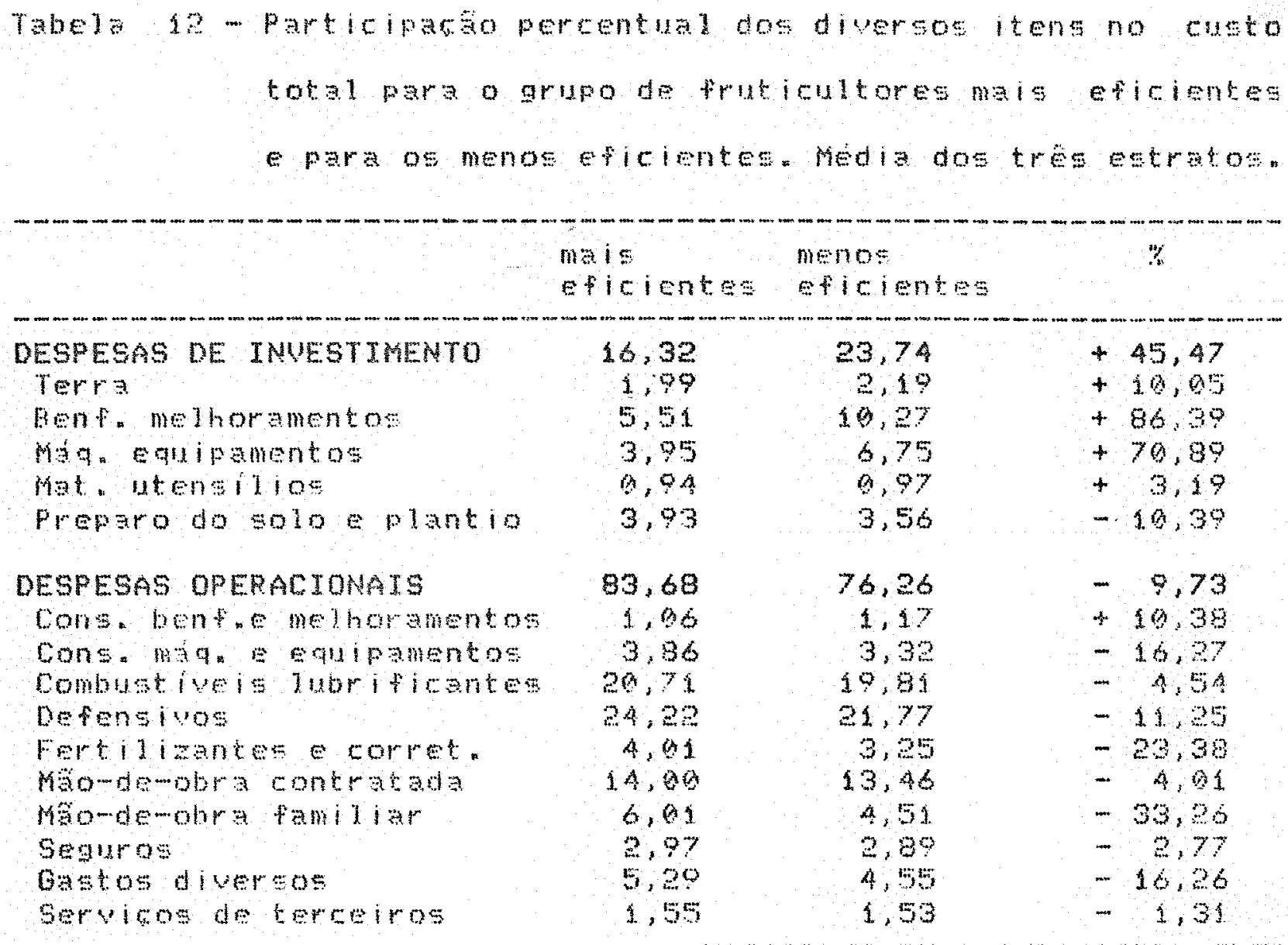

Fonte: Dados da pesarisa

trato II gastam naisem combustiveis e lubrificantes, defensivos

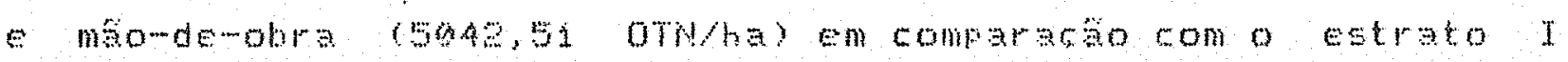
(4354, of or/ha) e con o estrato ITI (3789,49 OTN/ha) os menoa Efirienter gastam no estrato TI 5058,19 orNha em comparato com 44e7, 9 oTNha do estrato I 3901 , 45 oTh/ha do estrato III.

AS Tabelas 23,49 e 15 (Apondice) apresentam, por estrato, os diferentas indices calculados para cada produtor sendo en ordem decrestente pelo indice de eficiencia da exploraco. Conem destacar que seis produtores apresentan IEEx< o sendo

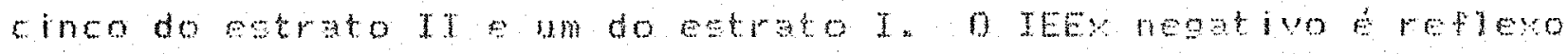


mais do baixo retimento (TET) do que do elevdos custos (TEP) destes produtores.

Qunto ao custo total/ha e custo total médiolig, o estrato III apresenta os melhores resultados, depois o estrato I finalmente o zetrato TI.

o rendimento por hectare é semelhante nos estratos IT e I mas expreseivante inferior no estrato II Este fato fam explicaço na qualidade da terra cen valory, pouca inversa em methoramentos permanentes e menor wtilizaso de tertilizantes e corretivos.

A receita liquida média em todos os estratos assume valores positiogs. o melhor resultado epresentado pelo estrato III (5705,50 oTUha) seguidopelo sstrato I (Ag17,go oTh/ha) finalmente o estrato II (305, 97 OTNhay.

A ntillyago dos valores medios andais de cada eatrato permite a comaraba com qual quer produtor assim, se interesan a um fruticulor saber como esta a suatioldade produtiva em relacso ao arupo ao qual pertence, basta valer-ae do programa de computador elaborado para obter os calculos dos custos. receitae indires de efiriencia reterentes ao sey pomar pesta forma a dificulade de calculos devido a propria estrutura produtiva da mara, tornawe simples e promite obter as diversas medidas do resultado economico de forma rapida. No ANExo a encontram-se as orientacies para a operacionalizaco dos cardos e

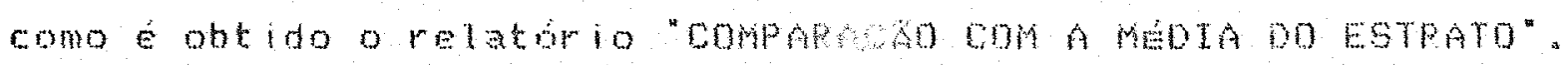
Utiliando o treste " nara comparar os custos to- 
taismedios dos pequenos e grandes produtores tho: $\bar{x} 3=\bar{x}_{1}$, Ha: $\bar{x} 3$ (Xi) conclui-se we, an nivel de signifiencia de $5 \%$,

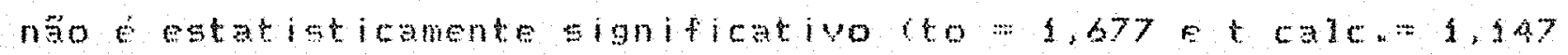
com 50 graus de liberdade), ou seja, estatisticamente o custo dos produtores arandes neo difere do custo dos produtores pequenoe, 0 aue refuta uma dae hipotese deste trabalho.

romprando as receitas liquidas doe requenoe arandes produtores (Ho: RLS = PLA, Ha: PL3 Y RLA) ronclui-se aue, ao nivel de significaneia de $5 \%$, nao esestaticamente eigniticativo co $=1,677$ e calco $=0,704$ com 50 graude liberdader, ou seja, estatisticamente a receit limida dos produtore grandes nao difere da receita liquida dos producores peruenos, o que rejeita a oura hipotese demetranglho. 


\section{CONCLUSOES.}

Embora o estrato ITI apregante menor custo cotal medio malor renda litula, näo observada diferena entatiotica com o estrato I. Portanto, os pomarsesrandes nato apresentam vantagens em relacto aos pomares pequenom.

Ao andisar a eficiencia observa-se aue no presente trabatho é posalvel um produtor apresentar indicede eficiencia economic acima da móda embora neo apresente indice de efictencla tecnica e indee de efiriencia preco reima da media o ous contrarla a afimacio de Brandt (1980). A explicasboreside no fato de que Brandt, para sua andise, usa valores mínimos.

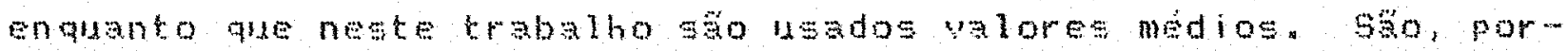
tanto, conceitos diferentes Para o presente trabatho decesa wio que o IET on o TEP apresentem um valor acima da medi qua compense o outro, abaixo da media. Eoseivel produrir menos ane a media (IET $(A)$ a um custo menor aue a media (IEP) 1 ) ou produzir mais que a média (TET) 1 y a un custo maior que a media (JEP \& 1), degde are a produto dos dois indices aruse um ualor maror que a un dads.

En termog de planejamento. os resultados mostram que o setor produtivo de mat eficiente, remunera todos os tators de produca a anda ha una renda residual para o empre- 


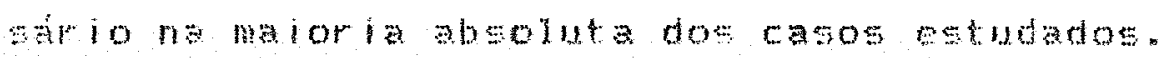

As despesas do investimento assumen importancia

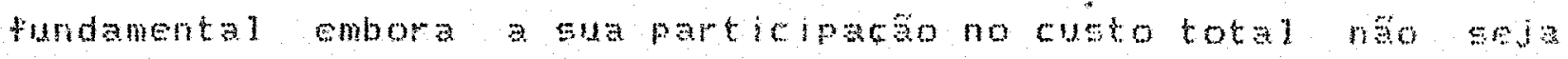
muto expressib. observare ase elas diminuem significatiamente com o aumento do tamanho do pomar, prinsipalmente benteitoriase melhoramentos máainas e equipamentos, o que e esperado segundo

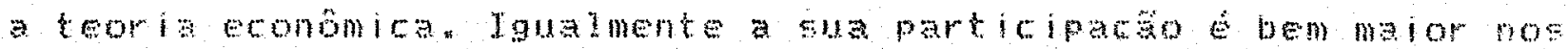
pomares menos eficientes destando-ge benteitoriss a melhoramento atse partimipam com $86,39 \%$ a maj en máninas e equpanentos

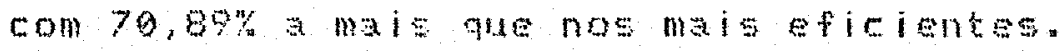

0 mas desemperho do estrato $x$ em relaso asos

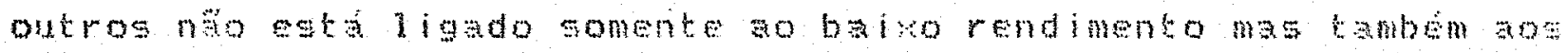
elevados custos. Mesmo que o rendimento foese igual ao do estato

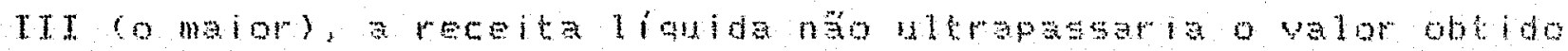
no estrato.

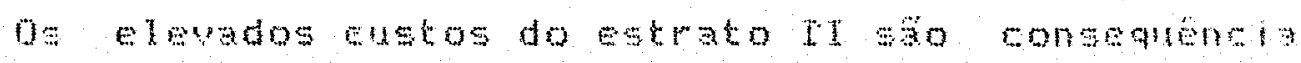

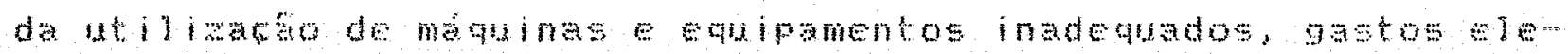
vados com conservazo de manumas e equipamentos e combugtueis lubriticantes. 0 baxo rendimento é consenuencia da pous wtili.

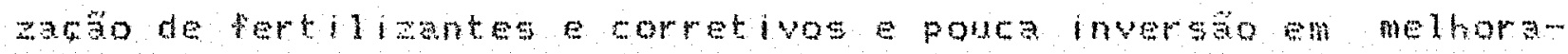
mento fundiarios no preparo do 9010 elantio.

A elaboracio de um programa de computador que permite obter de forma rapida os custos, as receitas e os diver. sos indices de eficiencia e particularmente interessante pela faGlidade do calculose por permitir, tabba, a obtenca do relaw torio aue indica a posica de cada fruticultor em relarácom a 
média do extrato.

Embora a atividade produtiva da mara encontra numa situaro boa, os problemas detectados por esta pesalisa da yem ser levados a conhecimento dos produtores, via extensabura1, objetivando melhorar ainda ma

Sugerimos culdados espeiais aunto a:

- fazer seguro contra granta e geada: no casotrata-sede segurar a producio pois a onorrencia destes evento é muto frequente e por prejudicar signiticatiwamento rendimento a aulidade da matc

- dimensionar aciequadamen as mádinas, zuipamentos a benfeitorise: desta forma os custos com tals fatores serlam reduzidos substancialmente tanto quando da auisiago como na manutencro pu

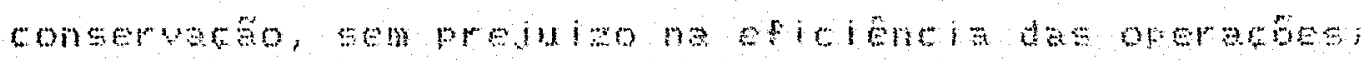

- melhorar as operabes ane snyolum oprepso do soto eplantio:

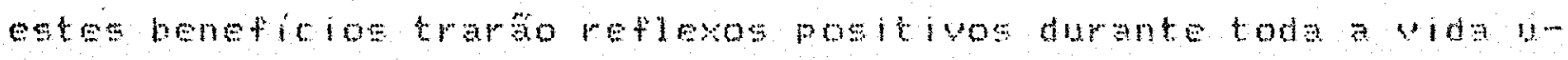
til do pomar, traduzindo-se principalmente en maior rendimento - maior dedicabo no gerenciamento da producto atreditamoe gue a maiores fahas estio na falk de conhecimentosternicos outi cientemente promndos onde o produtor possa se arolar paratonar sus $\operatorname{dectsigs}$.

Por considerarmos de relevaneia fundamenta 1 , sugerimos pesulsas adicionais e espertica na brea da comercializa-

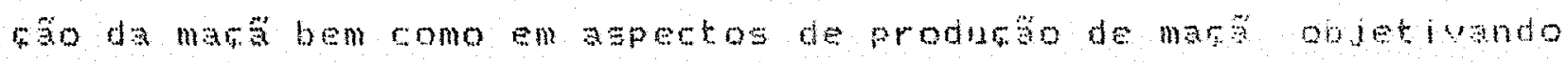
frutas de melhor apresentacas e tamento gue proporeionem melhor preso. 
REFERENCIAS BIELIOBRAFTCAS

BRANDT, BaA. Comercializaca agricola. Piracicaba, Livroceres. 1980: $195 \%$.

BRASIL. Fundara Instituto de begrafia e Estatistica-TebE. IX Recenseamento Beral do Brasil-1980. Censo Agropecuario da santa Catarina tolume 2 , tomo 3 numero 21,19 e 2 parten no de laneiro, 4983.784 .

ESTADO DE SAMTA CATAPTNA Instibuto de Planejamento e Economia

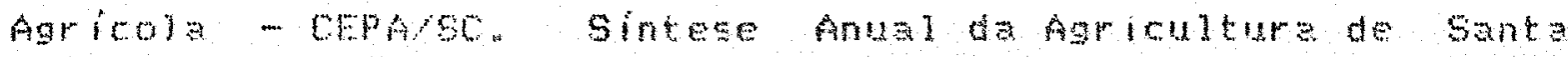

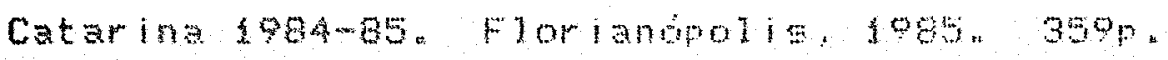

ESTADO DE SANTA CATARTMA EMpres Catarinenae de pesquisa Agropem

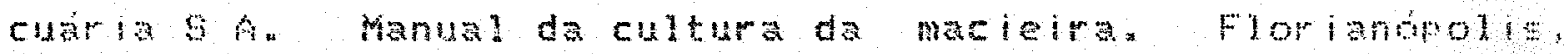
1986. $562 \%$ *

ESTADO DE SATTA CATARTHA Tnstituto de Ptanejamento E Economia Agricola - CEpaso sintese Anual da Agriculnura de Santa Catarina 1985-86. Volume i. 4235. Volume a 224p. Florianopom 1is. 1986

ESTADO DE SANTA CATARINA. Instituto de pianejamento e Economia Agrifola - OEPASC sintese Anual da Agricultura de Santa Catarina 1986-87. Florianopolis, 1987 Abz. 


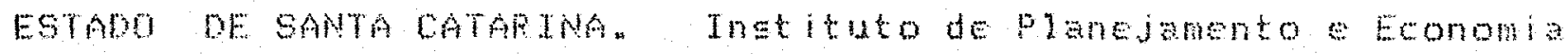
Agricole - CEPASC. Sintese Anual da Agricultura de Santa Catarina 1987-88. Florianopols, $598.417 \mathrm{p}$

FERGUSon, C.E. Microeconomia. Rio de Janeiro, Forense Uniura Eltaria, $10 \% 0^{\circ} 616 \mathrm{p}$

MARoUEs, P.U. Fatores condicionantes do nivel do ericiencia tenice entre agricultores de baika renda . Piracicaba, jo7b. Qep. Mestado - Escola Superior de Agrioulura "Liz dis oue imos"

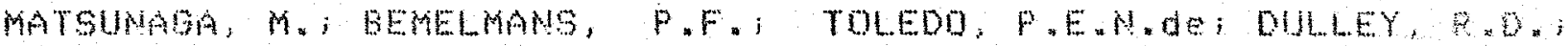
OKAWA, H. PEPROSO, I.A. Metodologia de muto de produra

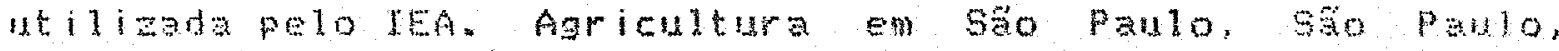
$23(1): 325-139,19 \%$

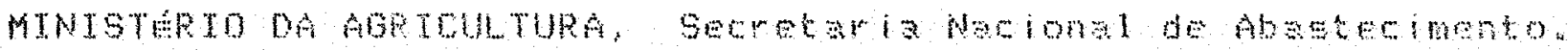
Secretaria Nacional de producso moropenaria programa na cional de producto e abastecimento de mas. (190\%-1900). BraSIID, EMBRATER, S9Q7, 27p*

NEUES, E, M, AMARO, A. A, Y YMABUTSH, $C, T$; COAPADO, M. A, $B$ Aspectos economicos da culturs e formaźo de mudas de marieira

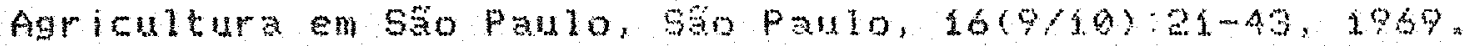

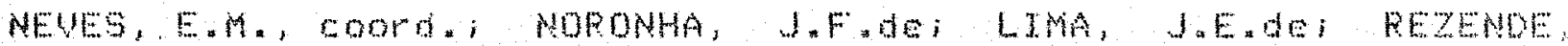

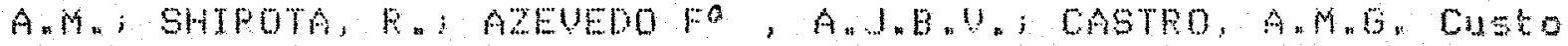
de producío de borracha natural em seringa cultivados. Rela torto de pesquisa piracicaba, FEALo, 1983. 84p.

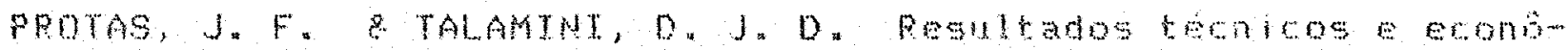
moos de proprledades suinicolas rom diferentes tamanhos de 
renanhos en Santa Catarina Revista de Economia Rural, Brasia Iin, 20(a):575-586, ont./dez. 1982.

SCHUH, 0.E. Coneiderafós tebricas sobre custos de produso na

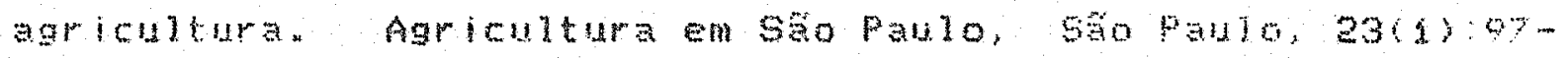
$121,1976$.

TOMPKIN, I. R. Estatistica metodos depesauisa em ciencias sociaise rurais. Piracicaba, ESAL, 196, 17p 
BIELTOGRAFTA RECOMENDADA

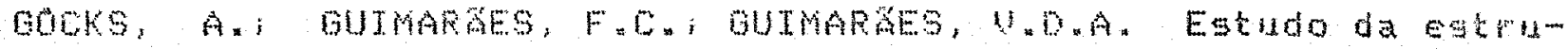
Lura do mercado da nacia nacional na CEASA de piracicaba, Piracicaba, Esho, bepartamento de Economia e sociologia Rural, 1907.200.

HEMTGKE, R. Aspectos sobre clastificaco comereialiandoda

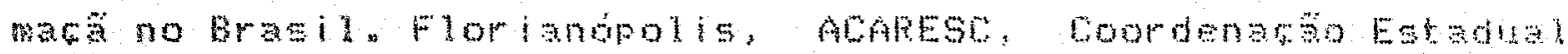
de Horticultura, 198,4 , 99 .

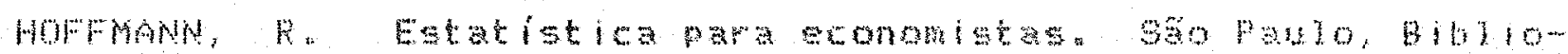

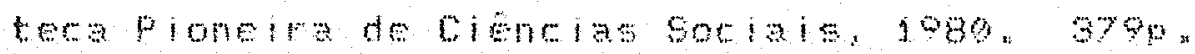

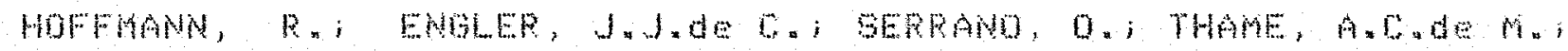
NEUEs, EM. Adminietracio da empresa aricola 39 ed. sao

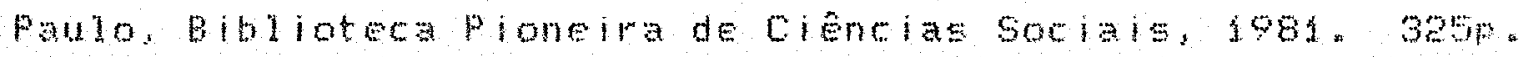
AEUES, E. M, SARTORELI, S. R. P; SHROTA, R, Custo de producáo de laranja no Estado de sáo Panlo. Piracicaba, Pelatório de

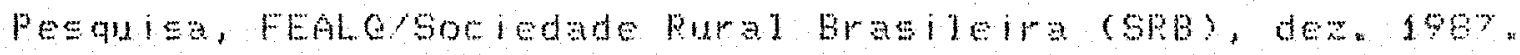
NORONHA, JF. Projetos agropecuariosi adinistracáo financeira, orcamento viabilidade economica. 2 ed sáp palo, Editora At $12=5$ A, 1987. 269\%. 
APENDTCE 
Tabela 13 -. Cassificato dos produtores segudo a eficioncia.

Pequenos modutores.

\begin{tabular}{|c|c|c|c|c|}
\hline $\begin{array}{c}\text { Produt or } \\
\text { ne }\end{array}$ & LET & IEP & TEE & IEEX \\
\hline 132 & 1,44 & 1,13 & 1,63 & 2,23 \\
\hline 510 & 1,28 & 1,06 & 1,35 & 1,76 \\
\hline 251 & 1,94 & 1,33 & 1,39 & 1,45 \\
\hline 479 & $1, A A$ & 1,24 & 1,20 & 1,36 \\
\hline 165 & 1,08 & 1,11 & 1,21 & 1,36 \\
\hline 125 & 1,00 & 1,23 & 1.23 & 1,29 \\
\hline 251 & 1,02 & 1,20 & 1,22 & 2,29 \\
\hline $3 A$ & 0,99 & 1,23 & 1.22 & 1.23 \\
\hline 480 & 0,96 & $1,2^{7}$ & 1,23 & 1,21 \\
\hline 023 & 0,99 & 1,20 & 1,18 & 3,20 \\
\hline $43=$ & 1,00 & 1,17 & 1,17 & 1,20 \\
\hline $10 \%$ & 0,96 & 1,23 & 1,10 & 1,39 \\
\hline 012 & 1.90 & 1,13 & 1,13 & 1,16 \\
\hline 476 & 1,0 & $i, 15$ & 1,21 & 1,33 \\
\hline $6 \because n$ & i. 0 & 1.00 & 1,69 & 1,12 \\
\hline 303 & 0,9 & 1,69 & 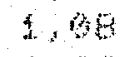 & 1.69 \\
\hline 369 & 1,80 & 0,99 & 1,03 & 5,68 \\
\hline 330 & $1,0,3$ & $0,9 \%$ & 1,02 & $1,0 \%$ \\
\hline 632 & 0,9 a & 1,16 & 1,09 & 1,95 \\
\hline 561 & 4,98 & 1,06 & 1,04 & 1,03 \\
\hline 580 & 0.99 & 1,02 & 1,01 & 0,90 \\
\hline 080 & 0,97 & 1.03 & 1,09 & 0,9 \\
\hline 130 & 0,99 & 0.98 & 0.97 & 0,96 \\
\hline 180 & 0,07 & 0,96 & 0,94 & 0.92 \\
\hline 060 & 0,98 & 0,90 & 0,96 & 0,01 \\
\hline 391 & 1,33 & 0,61 & 0,81 & 0,80 \\
\hline 216 & 0,96 & 0,95 & 0,02 & 0,85 \\
\hline 460 & 1,02 & $0,0 \%$ & 0,86 & 0,70 \\
\hline 445 & 0,94 & 0,90 & 0,89 & 0,76 \\
\hline 633 & 0,91 & 0,94 & 0,85 & 0,67 \\
\hline 498 & 1.01 & 0,79 & 0,79 & 0.62 \\
\hline 39 & $0,9 y$ & 0,70 & 0,76 & 9,64 \\
\hline 996 & 9,94 & 0,81 & 0,76 & 0,52 \\
\hline 584 & $s, 64$ & 1,30 & 0,83 & 0,45 \\
\hline 301 & 0,77 & 1,00 & 0,77 & 9,44 \\
\hline 204 & 0,06 & 0,73 & 0,7 & 0,39 \\
\hline $25 \%$ & 0,40 & $a, b 4$ & 9,32 & $-1,01$ \\
\hline
\end{tabular}

Fonte: Dados da resulsa. 
Tabela id - Claceificaro do produtores seaundo aficiencia Medios produtores.

\begin{tabular}{|c|c|c|c|c|}
\hline $\begin{array}{c}\text { Produtor } \\
\text { nes }\end{array}$ & TET & IEP & TEE & IEEX \\
\hline 613 & 1,80 & 1,11 & 2,05 & 5,64 \\
\hline $47 \%$ & 4,62 & 0,71 & 1,25 & 2,47 \\
\hline 609 & 1.23 & 1,00 & 1,24 & 2,17 \\
\hline $2 A 5$ & 1,06 & 1.08 & 1,15 & 3,6 \\
\hline$\$ 5 \%$ & 1,06 & 1,06 & 1,12 & 1,5 \\
\hline 657 & 1,03 & 1,10 & 1,12 & 1.99 \\
\hline 363 & 1,00 & 1,1 & 1,11 & 1,38 \\
\hline $68 \mathrm{~A}$ & $5,0 i$ & 1,10 & 1,10 & 1,35 \\
\hline 492 & 1.01 & 1,07 & 1,97 & 1.29 \\
\hline 960 & $9,9 \%$ & 1,12 & 1,08 & $1,2 \%$ \\
\hline 791 & 1,60 & 1,63 & 1.93 & 1.13 \\
\hline 136 & 1,04 & 0,98 & 1,02 & 1,12 \\
\hline 658 & 0,98 & 1,04 & 1,02 & 1,60 \\
\hline 400 & $0, p$ & $i, A j$ & 1,00 & 0,9 \\
\hline 192 & 0,97 & 1,09 & 0,99 & 0,97 \\
\hline 685 & 0,97 & 1,00 & 0.99 & 0,96 \\
\hline 376 & $\$, 01$ & 9,96 & 0,99 & $4, y$ \\
\hline $68 \%$ & 0,90 & 0,00 & $9,9 \%$ & $a, b$ \\
\hline 331 & $n, 9 b$ & 1,02 & 0,97 & $0,8,4$ \\
\hline 110 & 0,00 & 0,95 & 6,94 & 3,75 \\
\hline 248 & $0,8 d$ & 1.08 & 0.90 & 0,47 \\
\hline 506 & 9,96 & $0,8^{7}$ & 0,04 & $a, 24$ \\
\hline 631 & 0,93 & 0,90 & 0,84 & 0,22 \\
\hline 343 & 0,72 & 2,08 & 0,78 & $-0,0 \gamma$ \\
\hline$A \gamma 1$ & 0,86 & 9,90 & 0,77 & $-0,16$ \\
\hline 88 & 0,59 & 1,00 & 0,64 & $-\infty, 76$ \\
\hline 5.3 & $\theta, 8$ & 9,81 & 0,60 & $-0,85$ \\
\hline $23 \%$ & 0,46 & 1,06 & 0,49 & $-1,47$ \\
\hline
\end{tabular}

Fonte: Dados da perabist. 


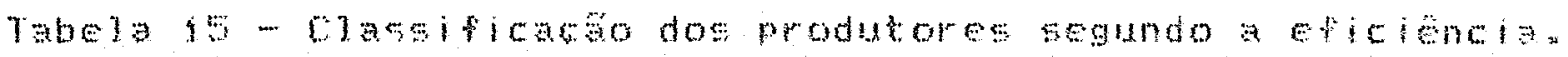
Brandes produtores.

\begin{tabular}{|c|c|c|c|c|}
\hline $\begin{array}{c}\text { Produtar } \\
\text { nt }\end{array}$ & IET & $I E P$ & IEE & IEFY \\
\hline 524 & 1,37 & 0,83 & 1,40 & 1,79 \\
\hline 562 & 1,10 & 1,09 & 1,30 & 1,4 \\
\hline 258 & 1,85 & 1,09 & 1,16 & 1,11 \\
\hline 05 & 1,00 & 1,00 & 1. $\theta 0$ & 1,01 \\
\hline 208 & 1,00 & 0,96 & 0.96 & 1,01 \\
\hline 936 & 1,00 & $1,0 \gamma$ & $1,0 y$ & 1.90 \\
\hline 120 & 1.00 & 1,06 & $1,0 \%$ & 1,90 \\
\hline $5 A$ & 1,00 & 1.03 & 1,95 & 1.90 \\
\hline 586 & 1.60 & $1,0 \times$ & $1,0 A$ & 1. 96 \\
\hline 013 & 1,00 & 1,00 & 1,00 & 1,00 \\
\hline 530 & 1,00 & 0,98 & 0,90 & $1, \infty 0$ \\
\hline 640 & 1,00 & $8,9 y$ & 0,97 & 0.09 \\
\hline 54 & 0,92 & 0,91 & 0,84 & $\theta, 80$ \\
\hline 547 & 0,00 & 1.06 & 6,95 & 0,57 \\
\hline 648 & 0,60 & 9.97 & 0,64 & 9,29 \\
\hline
\end{tabular}

Fonte: Dados da pessulisa. 


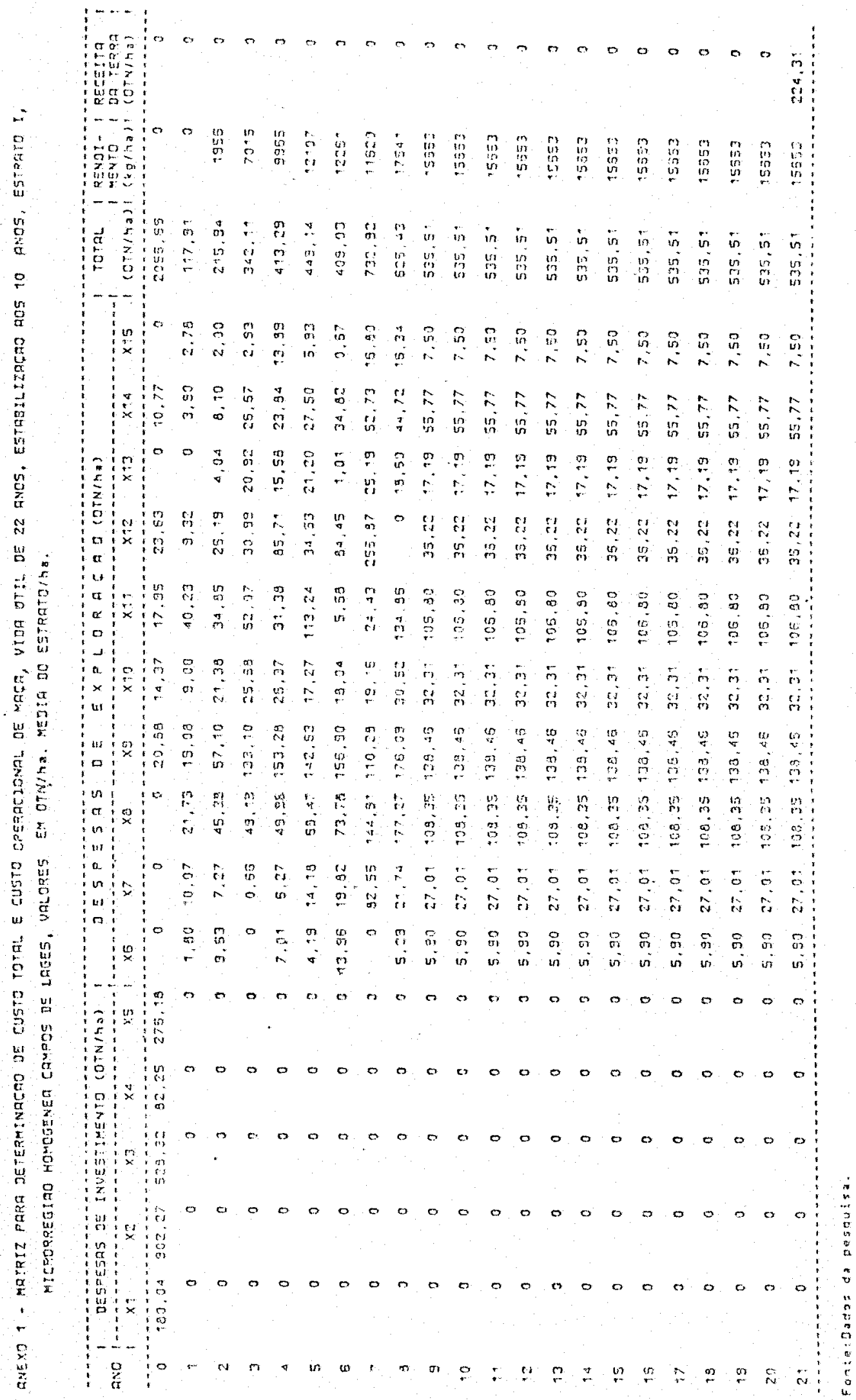




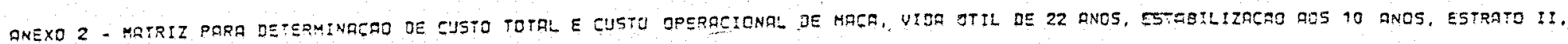

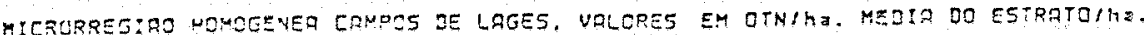

\begin{tabular}{|c|c|c|c|c|c|c|c|c|c|c|c|c|c|c|c|c|c|c|c|}
\hline avo & DE & $\begin{array}{l}5505 \\
10\end{array}$ & \begin{tabular}{c} 
SAS DE I \\
\hdashline$\times 2$
\end{tabular} & \begin{tabular}{c} 
KUEZT: \\
\hdashline$\times 3$ \\
\hdashline$\times 3$
\end{tabular} & 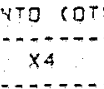 & 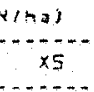 & $1 \times 5$ & $\begin{array}{l}559 \\
\times 7\end{array}$ & 5595 & $\begin{array}{r}0 E \\
\times 9 \\
\times 9\end{array}$ & $\begin{array}{c}E \times P \\
\times 10 \\
\times 10\end{array}$ & $x+1$ & $x \div 2$ & \begin{tabular}{l} 
(ha) \\
\hdashline$\times ! 3$ \\
$\times 13$
\end{tabular} & $x: 4$ & $\begin{array}{r}x+2 \\
\times 15 \\
\end{array}$ & $\begin{array}{l}\text { TOTGL } \\
\text { (OTNGA)! }\end{array}$ & 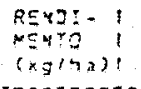 & 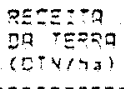 \\
\hline 0 & 115 & 97 & 503.67 & 297.23 & 67.35 & 253,75 & $12,: 8$ & 8.13 & 32.14 & 153.39 & 3.75 & 0 & 20.30 & 2.43 & 3.11 & 0 & 1633,77 & 2 & ? \\
\hline$\uparrow$ & & 0 & 0 & 0 & c & 0 & 2 & 7.33 & 49.79 & 179.91 & 7,03 & 8.14 & 20,42 & 2.5 & 3,76 & 0 & 229.92 & 0 & 3 \\
\hline 2 & & 0 & 3 & 2 & 0 & 0 & 3,29 & 9.89 & 93.19 & 144.57 & 5.35 & 42.52 & 28,19 & $8,2=$ & 0.07 & 5,50 & $35:, 13$ & 350 & 2 \\
\hline 3 & & 0 & $a$ & 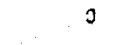 & 0 & 0 & 5.49 & 13,17 & 121,19 & 171.72 & 8.95 & $80,3:$ & ร.งิ & 19.75 & 99.49 & 7.93 & 435.47 & 4293 & $?$ \\
\hline 4 & & 0 & 0 & 3 & 0 & 0 & 5.87 & 22.24 & 95,43 & 207,99 & 11.07 & 52.08 & 50.47 & 10,75 & $: 5,37$ & 7.17 & 499.32 & $77 \leq 2$ & 3 \\
\hline 5 & & 0 & 0 & 2 & 0 & ? & 0 & 35,53 & 505.14 & 152.70 & 12.25 & 207.25 & 67.99 & 22.53 & 27.79 & 18.85 & 1043.33 & $: 2789$ & 2 \\
\hline 6 & & 0 & 0 & 3 & 0 & B & 9.32 & $5.5:$ & 171.11 & 72.55 & 25.42 & $2 \%, 59$ & 14.05 & 10.59 & 2.72 & $2.5 ?$ & $322:=1$ & 50223 & 0 \\
\hline$?$ & & 2 & 3 & 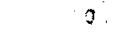 & 0 & 2 & 0.57 & 5.25 & 299.53 & 122.55 & 33,32 & $720,3:$ & 49.75 & 57.53 & 3.27 & 15.93 & 57249 & $9 \div 2$ & $?$ \\
\hline 3 & & s & 3 & 3 & $a$ & 3 & 5,22 & 10.52 & $: 10.44$ & $152, .2$ & 0,25 & $24,: 4$ & 3 & 3 & 5.97 & 0 & $3 \div 2.53$ & $143 \geq 1$ & 3 \\
\hline 3 & & 2 & 0 & 2 & 3 & 3 & $19,2=$ & 30,25 & 995.00 & 13580 & $\because \therefore 24$ & $\because 2.55$ & 7.25 & 29.27 & 79.49 & 13.21 & 534,15 & $=28$. & $?$ \\
\hline 13 & & 3 & 0 & 0 & 0 & 0 & 11,72 & 34.25 & 195,08 & 132.50 & 27,24 & $1: 2.56$ & 17.25 & $22,2^{7}$ & 35.89 & $: 3,21$ & 594,13 & $1208:$ & $?$ \\
\hline 11 & & 0 & 0 & 3 & 0 & 0 & 94.72 & 24.25 & $: 95,08$ & $: 25,50$ & $2 \uparrow, 2 d$ & 112.58 & 17,55 & 22.27 & 39,89 & $: 3,2^{4}$ & 534,15 & 12054 & ? \\
\hline$\because$ & & 0 & 0 & 0 & 0 & 0 & 11.72 & 34,25 & 195.08 & 175.50 & $2 \div, 24$ & $: 12,5 \Xi$ & 17.25 & 22.27 & 39.53 & $13.2:$ & 524,5 & 12254 & 9 \\
\hline 13 & & 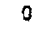 & 0 & 0 & 0 & 0 & $1: 78$ & 34,25 & 425,08 & 135,50 & 21.24 & $: 2.55$ & 17,25 & $=2.27$ & 39.39 & $+3.2 ?$ & $59 \div .9$ & 12054 & $?$ \\
\hline 74 & & 0 & 0 & 0 & 0 & ? & 13,72 & 30,25 & 185,08 & : $: 35.50$ & 27.24 & $1:=.56$ & 17.25 & 22.27 & 39.93 & 2.21 & 59.15 & 12054 & 3 \\
\hline 15 & & 0 & 0 & 0 & 0 & 0 & 11,72 & 34,25 & $15 \vec{a}, 60$ & 135,80 & $2: \therefore=4$ & $1: 2.55$ & 17,25 & 22.27 & 39.98 & 13,21 & 594.15 & 12054 & $a$ \\
\hline 16 & & 0 & 0 & 0 & 0 & 6 & $7 \div, 72$ & 34.25 & 185,09 & 135.50 & $21+24$ & 112.60 & 17.25 & 22.27 & 39.89 & 13.27 & 534.18 & 12254 & 3 \\
\hline 17 & & $?$ & c & c & 0 & 3 & 11.72 & 34.25 & 185.08 & 735.60 & 21.24 & 112.60 & 17.25 & 22,27 & 39.39 & 13.21 & 534,15 & 12054 & a \\
\hline 18 & & $\varepsilon$ & 0 & 0 & 0 & 0 & 11.72 & 34,25 & 185,08 & 135,50 & 29,24 & $1: 2.05$ & 17.25 & 22,27 & 39.39 & 13.21 & $594,: 5$ & $1205=$ & 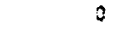 \\
\hline 29 & & : & 0 & $a$ & $?$ & 0 & 11,72 & 34.55 & 193.09 & 135,50 & 21,24 & $: 12.85$ & 9.25 & $22.2 \%$ & 39.38 & 13.21 & 530.15 & 12084 & 0 \\
\hline 20 & & $\dot{0}$ & $c$ & o & 0 & 0 & 11.72 & 34,25 & 185.03 & 125.60 & $2:, 24$ & 112,63 & 17,25 & 32.27 & 39.38 & 13,24 & 524.15 & 2054 & 3. \\
\hline $2:$ & & 0 & 0 & 0 & 0 & 0 & 11,72 & 34,25 & 185.05 & 135,00 & 21,24 & 12.55 & 17,65 & 22.27 & 33.38 & 13.24 & 594,15 & 12254 & 155.25 \\
\hline
\end{tabular}

Fontulados do percuisa. 


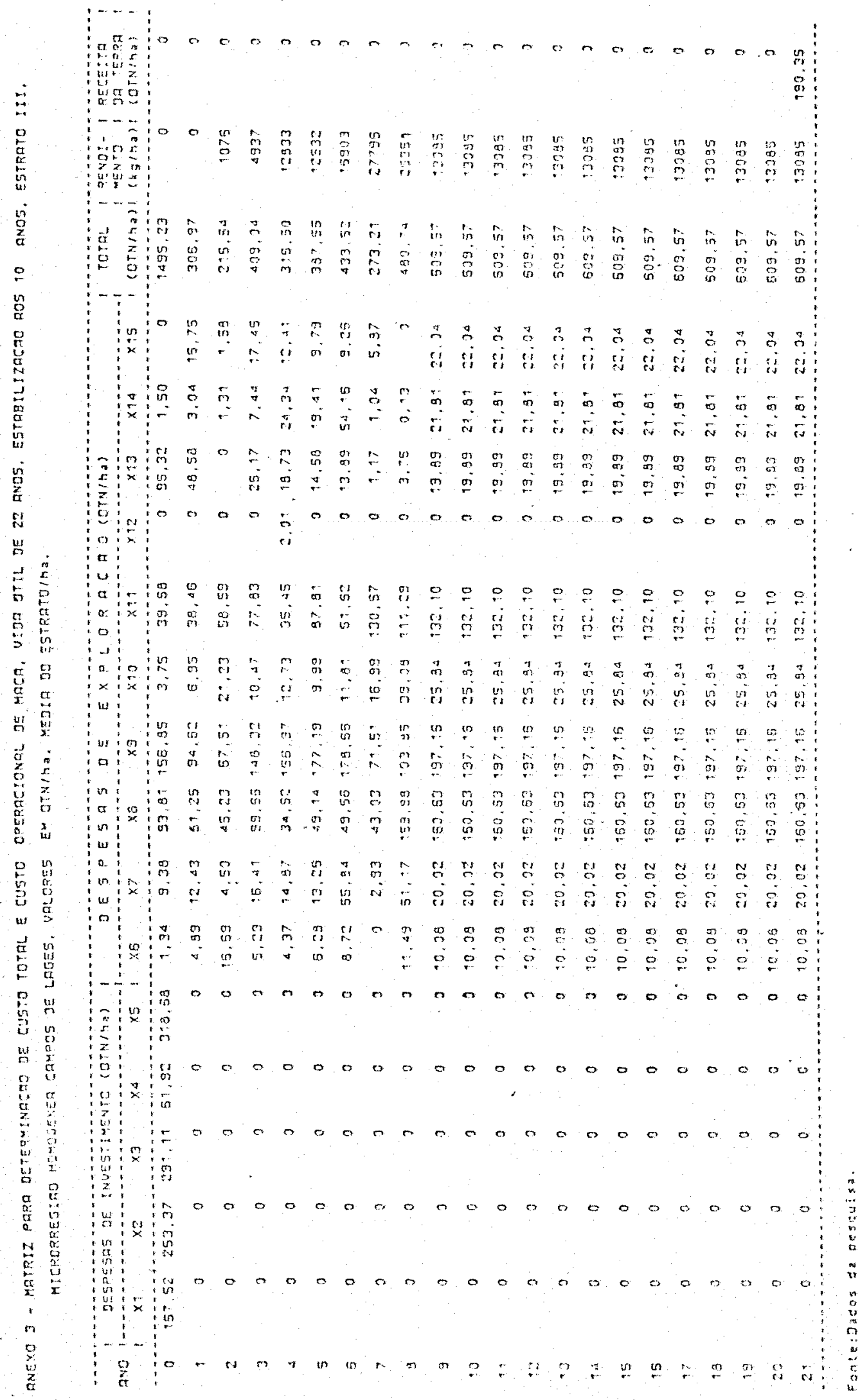




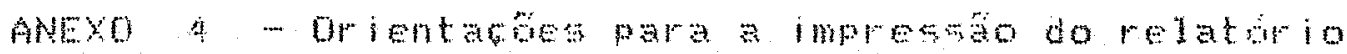

\section{COAPARAGQO DOM A MEOTA DO ESTRATO}

Para abualizar on verificar a posisa relakiva de

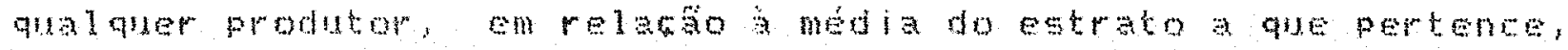
proceda da segunte roma:

a) Verifique em aue estrato oprodutor se wanadrac I, II on III conforme a area do pomar:

b) Escolta a opto OTN ou USg para a comparato;

c) depole da memor la (RAM) do computador carragda con o apli cativo Lotus $1-2-3$ introdus no "drive" A o disages com as

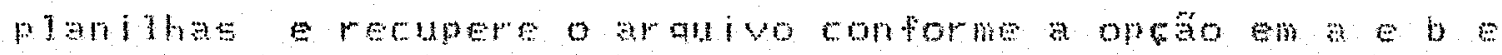
nas geguintes informages:

- Ho ectatoI, se o pomarten ibanos on mis, utilizeo

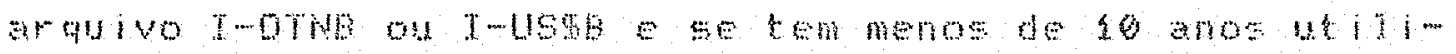
ze o aranivo T-OTH on T-USw.

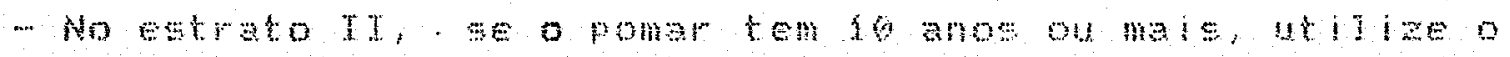

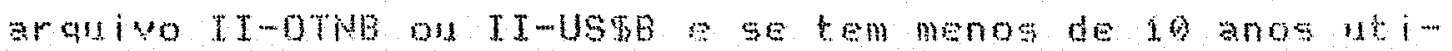
1ize o ar quivo II-OTH on TI-USt.

- No estrato TIT, se opomar tem jo anos on mas. Heilige o

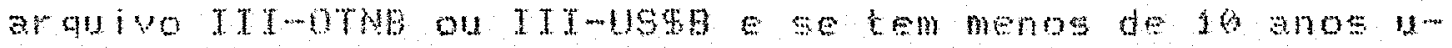
tilige o arativo ITI-OTh on III-USwi

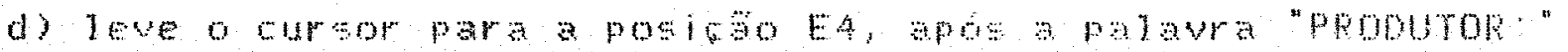
edigite a nome do produtor e tecle EuTER atilize no má Ximo 8 caracteres para o nome do produtory.

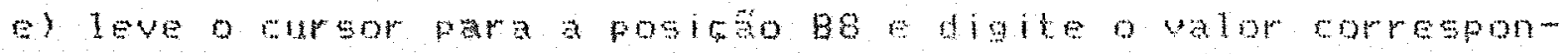


dente a um hectare de terra, depois tecle ImTEP

f) proceda de forma ansloga de Co a FB antrando com os valores

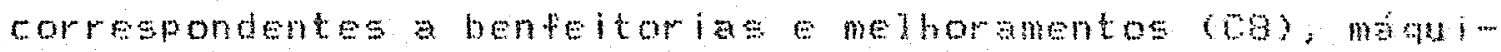

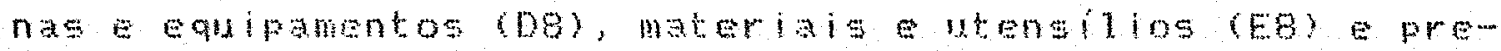

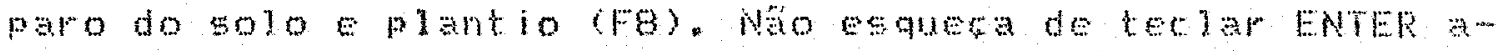
pos digitar cada valori

a) leve o cursor par a columa a e conforme a idado do pomar escolha a Imba Entme rom os valores correspondentes a congervaso de benteltorias e melhoramentos (colung 0 ,

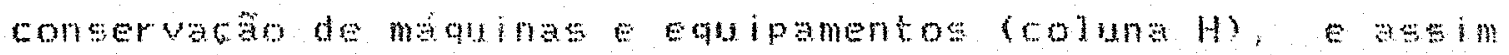
por diante a servifos de terceiros (colunap);

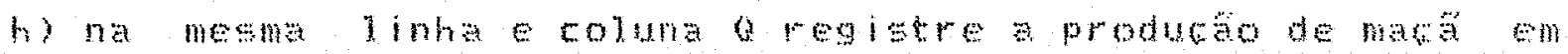
L 1 Hai

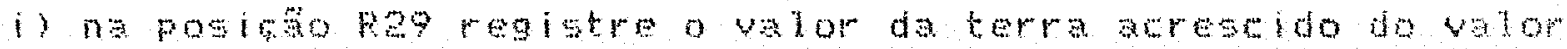

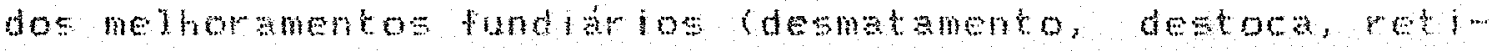
rada de podras, abertura de estradas. etcan;

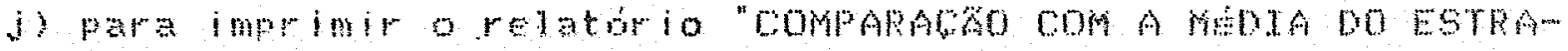
$\mathrm{TO}^{*}$ siga os seguntes comandos:

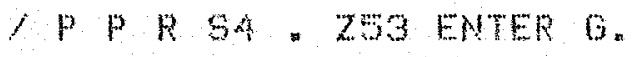




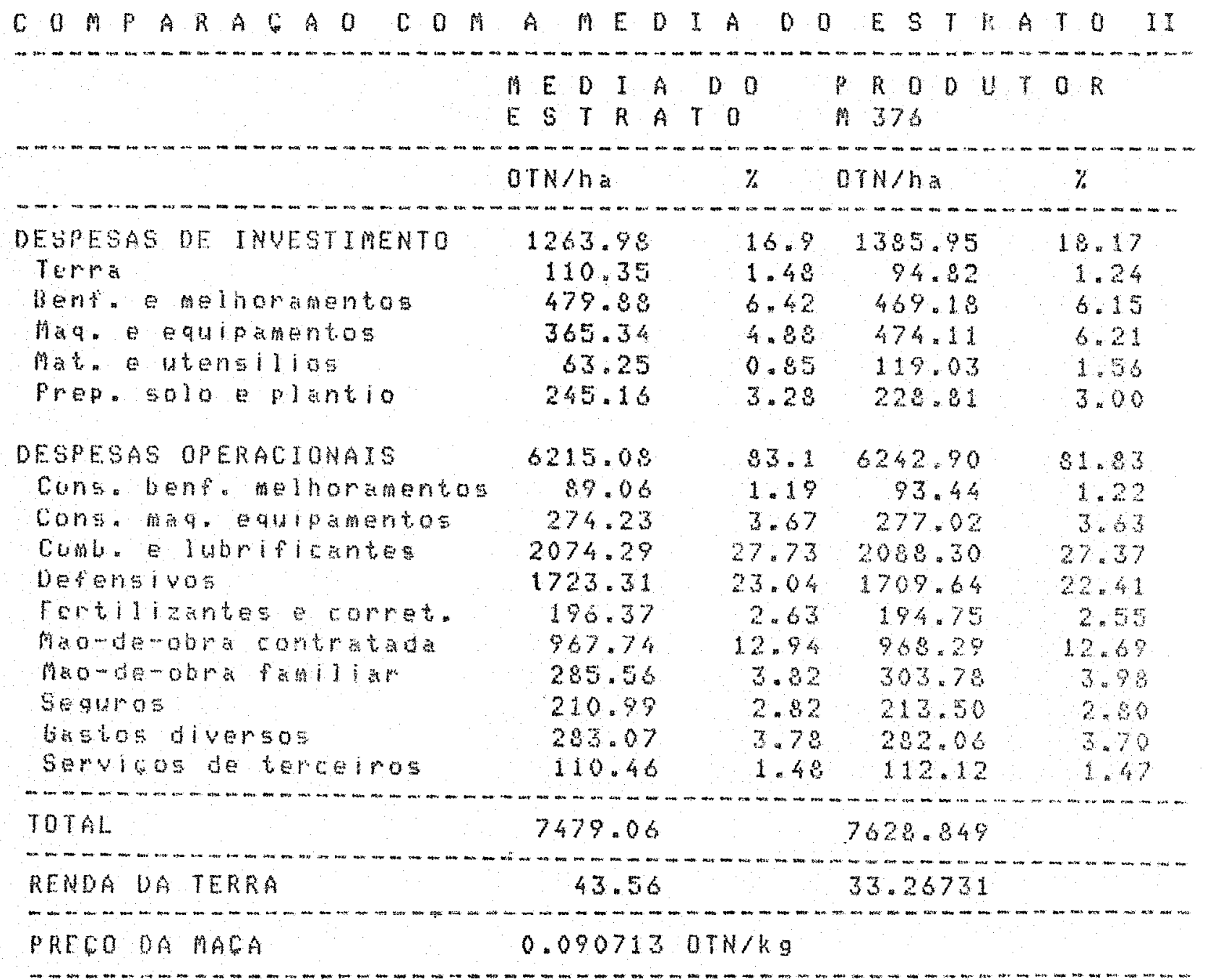

RENDIAENTO ( $\mathrm{kg} / \mathrm{h}$ 学)

CUSTO TOTAL MEOTO (OTN/Kg)

RECEITA DRUTA COTW/ha)

RECEITA LIQUIDA rOTW/TA?

\begin{tabular}{cc}
$E S T R A T O$ & $n 376$ \\
\hline 102303 & 10298.6 \\
0.073049 & 0.074074 \\
9331.03 & 9375.674 \\
1051.97 & 1746.824
\end{tabular}

OS SEOUINTES INDICES:

OPRODUTOR A 376 .EM RELACAOAOESTRATO IX. AFRESENTA 


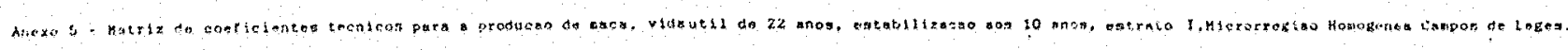

\begin{tabular}{|c|c|c|c|c|c|c|c|c|c|c|c|c|c|c|c|c|c|c|c|c|c|c|c|}
\hline & tin ithasesex & 0 & 1 & $2^{n}=$ & 3 & 4 & 5 & $B$ & 7 & $\mathrm{~B}$ & 9 & 10 & 11 & 12 & 13 & 14 & is & 16 & 17 & 28 & 19 & 20 & $z$ \\
\hline 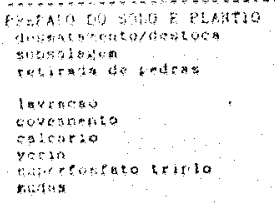 & 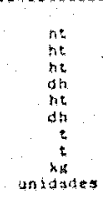 & $\begin{array}{c}28,8 \\
10.8 \\
35,1 \\
42.8 \\
18.4 \\
31.4 \\
8 \\
0.2 \\
23.2 \\
62.4\end{array}$ & $\begin{array}{l}0 \\
0 \\
0 \\
0 \\
0 \\
0 \\
0 \\
0 \\
0 \\
0 \\
0\end{array}$ & $\begin{array}{l}0 \\
0 \\
0 \\
0 \\
0 \\
0 \\
0 \\
0 \\
0 \\
0 \\
0\end{array}$ & $\begin{array}{l}0 \\
0 \\
0 \\
0 \\
0 \\
0 \\
0 \\
0 \\
0 \\
0 \\
0 \\
0\end{array}$ & $\begin{array}{l}0 \\
0 \\
0 \\
0 \\
0 \\
0 \\
0 \\
0 \\
0 \\
0 \\
0 \\
0\end{array}$ & $\begin{array}{l}0 \\
0 \\
0 \\
0 \\
0 \\
0 \\
0 \\
0 \\
0 \\
0 \\
0\end{array}$ & $\begin{array}{c}0 \\
0 \\
0 \\
0 \\
0 \\
0 \\
0 \\
0 \\
0 \\
0 \\
0\end{array}$ & $\begin{array}{l}0 \\
0 \\
0 \\
0 \\
0 \\
0 \\
0 \\
0 \\
0 \\
0 \\
0 \\
0\end{array}$ & $\begin{array}{l}0 \\
0 \\
0 \\
0 \\
0 \\
0 \\
0 \\
0 \\
0 \\
0 \\
0 \\
0\end{array}$ & $\begin{array}{l}0 \\
0 \\
0 \\
0 \\
0 \\
0 \\
0 \\
0 \\
0 \\
0\end{array}$ & $\begin{array}{l}0 \\
0 \\
0 \\
0 \\
0 \\
0 \\
0 \\
0 \\
0 \\
0 \\
0\end{array}$ & $\begin{array}{l}0 \\
0 \\
0 \\
0 \\
0 \\
0 \\
0 \\
0 \\
0 \\
0 \\
0 \\
0 \\
0\end{array}$ & $\begin{array}{l}0 \\
0 \\
0 \\
0 \\
0 \\
0 \\
0 \\
0 \\
0 \\
0\end{array}$ & $\begin{array}{l}0 \\
0 \\
0 \\
0 \\
0 \\
0 \\
0 \\
0 \\
0 \\
0\end{array}$ & $\begin{array}{l}0 \\
0 \\
0 \\
0 \\
0 \\
0 \\
0 \\
0 \\
0 \\
0 \\
0\end{array}$ & $\begin{array}{l}0 \\
0 \\
0 \\
0 \\
0 \\
0 \\
0 \\
0 \\
0 \\
0 \\
0\end{array}$ & $\begin{array}{l}0 \\
0 \\
0 \\
0 \\
0 \\
0 \\
0 \\
0 \\
0 \\
0\end{array}$ & $\begin{array}{l}0 \\
0 \\
0 \\
0 \\
0 \\
0 \\
0 \\
0 \\
0 \\
0\end{array}$ & $\begin{array}{l}0 \\
0 \\
0 \\
0 \\
0 \\
0 \\
0 \\
0 \\
0 \\
0\end{array}$ & $\begin{array}{l}0 \\
0 \\
0 \\
0 \\
0 \\
0 \\
0 \\
0 \\
0 \\
0 \\
0 \\
0\end{array}$ & $\begin{array}{l}0 \\
0 \\
0 \\
0 \\
0 \\
0 \\
0 \\
0 \\
0 \\
0 \\
0 \\
0\end{array}$ & $\begin{array}{l}0 \\
0 \\
0 \\
0 \\
0 \\
0 \\
0 \\
0 \\
0 \\
0 \\
0\end{array}$ \\
\hline 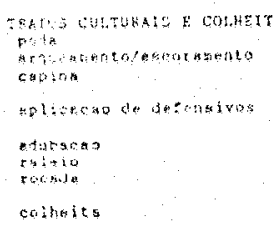 & 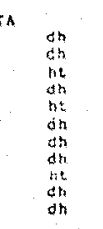 & $\begin{array}{c}3 \\
30 \\
30 \\
15 \\
3 \\
3.3 \\
:\end{array}$ & $\begin{array}{r}3.0 \\
7.8 \\
-9.8 \\
19.0 \\
9.9 \\
2.8 \\
2.8 \\
1.5 \\
2.8\end{array}$ & $\begin{array}{r}16.4 \\
4.8 \\
4.8 \\
25.2 \\
31.7 \\
15.1 \\
8.4 \\
43 \\
4.3 \\
10.4 \\
10.1\end{array}$ & $\begin{array}{r}15.4 \\
23.4 \\
18.4 \\
28.5 \\
28.5 \\
8 \\
1.8 \\
4.8 \\
11.8 \\
8.8\end{array}$ & 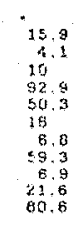 & $\begin{array}{r}25.4 \\
7.1 \\
59.8 \\
53.8 \\
15.8 \\
32.5 \\
3.2 \\
26.7 \\
77 \\
32 \\
32\end{array}$ & 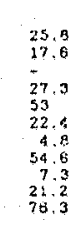 & $\begin{array}{c}58.7 \\
68.7 \\
125 \\
125 \\
1.65 \\
36.7 \\
26.6 \\
1.33 \\
100 \\
158 \\
159\end{array}$ & $\begin{array}{r}34.2 \\
22.5 \\
33.5 \\
39.5 \\
93.7 \\
3.4 \\
32.7 \\
13.5 \\
13 \\
106.7\end{array}$ & 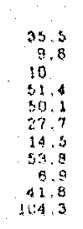 & $\begin{array}{r}35.5 \\
9.9 \\
10 \\
3.4 \\
3.1 \\
148 \\
53.8 \\
6.9 \\
42.8 \\
194.3\end{array}$ & $\begin{array}{r}35.5 \\
8.6 \\
100 \\
35.4 \\
350 \\
27.7 \\
14.5 \\
53.8 \\
61.9 \\
40.8 \\
104.3\end{array}$ & $\begin{array}{r}35.5 \\
9.8 \\
10.8 \\
51.4 \\
57.1 \\
27.7 \\
14.5 \\
53.8 \\
61.9 \\
41.8 \\
104.3\end{array}$ & 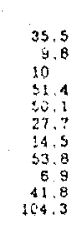 & 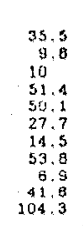 & $\begin{array}{r}35.5 \\
35 \\
8.8 \\
10.4 \\
50.4 \\
30.1 \\
21.7 \\
11.5 \\
5.8 \\
6.9 \\
10.9 \\
104.3\end{array}$ & $\begin{array}{r}35.5 \\
9.8 \\
90 \\
10.4 \\
51.4 \\
57.7 \\
27.7 \\
14.5 \\
53.8 \\
61.9 \\
41.8 \\
104.3\end{array}$ & $\begin{array}{r}35.5 \\
9,8 \\
10.8 \\
31.4 \\
50.1 \\
37.7 \\
14.5 \\
53.8 \\
81.9 \\
41.8 \\
104.3\end{array}$ & 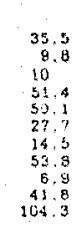 & 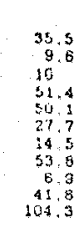 & 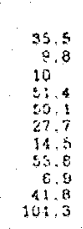 & $\begin{array}{r}35.5 \\
8.8 \\
10 . \\
11.9 \\
50 . \\
27 . \\
14 . \\
53.8 \\
61.9 \\
41.8 \\
144.3\end{array}$ \\
\hline 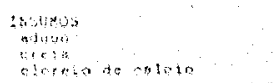 & $\begin{array}{l}3.8 \\
k 8 \\
k 8 \\
k 8\end{array}$ & 214 & $\begin{array}{l}242 \\
32.8\end{array}$ & $\begin{array}{r}257 \\
1,54 \\
; 45\end{array}$ & $\begin{array}{l}463 \\
124 \\
30\end{array}$ & $\begin{array}{r}74 \varepsilon \\
118 \\
\quad 8: 5 \\
\end{array}$ & $\begin{array}{r}511 \\
79 \\
\quad 40 \\
\end{array}$ & $\begin{array}{c}298 \\
-\end{array}$ & $\begin{array}{r}5,32 \\
42 \\
-\end{array}$ & $\begin{array}{r}693 \\
773,3 \\
33\end{array}$ & $\begin{array}{l}802 \\
x_{12}, 7\end{array}$ & $\begin{array}{c}552 \\
20.7 \\
42\end{array}$ & $\begin{array}{c}862 \\
20.7 \\
42\end{array}$ & $\begin{array}{r}652 \\
20.7 \\
42\end{array}$ & $\begin{array}{r}862 \\
\cdot 20,7 \\
42 \\
\end{array}$ & $\begin{array}{c}552 \\
20.7 \\
42\end{array}$ & $\begin{array}{l}6 \pm 2 \\
20.7 \\
4 ?\end{array}$ & $\begin{array}{r}662 \\
2 n .7 \\
42 \\
42\end{array}$ & $\begin{array}{r}582 \\
20.7 \\
42\end{array}$ & $\begin{array}{c}62_{2} \\
20.7 \\
42\end{array}$ & $\begin{array}{c}8 E 2 \\
20.7 \\
42\end{array}$ & $\begin{array}{r}642 \\
20.7 \\
42\end{array}$ & $\begin{array}{r}562 \\
207 \\
42\end{array}$ \\
\hline
\end{tabular}

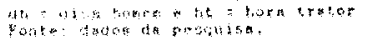




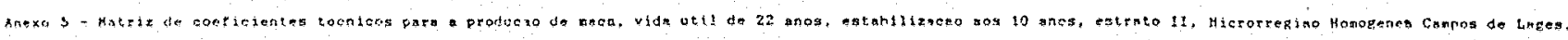

\begin{tabular}{|c|c|c|c|c|c|c|c|c|c|c|c|c|c|c|c|c|c|c|c|c|c|c|c|}
\hline & unidandes & $\therefore$ & 1 & $2^{n}=$ & 3 & 4 & 5 & 8 & ? & 3 & 8 & 10 & 11 & 12 & $\therefore 3$ & 14 & 15 & 18 & 17 & 18 & 18 & 20 & 21 \\
\hline 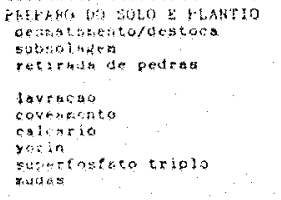 & 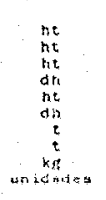 & $\begin{array}{c}16,1 \\
16.1 \\
32.3 \\
30.1 \\
16,7 \\
23.7 \\
9,8 \\
0.6 \\
250.8 \\
240\end{array}$ & $\begin{array}{l}0 \\
0 \\
0 \\
0 \\
0 \\
0 \\
0 \\
0 \\
0 \\
0 \\
0 \\
0\end{array}$ & $\begin{array}{l}0 \\
0 \\
0 \\
0 \\
0 \\
0 \\
0 \\
0 \\
0 \\
0 \\
0\end{array}$ & $\begin{array}{l}0 \\
0 \\
0 \\
0 \\
0 \\
0 \\
0 \\
0 \\
0 \\
0 \\
0\end{array}$ & $\begin{array}{l}0 \\
0 \\
0 \\
0 \\
0 \\
0 \\
0 \\
0 \\
0 \\
0 \\
0\end{array}$ & $\begin{array}{l}0 \\
0 \\
0 \\
0 \\
0 \\
0 \\
0 \\
0 \\
0 \\
0 \\
0 \\
0\end{array}$ & $\begin{array}{l}0 \\
0 \\
0 \\
0 \\
0 \\
0 \\
0 \\
0 \\
0 \\
0 \\
0 \\
0\end{array}$ & $\begin{array}{l}0 \\
0 \\
0 \\
0 \\
0 \\
0 \\
0 \\
0 \\
0 \\
0 \\
0\end{array}$ & $\begin{array}{l}0 \\
0 \\
0 \\
0 \\
0 \\
0 \\
0 \\
0 \\
0 \\
0 \\
0 \\
0 \\
0 \\
0\end{array}$ & $\begin{array}{l}0 \\
0 \\
0 \\
0 \\
0 \\
0 \\
0 \\
0 \\
0 \\
0 \\
0 \\
0\end{array}$ & $\begin{array}{l}0 \\
0 \\
0 \\
0 \\
0 \\
0 \\
0 \\
0 \\
0 \\
0 \\
0 \\
0\end{array}$ & $\begin{array}{l}0 \\
0 \\
0 \\
0 \\
0 \\
0 \\
0 \\
0 \\
0 \\
0 \\
0 \\
0\end{array}$ & $\begin{array}{l}0 \\
0 \\
0 \\
0 \\
0 \\
0 \\
0 \\
0 \\
0 \\
0\end{array}$ & $\begin{array}{l}0 \\
0 \\
0 \\
0 \\
0 \\
0 \\
0 \\
0 \\
0 \\
0 \\
0\end{array}$ & $\begin{array}{l}0 \\
0 \\
0 \\
0 \\
0 \\
0 \\
0 \\
0 \\
0 \\
0\end{array}$ & $\begin{array}{c}0 \\
0 \\
0 \\
0 \\
0 \\
0 \\
0 \\
0 \\
0 \\
0 \\
0 \\
0\end{array}$ & $\begin{array}{c}0 \\
0 \\
0 \\
0 \\
0 \\
0 \\
0 \\
0 \\
0 \\
0 \\
0\end{array}$ & $\begin{array}{l}0 \\
0 \\
0 \\
0 \\
0 \\
0 \\
0 \\
0 \\
0 \\
0 \\
0 \\
0\end{array}$ & $\begin{array}{l}0 \\
0 \\
0 \\
0 \\
0 \\
0 \\
0 \\
0 \\
0 \\
0\end{array}$ & $\begin{array}{l}0 \\
0 \\
0 \\
0 \\
0 \\
0 \\
0 \\
0 \\
0 \\
0 \\
0 \\
0\end{array}$ & $\begin{array}{l}0 \\
0 \\
0 \\
0 \\
0 \\
0 \\
0 \\
0 \\
0 \\
0 \\
0\end{array}$ & $\begin{array}{l}0 \\
0 \\
0 \\
0 \\
0 \\
0 \\
0 \\
0 \\
0 \\
0 \\
0 \\
0\end{array}$ \\
\hline 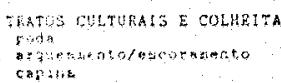 & A ${ }_{\substack{\text { on } \\
\text { dit } \\
\text { sit }}}$ & $\begin{array}{l}25 \\
25 \\
13\end{array}$ & $\begin{array}{r}8.3 \\
33.9 \\
7.5\end{array}$ & $\begin{array}{c}29.4 \\
22.5 \\
3\end{array}$ & $\begin{array}{l}19.1 \\
12.6 \\
\end{array}$ & $\begin{array}{r}3 i .2 \\
4.7\end{array}$ & $\begin{array}{r}61.5 \\
7.7\end{array}$ & $\begin{array}{r}10.3 \\
12.3 \\
0.8\end{array}$ & $\begin{array}{l}42.8 \\
=\end{array}$ & $\frac{11}{20}$ & $\begin{array}{r}26.7 \\
5.4\end{array}$ & $\begin{array}{r}56.7 \\
5.4\end{array}$ & $\begin{array}{r}28.7 \\
-5.4\end{array}$ & $\begin{array}{r}28,7 \\
5: 4\end{array}$ & $\begin{array}{r}28.7 \\
5.4\end{array}$ & $\begin{array}{r}25.7 \\
-5.4\end{array}$ & $\begin{array}{r}28.7 \\
5.4 \\
-\quad .4\end{array}$ & $\begin{array}{r}20.7 \\
5.7 \\
-5\end{array}$ & $\begin{array}{l}28.7 \\
5.4 \\
-4\end{array}$ & $\begin{array}{l}28.7 \\
3.4\end{array}$ & $\begin{array}{r}28.7 \\
5.4\end{array}$ & $\begin{array}{r}26.7 \\
5.8\end{array}$ & $\begin{array}{r}25.7 \\
3.4\end{array}$ \\
\hline 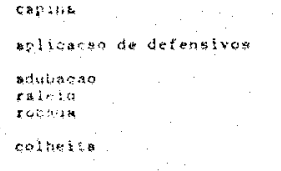 & 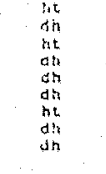 & $\begin{array}{r}20 \\
20 \\
40 \\
10 \\
4\end{array}$ & $\begin{array}{l}3.3 \\
2.8 \\
22.2 \\
3,6 \\
1 \\
8.3 \\
= \\
=\end{array}$ & $\begin{array}{rl}3 & 3.2 \\
39.9 \\
39.9 \\
7.3 \\
33.3 \\
35.7 \\
1.1 \\
29.1 \\
29.7\end{array}$ & $\begin{array}{l}-4.3 \\
37.4 \\
3.4 \\
6.3 \\
25.5 \\
5.1 \\
89\end{array}$ & $\begin{array}{l}24.7 \\
34.9 \\
44.4 \\
2.3 \\
76.3 \\
2.8 \\
3.4 \\
3.4\end{array}$ & $\begin{aligned} 78.9 \\
70.9 \\
89.5 \\
4 \\
69.6 \\
15.2 \\
109 \\
121\end{aligned}$ & 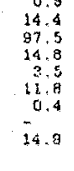 & $\begin{array}{l}36.8 \\
15.4 \\
53.2 \\
8.2 \\
37.5 \\
5.5 \\
25 \\
56\end{array}$ & $\begin{array}{r}20 \\
2 \\
32 \\
4 \\
10.7 \\
20 \\
6 \\
6.7 \\
8.3 \\
9.3\end{array}$ & $\begin{array}{l}36.5 \\
57.8 \\
13.1 \\
44.1 \\
57.6 \\
52.1 \\
22.8 \\
512.8\end{array}$ & 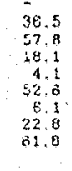 & $\begin{array}{l}38.5 \\
51.8 \\
58.1 \\
42.1 \\
52.6 \\
6.1 \\
22.8 \\
31.8\end{array}$ & $\begin{array}{l}38.5 \\
37.8 \\
38.1 \\
4.1 \\
52.6 \\
52.1 \\
72.8 \\
62.8\end{array}$ & $\begin{array}{l}35.5 \\
57.4 \\
18.2 \\
4.1 \\
52.6 \\
62.1 \\
27.8 \\
31.8\end{array}$ & 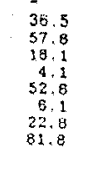 & $\begin{array}{l}36.5 \\
37.5 \\
51.8 \\
4.1 \\
5.1 \\
5.6 \\
5.1 \\
22.8 \\
21.8\end{array}$ & $\begin{array}{l}3.5 \\
35.5 \\
57.8 \\
4.1 \\
4.1 \\
5.6 \\
6.1 \\
22.8 \\
82.8\end{array}$ & 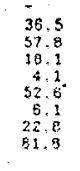 & $\begin{array}{l}36.5 \\
36.5 \\
18.8 \\
4.1 \\
52.1 \\
6.1 \\
22.8 \\
81.8\end{array}$ & 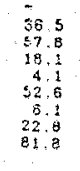 & 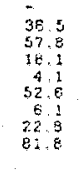 & 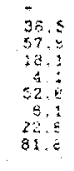 \\
\hline 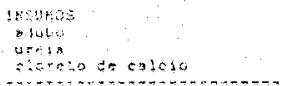 & 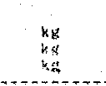 & 138 & $\begin{array}{l}225 \\
112\end{array}$ & 285 & $\begin{array}{c}350 \\
2 \\
2\end{array}$ & 519 & 877 & $\begin{array}{r}502 \\
30 \\
43 \\
43\end{array}$ & $\begin{array}{r}723 \\
17 \\
21 \\
21\end{array}$ & $\begin{array}{r}535 \\
33 \\
18 \\
\hdashline\end{array}$ & $\begin{array}{r}856 \\
498 \\
344 \\
-34.4\end{array}$ & $\begin{array}{r}85.5 \\
28 \\
34.4 \\
-34.4\end{array}$ & $\begin{array}{c}8 \leqslant 8 \\
98 \\
34,4 \\
34.2\end{array}$ & 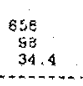 & $\begin{array}{c}658 \\
560 \\
34.4 \\
34.4\end{array}$ & $\begin{array}{l}658 \\
998 \\
34.4\end{array}$ & $\begin{array}{c}838 \\
398 \\
34.4\end{array}$ & $\begin{array}{c}658 \\
95 \\
34.4 \\
-34\end{array}$ & $\begin{array}{l}6.8 \\
38 \\
34.4\end{array}$ & \begin{tabular}{c}
656 \\
95 \\
95 \\
34.4 \\
\hdashline
\end{tabular} & $\begin{array}{c}85.8 \\
98 \\
34,4\end{array}$ & $\begin{array}{c}858 \\
35 \\
3: 1\end{array}$ & $\begin{array}{c}558 \\
989 \\
34.4\end{array}$ \\
\hline
\end{tabular}

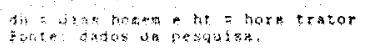




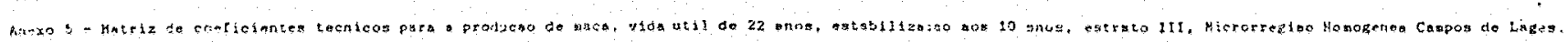

\begin{tabular}{|c|c|c|c|c|c|c|c|c|c|c|c|c|c|c|c|c|c|c|c|c|c|c|c|}
\hline & un!todes & 0 & $:$ & $n^{n} 0$ & 3 & 4 & 5 & $a$ & 7 & 8 & 2 & 10 & 11 & 12 & 23 & 14 & $: 5$ & in & 17 & 28 & 10 & 20 & 21 \\
\hline 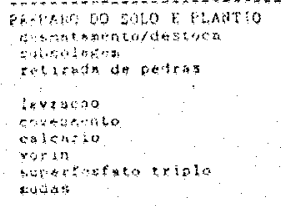 & 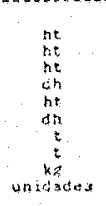 & $\begin{array}{l}17.3 \\
16 \\
20.2 \\
20.7 \\
10.9 \\
10.8 \\
20.7 \\
28.5 \\
28.5 \\
659\end{array}$ & $\begin{array}{l}0 \\
0 \\
0 \\
0 \\
0 \\
0 \\
0 \\
0 \\
0 \\
0 \\
0 \\
0\end{array}$ & $\begin{array}{l}0 \\
0 \\
0 \\
0 \\
0 \\
0 \\
0 \\
0 \\
0 \\
0 \\
0 \\
0\end{array}$ & $\begin{array}{l}0 \\
0 \\
0 \\
0 \\
0 \\
0 \\
0 \\
0 \\
0 \\
0\end{array}$ & $\begin{array}{l}0 \\
0 \\
0 \\
0 \\
0 \\
0 \\
0 \\
0 \\
0 \\
0\end{array}$ & $\begin{array}{l}0 \\
0 \\
0 \\
0 \\
0 \\
0 \\
0 \\
0 \\
0 \\
0 \\
0\end{array}$ & $\begin{array}{r}0 \\
0 \\
0 \\
0 \\
0 \\
0 \\
0 \\
0 \\
0 \\
0 \\
0\end{array}$ & $\begin{array}{l}0 \\
0 \\
0 \\
0 \\
0 \\
0 \\
0 \\
0 \\
0 \\
0 \\
0 \\
0\end{array}$ & $\begin{array}{l}0 \\
0 \\
0 \\
0 \\
0 \\
0 \\
0 \\
0 \\
0 \\
8 \\
0\end{array}$ & $\begin{array}{l}0 \\
0 \\
0 \\
0 \\
0 \\
0 \\
0 \\
0 \\
0 \\
0\end{array}$ & $\begin{array}{l}0 \\
0 \\
0 \\
0 \\
0 \\
0 \\
0 \\
0 \\
0 \\
0\end{array}$ & $\begin{array}{l}0 \\
0 \\
0 \\
0 \\
0 \\
0 \\
0 \\
0 \\
0 \\
0 \\
0 \\
0 \\
0\end{array}$ & $\begin{array}{l}0 \\
0 \\
0 \\
0 \\
0 \\
0 \\
0 \\
0 \\
0 \\
0 \\
0\end{array}$ & $\begin{array}{l}0 \\
0 \\
0 \\
0 \\
0 \\
0 \\
0 \\
0 \\
0 \\
0 \\
0\end{array}$ & $\begin{array}{l}0 \\
0 \\
0 \\
0 \\
0 \\
0 \\
0 \\
0 \\
0 \\
0 \\
0\end{array}$ & $\begin{array}{l}0 \\
0 \\
0 \\
0 \\
0 \\
0 \\
0 \\
0 \\
0 \\
0 \\
0\end{array}$ & $\begin{array}{l}0 \\
0 \\
0 \\
0 \\
0 \\
0 \\
0 \\
0 \\
0 \\
0 \\
0\end{array}$ & $\begin{array}{l}0 \\
0 \\
0 \\
0 \\
0 \\
0 \\
0 \\
0 \\
0 \\
0 \\
0 \\
0\end{array}$ & $\begin{array}{l}0 \\
0 \\
0 \\
0 \\
0 \\
0 \\
0 \\
0 \\
0 \\
0 \\
0\end{array}$ & $\begin{array}{l}0 \\
0 \\
0 \\
0 \\
0 \\
0 \\
0 \\
0 \\
0 \\
0 \\
0\end{array}$ & $\begin{array}{l}0 \\
0 \\
0 \\
0 \\
0 \\
0 \\
0 \\
0 \\
0 \\
0 \\
0 \\
0\end{array}$ & $\begin{array}{l}0 \\
0 \\
0 \\
0 \\
0 \\
0 \\
0 \\
0 \\
0 \\
0 \\
0 \\
0\end{array}$ \\
\hline 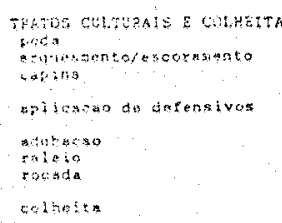 & 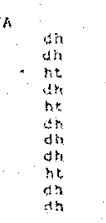 & $\begin{array}{l}12.5 \\
25 \\
= \\
28 \\
54.5 \\
21.5 \\
4 \\
-5 \\
=\end{array}$ & $\begin{array}{l}15,5 \\
12,5 \\
20 \\
20 \\
55 \\
22,5 \\
3 \\
\vdots \\
\vdots \\
=\end{array}$ & 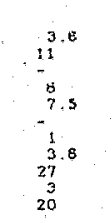 & $\begin{array}{l}3.5 \\
3.7 \\
-3 \\
8 \\
48 \\
38 \\
4.4 \\
2.5 \\
3.7 \\
3.7 \\
3.4\end{array}$ & $\begin{array}{l}8.3 \\
5.6 \\
10 \\
14 \\
5.5 \\
2.0 \\
3.3 \\
33.5\end{array}$ & $\begin{array}{l}8.8 \\
3.8 \\
30 \\
21 \\
11.7 \\
20.8 \\
2.5 \\
37.5\end{array}$ & $\begin{array}{l}1: \\
2 \\
-8.5 \\
20.8 \\
6 \\
23.3 \\
23.3 \\
2,3.3 \\
33.3\end{array}$ & 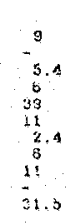 & $\begin{array}{l}50 \\
4 \\
4 \\
4 \\
20 \\
12 \\
12.5 \\
13 \\
13 \\
1.2 \\
52\end{array}$ & 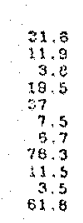 & $\begin{array}{r}31.8 \\
11.9 \\
15.8 \\
15 \\
37 \\
7.5 \\
6.7 \\
76.3 \\
11.5 \\
3.5 \\
6.2\end{array}$ & $\begin{array}{r}31.8 \\
11.8 \\
3.3 \\
19.5 \\
37.5 \\
7.5 \\
8.7 \\
60.3 \\
113 \\
31.5 \\
01.8\end{array}$ & $\begin{aligned} 31.8 \\
11.9 \\
3.9 \\
3.8 \\
37.5 \\
77.5 \\
7.7 \\
78,3 \\
11.5 \\
3,5 \\
01,8\end{aligned}$ & $\begin{array}{r}31.8 \\
11.9 \\
11.8 \\
19.5 \\
19.5 \\
7.5 \\
6.5 \\
76.7 \\
11.5 \\
3.5 \\
81,8\end{array}$ & $\begin{array}{r}31.8 \\
11.9 \\
3.8 \\
19.5 \\
31.5 \\
7.5 \\
8.7 \\
78.3 \\
11.5 \\
31.8 \\
81.8\end{array}$ & $\begin{array}{l}31.3 \\
11,3 \\
3.5 \\
19.5 \\
37.5 \\
7.3 \\
6.7 \\
78.3 \\
1.1 .5 \\
9.5 \\
61.3\end{array}$ & 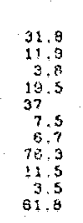 & $\begin{array}{l}31.6 \\
11.5 \\
3.8 \\
19.5 \\
37.5 \\
7.5 \\
8.7 \\
75.7 \\
11.5 \\
3.5 \\
81.8\end{array}$ & $\begin{array}{r}31.8 \\
11.9 \\
3.8 \\
39.5 \\
37 \\
7.5 \\
6.7 \\
76,3 \\
11.5 \\
3.5 \\
61.8\end{array}$ & 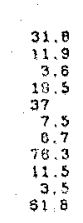 & $\begin{aligned} 31.6 \\
11.6 \\
3.8 \\
19.5 \\
3 \% \\
7.5 \\
76.7 \\
76.9 \\
11.5 \\
3.5 \\
81.8\end{aligned}$ & 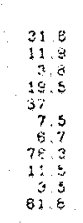 \\
\hline 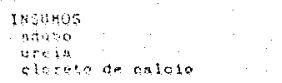 & $\begin{array}{l}k=2 \\
k, z \\
k, z\end{array}$ & 130 & $\begin{array}{c}155 \\
55 \\
-5\end{array}$ & $\begin{array}{r}275 \\
118 \\
10\end{array}$ & 426 & $\begin{array}{c}518 \\
=\end{array}$ & 568 & $\stackrel{872}{=}$ & $\begin{array}{c}880 \\
94 \\
281\end{array}$ & $\begin{array}{r}1183 \\
-35\end{array}$ & $\begin{array}{l}5 \% \\
73 \\
74.1\end{array}$ & $\begin{array}{c}571 \\
73 \\
74.8\end{array}$ & $\begin{array}{c}571 \\
73 \\
74.4\end{array}$ & $\begin{array}{c}57 \\
73 \\
74.4\end{array}$ & $\begin{array}{l}57 . \\
73 \\
74.4\end{array}$ & $\begin{array}{l}571 \\
73 \\
74.4\end{array}$ & $\begin{array}{c}571 \\
733 \\
74.4\end{array}$ & $\begin{array}{c}571 \\
73 \\
74.4\end{array}$ & $\begin{array}{c}571 \\
73 \\
74,4\end{array}$ & $\begin{array}{c}571 \\
73 \\
74,4\end{array}$ & $\begin{array}{c}579 \\
73 \\
74,4\end{array}$ & $\begin{array}{r}571 \\
73 \\
744\end{array}$ & $\begin{array}{c}571 \\
774 \\
74,6\end{array}$ \\
\hline
\end{tabular}

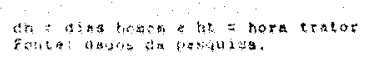

